\author{
Universidade de São Paulo \\ Instituto de Física
}

\title{
A saturação de gluons em futuros aceleradores
}

\author{
Erike Roberto Cazaroto \\ Orientador: Prof. Dr. Fernando Silveira Navarra \\ Coorientador: Prof. Dr. Victor Paulo Barros Gonçalves \\ Tese de doutorado apresentada ao \\ Instituto de Física para a obtenção \\ do título de Doutor em Ciências
}

Comissão Examinadora:

Prof. Dr. Fernando Silveira Navarra (orientador) (IFUSP)

$\operatorname{Prof}^{a}$. Dr ${ }^{a}$. Frederique Marie Brigitte Sylvie Grassi (IFUSP)

Prof. Dr. Marcelo Gameiro Munhoz (IFUSP)

Prof. Dr. Marcio José Menon (UNICAMP)

Prof. Dr. Magno Valerio Trindade Machado (UfRGS)

São Paulo 


\section{FICHA CATALOGRÁFICA \\ Preparada pelo Serviço de Biblioteca e Informação \\ do Instituto de Física da Universidade de São Paulo}

Cazaroto, Érike Roberto

A saturação de gluons em futuros aceleradores. São Paulo, 2012.

Tese (Doutorado) - Universidade de São Paulo. Instituto de Física, Depto. Física Experimental.

Orientador: Prof. Dr. Fernando Silveira Navarra

Área de Concentração: Física

Unitermos: 1. Física de partículas;

2. Fenomenologia; 3. Gluons; 4. Aceleradores

USP/IF/SBI-078/2012 
Dedico esta tese à toda a minha família e amigos, em especial à minha tia Creusa Maria Cazaroto e à minha avó Geni Valim Tofoli. 


\section{Agradecimentos}

- Agradeço ao professor Fernando Navarra, pela orientação e amizade.

- Agradeço ao professor Victor Gonçalves, pela coorientação e amizade.

- Agradeço aos professores, aos colegas e ex-colegas do corredor e aos amigos do GRHAFITE: Marina Nielsen, Manoel Robillota, Celso Lima, Jorge Noronha, Renato Higa, Dunga, Sérgio, David, Ricardo, Jorgivan, Simone, Carina, Arthur, Patrícia, Daniela, Babi, Raphael, Samuel, André, Stefano, Emmanuel, Camila, João, pela companhia agradável ao longo desses anos.

- Agradeço ao pessoal da secretaria, ao Paulo e ao Anderson por estarem sempre dispostos a ajudar no que fosse necessário.

- Agradeço ao Sérgio pela ajuda nas dificuldades com o Latex e com outros problemas computacionais.

- Agradeço ao Stefano, ao João e ao Samuel pela parceria na hora de fazer o café de todas as tardes.

- Agradeço de modo geral a todos professores e colegas que contribuiram para a minha formação ao longo desses anos no Instituto de Física da USP.

- Agradeço ao CNPq pelo apoio financeiro durante os 7 primeiros meses de Doutorado e à FAPESP pelo apoio financeiro do $8^{0}$ mês em diante. 


\section{Resumo}

Neste trabalho nós fazemos predições para o comportamento de grandezas observáveis a serem medidas nos futuros aceleradores de partículas e também no LHC. Nós estudamos três processos: elétron-núcleo $(e A)$, fóton-fóton $(\gamma \gamma)$ e próton-núcleo $(p A)$. Nos processos $e A$ nós calculamos as seções de choque de produção de mesons vetoriais e de fótons reais usando os modelos de saturação rcBK e b-CGC. Nós verificamos que apenas a produção de mesons pesados poderá nos dizer qual destes dois modelos é o mais correto para descrever a seção de choque dipolo-próton. No estudo dos processos $\gamma \gamma$ nós calculamos as seções de choque de espalhamento e a função de estrutura do fóton. Nós propomos um novo modelo de saturação para a interação entre dois dipolos de cor e comparamos suas predições com aquelas de um modelo disponível na literatura para esta interação. Nós verificamos que o nosso modelo prediz um crescimento bem menos acentuado para os observáveis calculados do que prediz o outro modelo. No último processo que estudamos, a colisão $p A$, nós calculamos as seções de choque de produção de charme e de bottom nas energias do LHC. Nós verificamos que os dados sobre a produção de charme serão os mais promissores na identificação de sinais de física de saturação. Nós também verificamos que o efeito de "shadowing" nuclear causa uma diminuição considerável na seção de choque de produção de charme, o que indica que este observável poderá ser útil na determinação da magnitude deste efeito. Por outro lado, apenas a seção de choque de produção de bottom apresenta o efeito de "antishadowing". 


\section{Abstract}

In this thesis we make predictions for the behavior of observables that will be measured in future particle colliders and also at the LHC. We address three different types of collisions: electron-ion $(e A)$, photon-photon $(\gamma \gamma)$ and proton-nucleus $(p A)$. For $e A$ processes we calculate the vector meson and real photon production cross section using the saturation models rcBK and b-CGC. We observe that only the production of heavy mesons will be useful to determine which saturation model correctly describes the dipole-proton interaction. For the $\gamma \gamma$ process we calculate the total cross section as well as the photon structure function. We propose a new saturation model for the interaction between two color dipoles and we compare its predictions with those of other models available in the literature. We observe that our model predicts a much smoother growth of the observables than the other models. As for $p A$ collisions, we calculate the cross section of charm and bottom production at LHC energies. We observe that charm production is very sensitive to saturation effects as well as to nuclear shadowing effects. Therefore, this observable can be useful to determine the dynamics of QCD at high energies, as well as the magnitude of the shadowing. On the other hand, only the bottom production cross section is sensitive to antishadowing effect. 


\section{Conteúdo}

$\begin{array}{ll}\text { Introdução } & 1\end{array}$

1 A estrutura dos hádrons 5

1.1 Espalhamento Inelástico Profundo f . . . . . . . . . . . . . . . 5

1.1.1 Variáveis cinemáticas utilizadas no DIS . . . . . . . . . 7

1.1.2 Seções de choque e as funções de estrutura . . . . . . . . . . . . 8

1.1.3 Espalhamento Inelástico Profundo Difrativo - DDIS . . . . . . . 9

1.1.4 Espalhamento Compton Profundamente Virtual - DVCS . . . . 10

1.2 Os constituintes internos do hádron . . . . . . . . . . . . . . . . . . 10

1.2.1 O modelo a pártons . . . . . . . . . . . . . . . . . 11

1.2 .2 As equações de DGLAP . . . . . . . . . . . . . . . . 12

1.2.3 As equações de DGLAP no limite de pequeno $x \ldots 14$

1.3 O DIS nuclear . . . . . . . . . . . . . . . . . . . 15

1.3.1 "Shadowing" nuclear . . . . . . . . . . . . . . . . . 16

1.3.2 Parametrizações das distribuições nucleares de pártons . . . . 17

2 O formalismo de dipolos de cor $\quad 19$

2.1 Dipolos de cor . . . . . . . . . . . . . . . . . . . . . . . . . . 19

2.1.1 A amplitude de espalhamento dipolo-hádron . . . . . . . . . . . 21

2.1.2 Formalismo de dipolo e a fatorização $k_{T} \ldots \ldots$. . . . . . . . 21

2.2 Aplicações . . . . . . . . . . . . . . . . . . . . . . . . . . . . . . . 22

2.2.1 Produção exclusiva de fótons e mésons vetoriais . . . . . . . . 22 
2.2.2 Espalhamento fóton-fóton . . . . . . . . . . . . 26

2.2.3 Produção de charme em colisões $p A \ldots \ldots$. . . . . . . . 27

3 Modelos para a seção de choque dipolo-hádron 31

3.1 A Dinâmica Linear da QCD . . . . . . . . . . . . . . . . . 31

3.1.1 O Modelo CT . . . . . . . . . . . . . . . 32

3.1 .2 Generalização Nuclear do Modelo CT . . . . . . . . . . . . . 32

3.2 A Dinâmica Não-Linear da QCD . . . . . . . . . . . . . . . . . . 33

3.2.1 O Color Glass Condensate - CGC . . . . . . . . . . . . . . 34

3.2 .2 Uma visão geométrica da escala de saturação . . . . . . . . . 35

3.3 Modelos de saturação . . . . . . . . . . . . . . . . . . . . . 38

3.3.1 A equação de Balitsky-Kovchegov $(\mathrm{BK}) \ldots \ldots$. . . . . . . 38

3.3.2 Os modelos fenomenológicos . . . . . . . . . . . . . 40

3.3 .3 O modelo de GBW . . . . . . . . . . . . . . . 40

3.3 .4 O modelo IIM-S . . . . . . . . . . . . . . . . . . . . . 41

3.3.5 O modelo b-CGC . . . . . . . . . . . . . . . . . 42

3.3.6 O modelo rcBK . . . . . . . . . . . . . . . . 43

3.4 Generalização nuclear dos modelos de saturação . . . . . . . . . . . . . 44

3.4.1 O Modelo de Glauber-Mueller . . . . . . . . . . . . . . . 45

3.5 Generalização nuclear da escala de saturação . . . . . . . . . . . . . 46

3.5.1 Por que um núcleo $A$ como alvo? . . . . . . . . . . . . 47

4 Processos exclusivos em colisões elétron-íon $\quad 48$

4.1 Resultados . . . . . . . . . . . . . . . . . . . . . 49

4.2 Conclusão . . . . . . . . . . . . . . . . . . . . . 53

5 Espalhamento fóton-fóton $\quad 54$

5.1 Modelos para a seção de choque dipolo-dipolo . . . . . . . . . . . 55

5.2 Resultados . . . . . . . . . . . . . . . . . . 57

5.3 Conclusão . . . . . . . . . . . . . . . . . . . . . . . . 61 
6 Produção de quarks pesados em colisões próton-núcleo 63

6.1 O referencial do CGC . . . . . . . . . . . . . . . . . 64

6.2 Efeitos de saturação na produção de charme e de bottom . . . . . . . 65

6.2.1 Resultados . . . . . . . . . . . . . . . . . 68

6.3 Efeitos de shadowing na produção de charme e de bottom . . . . . . . 74

6.3.1 Resultados . . . . . . . . . . . . . . . 75

6.4 Conclusão . . . . . . . . . . . . . . . . . . . . 77

$\begin{array}{lll}7 & \text { Conclusão } & 78\end{array}$

$\begin{array}{lr}\text { Referências Bibliográficas } & 80\end{array}$ 


\section{Lista de Figuras}

1.1 Espalhamento Inelástico Profundo elétron-próton. . . . . . . . . . . . . 6

1.2 Razão $R_{F_{2}}^{A}=F_{2}^{A} /\left(A F_{2}^{N}\right)$ (Extraído de [16]) . . . . . . . . . . . . 16

1.3 Razão $R_{g}=x g_{A} /\left(A x g_{N}\right)$ predita pelas parametrizações EKS 98, DS, HKN e EPS 08 para $A=208$ e $Q^{2}=2,5 G e V^{2}$. Extraído de [1]. . . . . 18

2.1 No formalismo de dipolo, $\gamma^{*}$ flutua num par $q \bar{q}$ antes de interagir com o alvo $A \ldots \ldots \ldots \ldots \ldots$

2.2 Diagrama ilustrando a interação entre dois fótons no formalismo de dipolo de cor. A área acinzentada representa o campo gluônico de um dos dipolos. . . . . . . . . . . . . . . . . . 26

2.3 Os três gráficos de mais baixa ordem, no formalismo de dipolo de cor, que contribuem para o a produção de quarks pesados em colisões hádron-hádron. Extraído de [25]. . . . . . . . . . . . . . . . . . 28

3.1 Resolução com a qual os glúons são "vistos" pelo dipolo. . . . . . . . . . . 35

3.2 Aumento da densidade de glúons com a energia. . . . . . . . . . . . . 37

3.3 Representação da evolução feita pela Equação de BK sobre o par $q \bar{q}$,

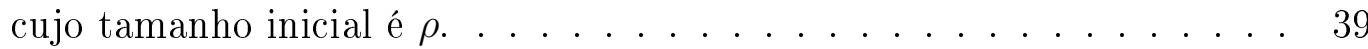

3.4 Comportamento das amplitudes de espalhamento rcBK (linha sólida) e IIM-S (linha tracejada) com a separação $r$ do par $q \bar{q}$ para diferentes valores de $x$ : (a) $x=10^{-3}$ e (b) $x=10^{-6} \ldots \ldots \ldots 4$ 
4.1 Seção de choque coerente em função da energia para diferentes estados finais exclusivos e $Q^{2}=1 G e V^{2} \ldots \ldots \ldots \ldots$. . . . . . . . 50

4.2 Seção de choque coerente em função da virtualidade para diferentes estados finais exclusivos e $W=500 \mathrm{GeV} \ldots \ldots$. . . . . . . . . . 51

4.3 Seção de choque incoerente em função da energia para diferentes estados finais exclusivos e $Q^{2}=1 G e V^{2} \ldots \ldots \ldots \ldots$. . . . . . . . . 52

4.4 Seção de choque incoerente em função da virtualidade para diferentes estados finais exclusivos e $W=500 \mathrm{GeV}$.

5.1 Seção de choque total $\gamma \gamma$, como função da energia $W$, usando os modelos 1 e 2, cada qual calculado com as amplitudes de espalhamento a) rcBK e b) IIM-S. Dados experimentais obtidos de [42] . . . . . . . . . . . . . 58

5.2 A seção de choque total $\gamma^{*} \gamma^{*}$ como função de $Y \equiv \ln \left(W^{2} / Q_{1} Q_{2}\right)$ para diferentes valores de $Q^{2}\left(Q^{2}=Q_{1}^{2}=Q_{2}^{2}\right) \ldots \ldots \ldots$

5.3 A função de estrutura $F_{2}^{\gamma}\left(x, Q^{2}\right)$ do fóton, como função de $x$, para diferentes valores das virtualidades $Q_{1}^{2}$ e $Q_{2}^{2}$. . . . . . . . . . 60

6.1 Esquematização da produção de quarks na região de grande rapidez $(y>0)$ nos processos $h_{1} h_{2} \ldots \ldots \ldots \ldots 4 \ldots \ldots \ldots \ldots$

6.2 Seções de choque de produção de charme (esquerdo) e bottom (direito) em colisões próton-próton como função da energia total no centro de massa da colisão $(\sqrt{s}) \ldots \ldots \ldots$. . . . . . . . . . . . . 68

6.3 Seções de choque de produção de charme (esquerdo) e de bottom (direito), como função da energia no centro de massa $(\sqrt{s})$, em colisões próton-próton, obtidas usando o Modelo CT e diferentes valores para as massas dos quarks pesados.

6.4 Seção de choque total de produção de charme (esquerdo) e de bottom (direito) em colisões pPb, pCa e pp como função da energia no centro de massa $(\sqrt{s}) \ldots \ldots \ldots \ldots \ldots \ldots$. . . . . . . . . . . . . . . . . . . 
6.5 Distribuições na rapidez para produção de charme (esquerdo) e de bottom (direito) em colisões pp, pCa e pPb para $\sqrt{s}=7 \mathrm{TeV} \ldots \ldots 72$

6.6 Razão normalizada da distribuição em rapidez da seção de choque total de produção de charme em colisões pCa (esquerdo) e pPb (direito) para $\sqrt{s}=8,8 \mathrm{TeV}$.

6.7 Razão normalizada da distribuição em rapidez da seção de choque total de produção de bottom em colisões pCa (esquerdo) e pPb (direito) para $\sqrt{s}=8,8 \mathrm{TeV}$.

6.8 Distribuição em rapidez da seção de choque total de produção de charme (esquerdo) e de bottom (direito) em colisões $\mathrm{Ap}$, onde $\mathrm{A}=\mathrm{Pb}$, para

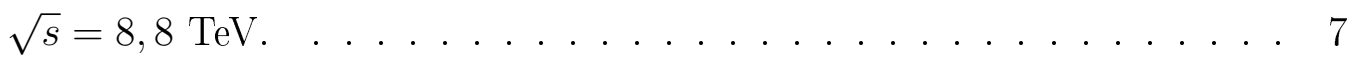

6.9 Razão entre as distribuições em rapidez, com e sem efeito de shadowing, para colisões $\mathrm{Pb}$. . . . . . . . . . . . . . 76 


\section{Introdução}

O efeito de "shadowing" ou efeito de sombreamento nuclear é comprovado experimentalmente. O que ainda não sabemos muito bem, por falta de dados experimentais de precisão, é a magnitude deste efeito. Conforme será visto no capítulo 1, existem várias parametrizações disponíveis na literatura para descrever o efeito de shadowing, mas elas ainda são bastante divergentes entre si. A saturação da distribuição de glúons, por outro lado, é um efeito que ainda não sabemos em qual valor de energia acontece. Do ponto de vista teórico, espera-se que a distribuição de glúons sature em altas energias, fazendo com que todas as grandezas observáveis obtidas a partir dela tenham um comportamento assintótico suave. Um bom exemplo desta mudança de comportamento é o que acontece com as seções de choque hadrônicas calculadas a partir de interações partônicas. De qualquer forma, supondo que a saturação realmente aconteça, existem vários modelos de saturação disponíveis na literatura, os quais levam a resultados diferentes para as grandezas obseváveis. Existem portanto três questões em aberto relacionadas aos dois temas citados acima:

- Qual é a magnitude do shadowing nuclear?

- A distribuição de glúons satura no regime de altas energias?

- Dentre os modelos de saturação existentes, qual descreve melhor este efeito?

Na referência [2] nós abordamos a primeira questão. Nós calculamos as funções de estrutura longitudinal e de charme que serão medidas nos futuros colisores elétron- 
Íon $(e A)$. Nós mostramos que, se estas funções de estrutura forem medidas com boa precisão, será possível conhecer a magnitude do efeito de "shadowing" nuclear na distribuição de glúons. Já na referência [3] nós abordamos a segunda questão. Nós calculamos estes mesmos observáveis utilizando um modelo de saturação, o qual nós chamamos de "b-CGC", e comparamos seus resultados com aqueles obtidos sem saturação. Nós concluímos que estes observáveis não serão úteis para detectar sinais de saturação. Mais recentemente abordamos a terceira questão, ou seja, supondo que a distribuição de glúons sature, qual modelo descreve melhor este efeito? Até o final de 2009, o modelo que acreditávamos ser o melhor era o modelo "b-CGC". Entretanto, em 2010 foi disponibilizado na literatura um código Fortran que calcula a solução numérica da Equação de BK com acoplamento variável (rcBK). Desde então, o uso deste modelo tornou-se frequente na literatura e nós decidimos comparar suas predições com aquelas do modelo b-CGC para verificarmos quão diferentes são os resultados e também para verificarmos quais são os observáveis mais sensíveis à seção de choque dipolo-próton.

Em [4] calculamos alguns observáveis que serão medidos nos futuros colisores $e A$. Usamos tanto o modelo b-CGC quanto o modelo rcBK, para poder comparar suas predições. Dessa forma, se ficar comprovado que a distribuição de glúons satura, em princípio os nossos resultados poderiam ser comparados com os dados experimentais a fim de verificar qual destes dois modelos descreve melhor a saturação. Este trabalho será descrito no capítulo 4.

Na Ref. [5] abordamos a mesma questão que em [4], ou seja, qual modelo descreve melhor o efeito de saturação? Entretanto, desta vez, nós preferimos substituir o modelo b-CGC pelo modelo "IIM-S". Uma descrição destes dois modelos será feita no Capítulo 3. O modelo IIM-S é idêntico ao modelo b-CGC, com excessão do fato de que ele não possui dependência no parâmetro de impacto. O motivo de termos escolhido este modelo foi que os parâmetros dele foram determinados mais recentemente do que os do modelo b-CGC, sendo que, com essa nova determinação de seus parâmetros, o modelo IIM-S descreveu muito bem os dados experimentais de HERA. Em [5] nós consideramos colisões fóton-fóton $(\gamma \gamma)$. Nós propusemos uma nova expressão para 
a seção de choque dipolo-dipolo e comparamos os resultados do nosso modelo com aqueles de um modelo disponível na literatura. Este trabalho será descrito no capítulo 5 .

Em [6] voltamos a tratar das duas primeiras questões levantadas acima. Nós analisamos a magnitude do efeito de shadowing nas seções de choque de produção de charme e de bottom em processos próton-núcleo $(p A)$ e analisamos também a possibilidade de identificar sinais de saturação nestes observáveis. Os nossos cálculos foram feitos nas energias do LHC e poderão ser comparados com os dados deste colisor num futuro próximo, quando forem realizados experimentos de colisões $p A$. Este trabalho será descrito no capítulo 6.

Como se pode ver, nós abordamos os três processos $e A, \gamma \gamma$ e $p A$. Para o primeiro processo, nós fizemos predições para observáveis que serão medidos nos futuros aceleradores eRHIC e LHeC. O eRHIC está planejado para ser construído no lugar do atual RHIC (Relativistic Heavy Ion Collider) e o LHeC faz parte do LHC (Large Hadron Collider). Para o segundo processo, $\gamma \gamma$, nós fizemos cálculos no regime cinemático do futuro International Linear Collider (ILC). E por último, nos processos $p A$, nós calculamos observáveis no regime cinemático do LHC.

Todos os cálculos feitos nestes trabalhos foram desenvolvidos no formalismo de dipolo de cor. Este formalismo será descrito no capítulo 2. Sua principal vantagem é que ele permite a inclusão, de forma natural, de efeitos de saturação na distribuição de glúons. Inspirados na tese de doutorado [7], incluímos três capítulos introdutórios, onde serão apresentados os principais conceitos necessários para que um leitor que não esteja familiarizado com a área possa entender nossos trabalhos. Estes três primeiros capítulos são bastante sucintos. O leitor interessado em se aprofundar mais nestes assuntos poderá consultar as referências indicadas. As duas principais referências são o livro "High-Energy Particle Diffraction" [8] e a tese de doutorado [7].

Os resultados originais estão todos contidos nos capítulos 4, 5 e 6, sendo que cada um destes capítulos descreve o conteúdo de um dos artigos que publicamos. Isso significa que o capítulo 4 descreve o trabalho que publicamos no artigo [4], o capítulo 
5 descreve o trabalho que publicamos no artigo [5] e o capítulo 6 descreve o trabalho que publicamos no artigo [6]. 


\section{Capítulo 1}

\section{A estrutura dos hádrons}

A melhor maneira de obter informações sobre a estrutura interna dos hádrons é através de experimentos de colisão. No que segue, faremos uma breve descrição de um dos principais tipos de experimentos usados no estudo da estrutura hadrônica, o Espalhamento Inelástico Profundo ("Deep Inelastic Scattering" ou DIS). Em seguida vamos tratar da estrutura dos hádrons no regime de energias muito altas. Este é o regime cinemático de interesse desta tese. Nesse regime, conforme veremos, a distribuição de glúons é a que predomina. Por último veremos que, ao contrário do bom conhecimento que temos sobre a distribuição de glúons em um núcleon (próton ou nêutron), o conhecimento atual desta mesma distribuição em um núcleo de número de massa $A$ é bastante incompleto no regime de altas energias.

\subsection{Espalhamento Inelástico Profundo}

O espalhamento inelástico profundo é um processo do seguinte tipo [8]:

$$
e p \rightarrow e X
$$

A expressão (1.1) representa uma situação em que um elétron (e) é lançado contra um próton $(p)$. Após a interação, apenas o elétron emergente é completamente iden- 


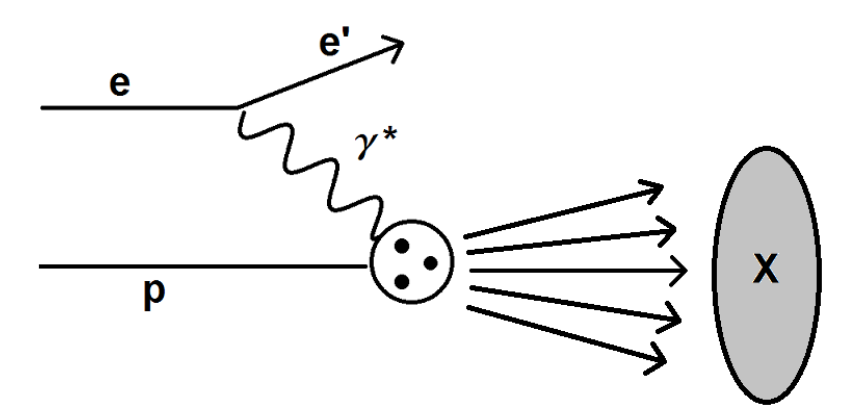

Figura 1.1: Espalhamento Inelástico Profundo elétron-próton.

tificado. Podemos dizer que esta interação fez o próton fragmentar-se num sistema $X$ de partículas. Interações desse tipo envolvem energias (no referencial do centro de massa) bem maiores do que a massa de repouso do próton. Nesse processo, o elétron é o projétil e o próton é o alvo. Definir quem é o projétil e quem é o alvo não é apenas uma questão de nomenclatura, já que, em geral, o problema de espalhamento é tratado no referencial de repouso do alvo.

Os processos de DIS podem ser classificados como inclusivos ou exclusivos [8]. Quando as partículas que compõem o sistema $X$ não são identificadas, dizemos que o processo é inclusivo. Por outro lado, quando todas elas são identificadas, dizemos que o processo é exclusivo. Como o elétron não possui carga de cor, sua interação com o próton é de natureza eletromagnética, e pode ser tratada no formalismo da eletrodinâmica quântica (QED). No formalismo da QED, essa interação é representada por diagramas de Feynman, sendo que o diagrama de mais baixa ordem é aquele esboçado na Figura 1.1. Como podemos ver, o elétron emite um fóton virtual $\left(\gamma^{*}\right)$ que, por sua vez, interage com os componentes do próton que possuem carga elétrica, ou seja, interage com os quarks. Do ponto de vista teórico, o fato de o elétron ser uma partícula fundamental e de a interação eletromagnética ser muito bem compreendida, torna os dados provenientes de processos de DIS mais simples de serem analisados do que os dados provenientes de processos próton-próton. Isso faz do DIS uma ferramenta bastante útil no estudo da estrutura interna dos hádrons. 


\subsubsection{Variáveis cinemáticas utilizadas no DIS}

As variáveis cinemáticas mais comuns, utilizadas no estudo do DIS, são [8]:

- $s \rightarrow$ quadrado da energia total do sistema ep no referencial do centro de massa

- $W \rightarrow$ energia total do sistema $\gamma^{*} p$

- $Q^{2} \rightarrow$ virtualidade do fóton $\left(\gamma^{*}\right)$ emitido pelo elétron

A virtualidade $Q^{2}$ do fóton é: $Q^{2}=-q^{2}$, onde $q$ é o quadrimomento de $\gamma^{*}$ [8]. O motivo do sinal negativo é que, no DIS, $q^{2}<0$ para um fóton virtual, e consequentemente a virtualidade $Q^{2}$, definida dessa maneira, é positiva.

Além dessas três variáveis cinemáticas, há uma quarta variável muito utilizada no estudo do DIS. É a variável $x$ de Bjorken, definida como [8]:

$$
x=\frac{Q^{2}}{2 m_{p} \nu}=\frac{Q^{2}}{W^{2}+Q^{2}-m_{p}^{2}},
$$

onde $m_{p}$ é a massa do próton e $\nu$ é a energia transferida do elétron para o próton através do fóton virtual. A variável $x$ de Bjorken assume apenas valores: $0<x<1$. No regime de Bjorken, i.e., $Q^{2} \rightarrow \infty, \nu \rightarrow \infty$ e $Q^{2} /\left(2 m_{p} \nu\right)=$ constante finita, esta variável é interpretada como a fração do momento hadrônico que é carregada por um de seus constituintes internos.

Nos processos de DIS, a variável $x$ possui valores típicos bem pequenos, $x<10^{-2}$. O regime cinemático de $x$ pequeno é aquele no qual $W^{2}$ é bem grande, sendo muito maior do que $Q^{2}$ e do que $m_{p}^{2}$. Nesse regime, $x$ pode ser aproximado por:

$$
x \approx \frac{Q^{2}}{W^{2}}
$$

Em geral, quando se fala em "variar $x$ ", fica implícito que $Q^{2}$ está sendo mantido fixo, e que a energia $W^{2}$ é que está sendo variada. Por isso, a expressão "pequeno $x$ ", que será bastante usada nesta tese, é sinônimo de "alta energia". Finalmente, fazemos também 
uso da variável rapidez, definida como:

$$
y=\frac{1}{2} \ln \frac{E+p_{z}}{E-p_{z}}
$$

onde $E$ é a energia da partícula e $p_{z}$ é seu momentum ao longo da direção longitudinal.

\subsubsection{Seções de choque e as funções de estrutura}

Nos processos de DIS, a principal grandeza física que se quer conhecer é a seção de choque da colisão $\gamma^{*} p$. Esta grandeza nos fornece informações valiosas sobre a estrutura interna do próton. Por exemplo, quanto maior é a seção de choque de colisão $\left(\sigma^{\gamma^{*} p}\right)$ entre o fóton virtual e o próton, maior é a quantidade de constituintes internos do próton.

A seção de choque total $\sigma^{\gamma^{*} p}$ pode ser expressa como a soma de duas contribuições [8]:

$$
\sigma^{\gamma^{*} p}=\sigma_{L}^{\gamma^{*} p}+\sigma_{T}^{\gamma^{*} p}
$$

onde os índices $L$ e $T$ referem-se às polarizações longitudinal e transversal do fóton virtual $\gamma^{*}$. Esta decomposição implica que estamos separando a interação total $\left(\sigma^{\gamma^{*} p}\right)$ em duas partes. Uma delas $\left(\sigma_{L}^{\gamma^{*} p}\right)$ resulta exclusivamente da interação dos componentes do próton com $\gamma^{*}$ de polarização longitudinal e a outra parte $\left(\sigma_{T}^{\gamma^{*} p}\right)$ resulta da interação com $\gamma^{*}$ de polarização transversal.

Na literatura, além das seções de choque, costumam-se definir também as funções de estrutura eletromagnética. A seção de choque total $\left(\sigma^{\gamma^{*} p}\right)$ está relacionada à função de estrutura eletromagnética total $\left(F_{2}\right)$ pela seguinte expressão [8]:

$$
\sigma^{\gamma^{*} p}=\frac{4 \pi^{2} \alpha_{e m}}{Q^{2}} F_{2}\left(x, Q^{2}\right)
$$

onde $\alpha_{e m}$ é a constante de acoplamento eletromagnético.

A grosso modo, $F_{2}$ nos dá uma medida da quantidade de constituintes do próton que carregam carga elétrica. Enquanto a seção de choque tem dimensão de área, a 
função de estrutura é adimensional.

\subsubsection{Espalhamento Inelástico Profundo Difrativo - DDIS}

Nos processos de DIS, e também nos processos de colisão $p p$, observa-se com certa frequência o chamado Espalhamento Difrativo [8]. A principal característica desse tipo de espalhamento é que, no estado final da colisão, o alvo $(p)$ está bem separado em rapidez $(Y)$ do sistema $X$ de partículas criado. No caso do Espalhamento Inelástico Profundo - DIS - a ocorrência de eventos difrativos é chamada de Espalhamento Inelástico Profundo Difrativo, ou DDIS da sigla em inglês. O DDIS é representado da seguinte maneira [8]:

$$
e+p \rightarrow e+p+[L R G]+X
$$

onde $[L R G]$ faz referência à expressão em inglês Large Rapidity Gap, ou grande "gap" de rapidez. Este grande gap de rapidez significa que há uma região do espaço de fase, no estado final da colisão, na qual não é observada nenhuma partícula. Esta região separa o alvo $p$ do sistema $X$ de partículas. Nos experimentos de DIS no HERA, as colaborações ZEUS e H1 obervaram que cerca de $10 \%$ dos eventos é de natureza difrativa.

Uma segunda característica dos eventos de natureza difrativa é que, quando o alvo é um núcleo, ele pode permanecer intacto após a colisão. Isso é algo impressionante, já que o processo é inelástico e envolve energias muito altas. No entanto, há também eventos difrativos onde o alvo nuclear é fragmentado em prótons ou núcleos mais leves. Por exemplo, considere o seguinte processo de DDIS, onde $A$ representa um íon qualquer:

$$
e+A \rightarrow e+A^{*}+[L R G]+X
$$

Neste processo o sistema nuclear $A^{*}$ está bem separado em rapidez do sistema $X$ de partículas. Esse fato, por si só, caracteriza o processo (1.8) como sendo de natureza difrativa. O sistema nuclear $A^{*}$ pode ser tanto igual como também diferente de $A$. Se $A^{*}=A$, i.e., se o alvo $A$ permanece intacto após a colisão, nós dizemos que este 
processo é coerente. Por outro lado, se $A^{*} \neq A$ nós dizemos que esse processo é incoerente.

\subsubsection{Espalhamento Compton Profundamente Virtual - DVCS}

O Espalhamento Compton usual pode ser representado da seguinte maneira:

$$
\gamma e \rightarrow \gamma e,
$$

onde $\gamma$ é um fóton real e $e$ é um elétron. Se no estado final da interação nós temos um fóton real, i.e., se o processo de espalhamento for:

$$
\gamma^{*} e \rightarrow \gamma e
$$

e $\gamma^{*}$ for "profundamente virtual" $\left(Q^{2} \gg 0\right)$, nós temos então o chamado Espalhamento Compton Profundamente Virtual - em inglês Deeply Virtual Compton Scattering (DVCS). Um dos trabalhos apresentados nesta tese é sobre o DVCS nuclear, i.e.:

$$
\gamma^{*} A \rightarrow \gamma A
$$

que é similar ao processo (1.10), porém com o elétron substituído pelo núcleo $A$.

\subsection{Os constituintes internos do hádron}

Hádron é um nome dado a qualquer partícula constituída por quarks. Os prótons, por exemplo, são compostos por três quarks, sendo dois deles de sabor up e um de sabor down. O nêutron possui uma estrutura semelhante, sendo composto por dois quarks down e um up. A principal característica dos quarks é que eles interagem entre si pela força forte, a qual é intermediada pela troca de glúons. Portanto, além de quarks, os hádrons possuem também glúons.

No que se segue, faremos uma breve descrição do modelo a pártons, como ori- 
ginalmente proposto por Bjorken e Feynman. Esse modelo foi muito importante na comprovação de que os hádrons possuem uma estrutura interna. Após a descrição deste modelo, serão apresentadas as equações de DGLAP. Estas equações são obtidas perturbativamente e descrevem o comportamento das distribuições de quarks e de glúons como funções da virtualidade $Q^{2}$ do fóton nos processos de DIS. Veremos que a distribuição de glúons é a que predomina no regime de altas energias (pequenos valores da variável $x$ de Bjorken).

\subsubsection{O modelo a pártons}

A idéia do modelo a pártons é que o próton não é uma partícula elementar, mas é composto por outras partículas, estas sim elementares. Estas partículas são chamadas "pártons".

Esse modelo implica que, num processo de DIS, por exemplo, o fóton virtual emitido pelo elétron vai interagir incoerentemente com os constituintes internos do próton. Com isso, a seção de choque $\gamma^{*} p\left(\sigma^{\gamma^{*} p}\right)$ é expressa como uma soma das seções de choque individuais $\gamma^{*}$-párton $(\hat{\sigma})$ da seguinte maneira:

$$
\frac{d^{2} \sigma^{\gamma^{*} p}}{d x d Q^{2}}=\sum_{i} \int_{0}^{1} d \xi f_{i}(\xi) \frac{d^{2} \hat{\sigma}_{i}}{d x d Q^{2}}
$$

A função $f_{i}(\xi)$ representa a probabilidade de haver, no interior do próton, um párton do tipo $i$ carregando uma fração $\xi$ do momento protônico. As funções $f_{i}(\xi)$ são conhecidas como "funções de distribuição de pártons".

Em 1969 Bjorken mostrou que, se o próton for composto por férmions puntiformes que não interagem entre si, quando ambos $\nu$ e $Q^{2} \rightarrow \infty$, as funções de estrutura $F_{i}$ do próton devem obedecer ao chamado scaling de Bjorken [8]. Esse "scaling" implica que as funções de estrutura passam a depender de uma única variável $x=Q^{2} /\left(2 m_{p} \nu\right)$, e não mais de $\nu$ e de $Q^{2}$ separadamente. Por exemplo, no caso da função de estrutura 
$F_{2}$ citada anteriormente, o scaling de Bjorken implica que:

$$
\left(\nu, Q^{2}\right) \rightarrow \infty \quad \rightarrow \quad F_{2}\left(\nu, Q^{2}\right) \approx F_{2}(x)
$$

Esta variável é a mesma já apresentada na Eq. (1.2), e é conhecida como variável $x$ de Bjorken. No mesmo ano em que Bjorken publicou seu trabalho, dados experimentais do SLAC confirmaram suas predições. Feynman interpretou isso como uma evidência de que o próton é composto por partículas elementares [9, 10], os pártons.

\subsubsection{As equações de DGLAP}

O modelo a pártons é apenas a aproximação de ordem zero do mundo real, pois os quarks não são objetos livres. A interação entre os quarks é intermediada pela troca de glúons e é descrita pela Cromodinâmica Quântica - em inglês Quantum Cromodynamics (QCD). No regime de altas energias (pequenas distâncias) a interação forte pode ser tratada perturbativamente e a teoria passa a ser chamada de QCD perturbativa. A QCD perturbativa prediz uma dependência suave em $Q^{2}$ para as funções de estrutura, uma dependência de tipo logarítmica. Portanto, ela prediz uma violação do scaling de Bjorken.

Um resultado interessante da QCD perturbativa é que as distribuições de pártons dentro do próton, em processos de DIS, não são fixas, mas dependem da virtualidade $Q^{2}$ do fóton emitido pelo elétron e da energia do sistema no referencial do centro de massa. A evolução das distribuições partônicas em $Q^{2}$ é dada pelas equações de Dokshitzer-Gribov-Lipatov-Altarelli-Parisi, ou simplesmente "equações de DGLAP". Para um quark $q_{i}$, de sabor $i$, por exemplo, a equação de DGLAP é dada por [11, 12]:

$$
\frac{\partial q_{i}\left(x, Q^{2}\right)}{\partial \ln Q^{2}}=\frac{\alpha_{s}}{2 \pi}\left[\int_{x}^{1} \frac{d x_{1}}{x_{1}}\left(P_{q q}\left(\frac{x}{x_{1}}\right) q_{i}\left(x_{1}, Q^{2}\right)+P_{q g}\left(\frac{x}{x_{1}}\right) g\left(x_{1}, Q^{2}\right)\right)\right]
$$


e para a distribuição de glúons temos:

$$
\frac{\partial g\left(x, Q^{2}\right)}{\partial \ln Q^{2}}=\frac{\alpha_{s}}{2 \pi}\left[\int_{x}^{1} \frac{d x_{1}}{x_{1}}\left(P_{g q}\left(\frac{x}{x_{1}}\right) q_{S}\left(x_{1}, Q^{2}\right)+P_{g g}\left(\frac{x}{x_{1}}\right) g\left(x_{1}, Q^{2}\right)\right)\right],
$$

onde $q_{S}\left(x, Q^{2}\right)$ é a distribuição de quarks singleto:

$$
q_{S}\left(x, Q^{2}\right)=\sum_{i}\left[q_{i}\left(x, Q^{2}\right)+\bar{q}_{i}\left(x, Q^{2}\right)\right]
$$

As funções $P_{i j}\left(P_{q q}, P_{q g}, P_{g q}, P_{g g}\right)$ são as chamadas "funções de splitting", e podem ser interpretadas como a probabilidade de um párton $i$ emitir um párton $j$. Em ordem dominante em $\alpha_{s}$ estas funções são dadas por [7, 11, 12]:

$$
\begin{aligned}
& P_{q q}^{(0)}(z)=C_{F}\left[\frac{1+z^{2}}{(1-z)_{+}}+\frac{3}{2} \delta(1-z)\right] \\
& P_{q g}^{(0)}(z)=\frac{1}{2}\left[z^{2}+(1-z)^{2}\right] \\
& P_{g q}^{(0)}(z)=C_{F}\left[\frac{1+(1-z)^{2}}{z}\right] \\
& P_{g g}^{(0)}(z)=2 C_{A}\left[\frac{z}{(1-z)_{+}}+\frac{1-z}{z}+z(1-z)\right]+\frac{11 C_{A}-2 n_{f}}{6} \delta(1-z)
\end{aligned}
$$

onde $C_{F}=\left(N_{C}^{2}-1\right) / 2 N_{C}, C_{A}=N_{C}, N_{C}$ é o número de cores, $n_{f}$ é o número de sabores e $z=x / x_{1}$. As distribuições "+" são dadas por [7]:

$$
\int_{0}^{1} d x \frac{f(x)}{(1-x)_{+}}=\int_{0}^{1} d x \frac{f(x)-f(1)}{1-x}
$$

As equações de DGLAP permitem determinar apenas a evolução das distribuições partônicas. As condições iniciais para a evolução são de natureza não-perturbativa, e não são determinadas pela teoria. As condições iniciais podem ser inferidas, por exemplo, através da análise de resultados experimentais para um certo valor de $Q^{2}$. À partir daí, as equações de DGLAP podem ser usadas para evoluir as distribuições partônicas para outros valores de $Q^{2}$. As distribuições obtidas por esse procedimento podem ser usadas para calcular seções de choque em qualquer tipo de processo de 
interesse, já que elas devem ser universais, independentes do processo considerado.

Existem na literatura diversos grupos que se dedicam a obter parametrizações para as distribuições partônicas, i.e., soluções das equações DGLAP para todos os tipos de pártons. Em nossos cálculos nós utilizaremos as distribuições partônicas propostas em [13], a qual nós chamaremos de GRV-98. Em [13] os parâmetros de entrada foram escolhidos apropriadamente para descrever os dados experimentais de $F_{2}^{p}\left(x, Q^{2}\right)$ (função de estrutura do próton) mais recentes da época (1998) obtidos no HERA.

\subsubsection{As equações de DGLAP no limite de pequeno $x$}

Observando as funções de splitting $P_{i j}$ apresentadas na subseção anterior, podemos notar que as funções associadas aos glúons $P_{g q}(z)$ e $P_{g g}(z)$ são singulares para $z \rightarrow 0$, ou seja, para $x \rightarrow 0$, pois $z=\frac{x}{x_{1}}$. As outras funções, associadas aos quarks, são regulares nesse limite. Isso implica que no limite de $x \rightarrow 0$ são os glúons que predominam. De fato, conforme foi discutido na Ref. [7], para $x$ muito pequeno a equação de DGLAP para $g\left(x, Q^{2}\right)$ pode ser aproximada por:

$$
\frac{\partial g\left(x, Q^{2}\right)}{\partial \ln Q^{2}}=\frac{\alpha_{s}}{2 \pi} \int_{x}^{1} \frac{d x_{1}}{x_{1}} \mathcal{P}_{g g}\left(\frac{x}{x_{1}}\right) g\left(x_{1}, Q^{2}\right)
$$

onde $\mathcal{P}_{g g}(z)=P_{g g}^{z \rightarrow 0}(z)=\frac{2 C_{A}}{z}$ representa o termo singular na função de splitting.

Em [8] foi derivada a seguinte solução para esta equação no caso em que $\alpha_{s}$ é considerado fixo:

$$
x g\left(x, Q^{2}\right)=G(y, \Gamma)=\frac{G\left(\omega_{0}, \Gamma_{0}\right)}{2}\left(\frac{\alpha_{s} N_{c} \Gamma}{\pi^{3} y^{3}}\right)^{\frac{1}{4}} e^{2 \sqrt{\frac{\alpha_{s} N_{c}}{\pi} \Gamma y}}
$$

onde $y=\ln (1 / x), \Gamma=\ln \left(Q^{2} / Q_{0}^{2}\right)$ e $G\left(\omega_{0}, \Gamma_{0}\right)$ contém toda a dependência na condição inicial.

Como podemos ver, a equação de DGLAP prevê um forte crescimento da distribuição de glúons na região de pequeno $x$. Para $x$ muito pequeno a quantidade de glúons 
é imensa, sendo muito maior do que a de qualquer outro tipo de párton. Isso implica que, nesse regime, ao calcular seções de choque hadrônicas, nós podemos desprezar a presença dos quarks e considerar apenas os glúons.

No caso particular do DIS, onde o elétron interage com o próton pela troca de um fóton virtual, a princípio o fóton virtual não interagiria com os glúons, mas apenas com os quarks, pois os glúons não possuem carga elétrica. Entretanto, conforme veremos no próximo capítulo, um fóton virtual pode flutuar num par quark-antiquark, que por sua vez "enxerga" os glúons. Portanto, mesmo nos processos de DIS, no limite de pequeno $x$ nós podemos desprezar a presença de quarks no hádron e levar em conta somente os glúons.

\subsection{O DIS nuclear}

Existe uma grande quantidade de dados experimentais, de alta precisão, sobre as funções de estrutura do próton medidas em processos DIS. A análise global destes dados, feita por vários grupos de pesquisadores, levou a um bom conhecimento sobre as funções de distribuição de pártons no próton. As parametrizações de distribuições partônicas, disponíveis na literatura, para o próton, são todas igualmente boas, dando resultados muito parecidos umas com as outras. Elas divergem, entretanto, na região de $x$ muito pequeno, onde não há dados.

No caso do núcleo, há poucos dados experimentais disponíveis de processos de DIS nuclear, ou seja, processos de espalhamento $e A$, e estes poucos dados não têm boa precisão. Sabemos muito pouco sobre as distribuições de pártons nucleares. Já há alguns anos vêm sendo discutidos projetos de construção de um colisor eletron-íon - em inglês Electron-Ion Collider (EIC) - o qual poderá nos fornecer uma quantidade grande de dados de alta precisão deste tipo de processo. O design original do EIC envolve duas propostas [14]. Uma delas é a construção do eRHIC no lugar do atual RHIC, onde as energias envolvidas serão maiores do que as atuais. A outra proposta é a construção do ELIC no atual Jefferson Lab [14]. O eRHIC permitirá experimentos com energias no 


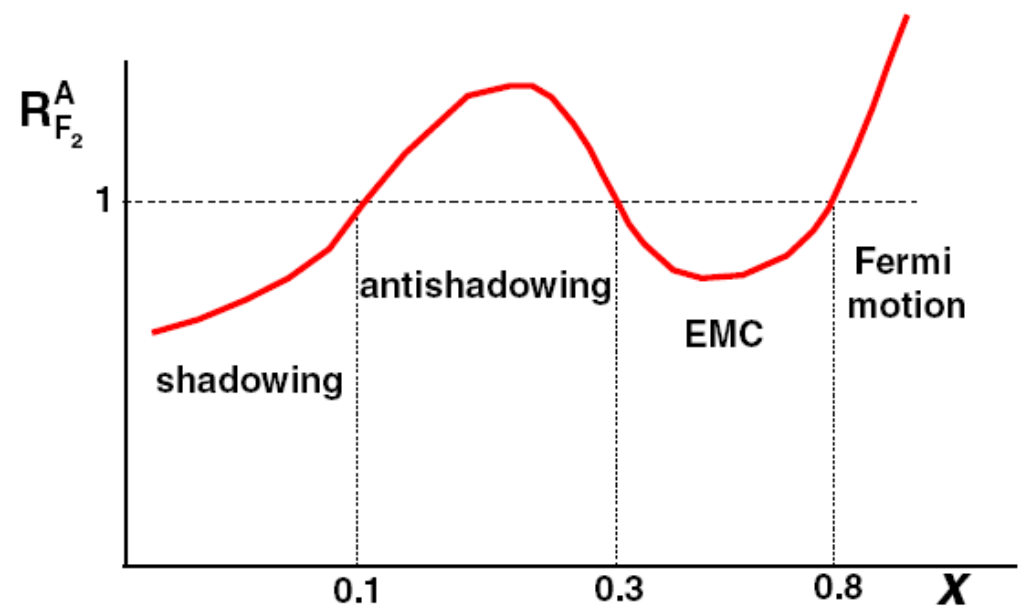

Figura 1.2: Razão $R_{F_{2}}^{A}=F_{2}^{A} /\left(A F_{2}^{N}\right)$ (Extraído de [16]) .

centro de massa $\sqrt{s}=60-90 \mathrm{GeV}$ e menor luminosidade $\mathcal{L} \approx 10^{33} \mathrm{~cm}^{-2} \mathrm{~s}^{-1}$, enquanto o ELIC terá energias $\sqrt{s} \leq 60 \mathrm{GeV}$ e maior luminosidade $\mathcal{L} \approx 10^{35} \mathrm{~cm}^{-2} \mathrm{~s}^{-1}$.

Como nossos trabalhos envolvem processos $e A$ com pequenos valores de $x$ (maiores energias no centro de massa), o projeto eRHIC é o mais interessante para nós.

\subsection{1 "Shadowing" nuclear}

Os dados obtidos em experimentos de DIS nuclear (colisões $e A$ ) mostram que a função de estrutura do núcleon ligado ao núcleo $\left(F_{2}^{A} / A\right)$ é diferente da função de estrutura do núcleon livre $\left(F_{2}^{N}\right)$, onde $A$ é o número de massa do núcleo [15].

A modificação na função de estrutura depende da região de $x$ considerada (veja Fig. 1.2). O chamado Nuclear Shadowing Effect, ou efeito de "shadowing" nuclear, acontece para:

$$
x<0,1 \quad, \quad 0,3<x<0,8
$$

e implica que a função de estrutura do núcleon ligado ao núcleo é menor do que a função de estrutura do núcleon livre. Um efeito contrário (antishadowing) acontece 
na região:

$$
0,1<x<0,3
$$

ou seja, nesta região há um efeito de aumento na função de estrutura do núcleon ligado ao núcleo com relação ao núcleon livre.

\subsubsection{Parametrizações das distribuições nucleares de pártons}

Dada a distribuição $f_{i}\left(x, Q^{2}\right)$ de um determinado párton do tipo $i$ em um núcleon, para obter a distribuição $f_{i}^{A}$ desse mesmo párton em um núcleo de número de massa $A$ é preciso multiplicar $f_{i}$ por um fator $R_{i}^{A}$, i.e.:

$$
\frac{f_{i}^{A}\left(x, Q^{2}\right)}{A} \equiv R_{i}^{A}\left(x, Q^{2}\right) f_{i}\left(x, Q^{2}\right)
$$

O fator de modificação nuclear $R_{i}^{A}$ seria igual a 1 se as distribuições de pártons em um núcleo fossem uma mera superposição das distribuições de pártons dos núcleons. Porém, como discutido na seção anterior, existem os fenômenos de shadowing e antishadowing, dependendo do valor de $x$ considerado, que implicam que $R_{i}^{A}$ é menor ou maior que 1 respectivamente.

$\mathrm{Na}$ Ref. [1] foi feito um estudo quantitativo detalhado da distribuição nuclear de glúons, que conforme já foi citado é a que predomina no regime de pequeno $x$. Nesse estudo foram utilizadas quatro diferentes parametrizações para o fator $R_{g}^{A}$, i.e., o fator de modificação nuclear da distribuição gluônica. As quatro parametrizações tomadas foram: EKS 98 [17], DS [18], HKN [19] e EPS 08 [20]. A idéia básica das parametrizações propostas para $R_{g}^{A}$ é considerar que as distribuições nucleares de pártons, Eq. (1.26), podem ser evoluídas usando as equações DGLAP, assim como é feito para as distribuições partônicas do próton livre. Diferentes parametrizações diferem, por exemplo, na forma das distribuições partônicas na escala inicial, no uso de diferentes conjuntos de dados experimentais, na ordem da evolução DGLAP, entre outras coisas. 


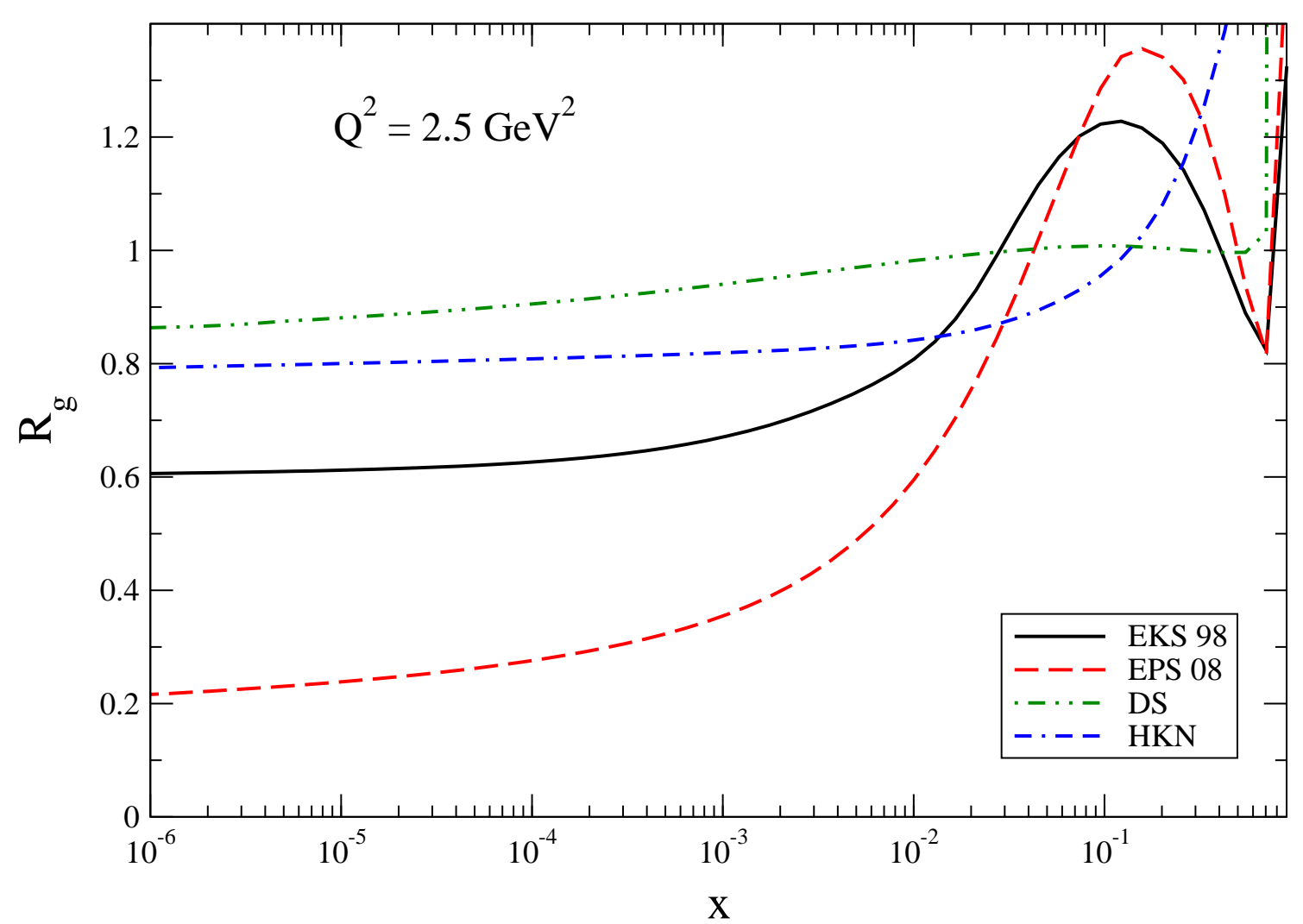

Figura 1.3: Razão $R_{g}=x g_{A} /\left(A x g_{N}\right)$ predita pelas parametrizações EKS 98, DS, HKN e EPS 08 para $A=208$ e $Q^{2}=2,5 G e V^{2}$. Extraído de [1].

Por exemplo, as parametrizações DS e HKN estão disponíveis em "Leading Order" (LO) e em "Next-to-Leading Order" (NLO) na constante de acoplamento, enquanto os grupos EKS e EPS fazem uma análise global apenas em LO. Para compararmos as diferentes parametrizações entre si, em [1] nós usamos DS e HKN em LO.

Na Fig. 1.3, extraída da Ref. [1], podemos ver o fator $R_{g}^{A}$ para o chumbo $(A=208)$ predito pelas quatro parametrizações citadas. Vemos que a incerteza na magnitude deste fator é muito grande. Os dois extremos são as curvas EPS 08 e DS. Enquanto a primeira prediz um forte efeito de shadowing nuclear na região de pequeno $x$, a segunda prediz um efeito fraco.

A conclusão é que, atualmente, sabemos muito pouco sobre a magnitude do efeito de shadowing. 


\section{Capítulo 2}

\section{O formalismo de dipolos de cor}

Em processos de colisão onde o alvo é um hádron, frequentemente usamos o formalismo de dipolo de cor para calcular as seções de choque. A principal vantagem desse formalismo é que, conforme veremos no capítulo 3, ele permite incluir, de forma natural, efeitos de saturação na distribuição de glúons.

\subsection{Dipolos de cor}

No capítulo anterior nós vimos que, nos processos de DIS, o elétron emite um fóton virtual, que por sua vez interage com o alvo hadrônico, que pode ser um próton $p$ ou um núcleo $A$. No referencial do alvo hadrônico, o formalismo de dipolo de cor faz uso do fato de que, no limite de grande $W^{2}$ (pequeno $x$ ), antes de interagir com o alvo, o fóton virtual flutua num par $q \bar{q}$ (quark-antiquark) [8] (veja Fig. 2.1). Como o fóton não carrega carga de cor, o par tem que ser "branco", o que implica que o antiquark carrega a anticor correspondente à cor carregada pelo quark. Daí o nome "dipolo de cor". No regime cinemático de $x$ muito pequeno, o tempo de vida do dipolo é muito maior do que o tempo de interação do dipolo com alvo. Por isso, podemos considerar o tamanho transversal $\rho$ do dipolo como sendo fixo durante a interação.

No formalismo de dipolo de cor, a seção de choque $\gamma^{*} p$ em processos de DIS, pode 


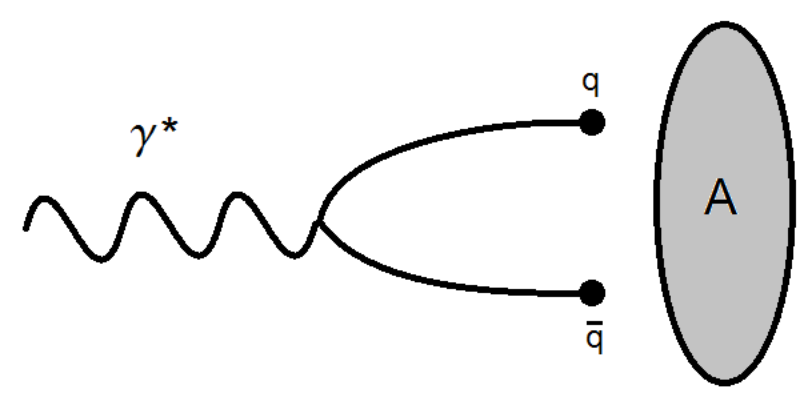

Figura 2.1: No formalismo de dipolo, $\gamma^{*}$ flutua num par $q \bar{q}$ antes de interagir com o alvo $A$.

ser fatorizada da seguinte maneira [8]:

$$
\sigma_{L, T}^{\gamma^{*} p}\left(x, Q^{2}\right)=\int_{0}^{1} d z \int d^{2} \vec{\rho}\left|\Psi_{L, T}(z, \rho)\right|^{2} \sigma_{d i p}(x, \rho)
$$

onde $L, T$ fazem referência respectivamente às polarizações longitudinal e transversal de $\gamma^{*}, \rho$ é o raio transversal do par $q \bar{q}, z(1-z)$ é a fração do momento do fóton virtual carregada pelo quark (antiquark) e $\sigma_{d i p}$ é a seção de choque dipolo-próton.

O termo $\left|\Psi_{L, T}\right|^{2}$ pode ser interpretado como a probabilidade do fóton virtual flutuar num par $q \bar{q}$. Na aproximação em que as massas dos quarks são nulas, este termo é dado por [8]:

$$
\begin{aligned}
\left|\Psi_{L}(z, \rho)\right|^{2} & =\frac{6 \alpha_{e m}}{(2 \pi)^{2}} \sum_{f} 4 e_{f}^{2} Q^{2} z^{2}(1-z)^{2} K_{0}^{2}(\varepsilon \rho) \\
\left|\Psi_{T}(z, \rho)\right|^{2} & =\frac{6 \alpha_{e m}}{(2 \pi)^{2}} \sum_{f} e_{f}^{2}\left[z^{2}+(1-z)^{2}\right] \varepsilon^{2} K_{1}^{2}(\varepsilon \rho)
\end{aligned}
$$

onde $\varepsilon^{2}=Q^{2} z(1-z), e_{f}$ é a carga fracionária do quark de sabor $f$ e $K_{0}$ e $K_{1}$ são as funções de Bessel modificadas. 


\subsubsection{A amplitude de espalhamento dipolo-hádron}

Em geral, a seção de choque dipolo-hádron $\left(\sigma_{d i p}\right)$ é escrita em termos de uma amplitude de probabilidade para que o espalhamento aconteça [8]:

$$
\sigma_{d i p}(x, \vec{\rho})=2 \int d^{2} \vec{b} \mathcal{N}(x, \vec{\rho}, \vec{b})
$$

onde $\mathcal{N}$ é a amplitude de espalhamento dipolo-hádron em um dado parâmetro de impacto $\vec{b}$. A maioria dos modelos existentes na literatura assume a seguinte fatorização $\operatorname{para} \mathcal{N}:$

$$
\mathcal{N}(x, \vec{\rho}, \vec{b})=\mathcal{N}(x, \vec{\rho}) S(\vec{b})
$$

Substituindo na Eq. (2.3), a função $S(\vec{b})$ é integrada e dá origem a um parâmetro $\sigma_{0}$ constante:

$$
\sigma_{d i p}(x, \vec{\rho})=\sigma_{0} \mathcal{N}(x, \vec{\rho})
$$

O parâmetro $\sigma_{0}$ está relacionado à QCD não-perturbativa, e em geral é considerado um parâmetro livre, escolhido de forma a descrever os dados experimentais.

No capítulo 3 veremos alguns modelos para $\mathcal{N}$.

\subsubsection{Formalismo de dipolo e a fatorização $k_{T}$}

Na fatorização colinear, a qual é usada na obtenção das equações de DGLAP, o momento do párton é considerado paralelo ao momento do hádron [8], tal que o párton carrega uma fração $x$ do momento hadrônico. Isso quer dizer que a componente transversal $k_{T}$ do momento partônico é desprezada.

Em energias muito altas $(x \rightarrow 0)$ esta fatorização deve ser generalizada de forma a permitir que os pártons possuam momento transversal $k_{T}$ não-nulo. É a chamada fatorização $k_{T}[7,8]$.

Na fatorização $k_{T}$, são introduzidas as distribuições de pártons não integradas em $k_{T}$. Em particular, a distribuição não integrada de glúons $f\left(x, k_{T}^{2}\right)$ está relacionada com 
a distribuição usual de glúons $x g\left(x, Q^{2}\right)$, que é solução da equação DGLAP, através da seguinte expressão [8]:

$$
x g\left(x, Q^{2}\right)=\int^{Q^{2}} \frac{d k_{T}^{2}}{k_{T}^{2}} f\left(x, k_{T}^{2}\right) .
$$

Nikolaev e Zakharov, e posteriormente Mueller, demonstraram em ordem dominante que a expressão (2.1) pode ser obtida no formalismo da fatorização $k_{T}$ [21]. A seção de choque dipolo-hádron origina-se da transformada de Fourier da distribuição de glúons não integrada, sendo $\rho$ a variável de Fourier conjugada a $k_{T}$.

Isso mostra que o formalismo de dipolo possui a vantagem de levar em conta o momento transverso dos pártons.

No formalismo de dipolo nós trabalhamos numa representação mista, em que as coordenadas transversais são tratadas no espaço das posições, no caso as coordenadas transversais do quark e do antiquark, enquanto a coordenada longitudinal é tratada no espaço dos momentos.

\subsection{Aplicações}

O objetivo da seção anterior foi apresentar o formalismo de dipolo de cor e a sua aplicação mais simples, que é o processo de DIS. Nesta seção veremos as aplicações desse formalismo a três outros processos, os quais são de interesse para essa tese.

\subsubsection{Produção exclusiva de fótons e mésons vetoriais}

Na Ref. [4] nós tratamos da produção exclusiva de mésons vetoriais em processos de DDIS nuclear, i.e., em processos de DIS Difrativo onde o alvo é um núcleo $A$ (veja seção 1.1.3). Além de mésons vetoriais, nós estudamos também a produção de fótons neste mesmo tipo de processo. A produção de fótons em processos ep é conhecida como espalhamento Compton profundamente virtual, ou DVCS da sigla em inglês (veja seção 1.1.4). A produção de fótons em processos $e A$ será chamada de DVCS 
nuclear.

Um evento de DDIS nuclear exclusivo pode ser representado por:

$$
\gamma^{*}+A \rightarrow E+[L R G]+A^{*},
$$

onde $[L R G]$ faz referência ao "Large Rapidity Gap" (veja seção 1.1.3), e E representa a partícula de interesse produzida no processo. Este processo só é diferente daquele esquematizado em (1.8) no sentido que estamos considerando apenas os eventos que produzem a partícula $E$ de interesse. Já no processo (1.8), que é inclusivo, todas as partículas produzidas, de todos os tipos, são conjuntamente representadas por $X$.

Conforme já vimos na seção anterior, no formalismo de dipolo de cor o fóton virtual se abre num par $q \bar{q}$ antes de interagir com o alvo. Quando o processo (2.7) é coerente, $A^{*}=A$, a seção de choque para a produção exclusiva da partícula $E$, no regime de altas energias, é dada por [22, 23]:

$$
\sigma^{c o h}\left(\gamma^{*} A \rightarrow E A\right)=\int d^{2} \vec{b}\left\langle\mathcal{N}^{A}(x, \vec{\rho}, \vec{b})\right\rangle^{2}
$$

onde:

$$
\left\langle\mathcal{N}^{A}\right\rangle=\int d^{2} \vec{\rho} \int d z \Psi_{E}^{*}(\vec{\rho}, z) \mathcal{N}^{A}(x, \vec{\rho}, \vec{b}) \Psi_{\gamma^{*}}\left(\vec{\rho}, z, Q^{2}\right)
$$

sendo $\mathcal{N}^{A}(x, \vec{\rho}, \vec{b})$ a amplitude de espalhamento dipolo-alvo, com o índice $A$ fazendo referência ao fato de termos um núcleo $A$ como alvo. $\Psi_{E}(\vec{\rho}, z)$ é a função de onda, no cone de luz, do estado final exclusivo.

Os cálculos das seções de choque no formalismo de dipolo de cor apresentam uma característica marcante que diferencia os processos de natureza difrativa daqueles de natureza não-difrativa. Nas seções de choque de processos difrativos, como (2.8), a amplitude de espalhamento dipolo-alvo aparece elevada ao quadrado dentro da integral no parâmetro de impacto. Já as seções de choque de processos não-difrativos dependem linearmente da amplitude de espalhamento. Por exemplo, substituindo (2.3) em (2.1), 
vemos que a amplitude de espalhamento dipolo-alvo entra de forma linear na integral que determina a seção de choque do DIS. Maiores detalhes sobre estas diferenças podem ser encontrados, por exemplo, na Ref. [8].

Para calcular a seção de choque de produção coerente, Eq. (2.8), é preciso primeiro determinar a amplitude (2.9) do processo, que por sua vez depende da partícula $E$, na qual estamos interessados. No caso do DVCS nuclear, $E=\gamma$, nós temos um fóton virtual no estado inicial e um fóton real no estado final. O fóton virtual possui uma componente longitudinal de polarização, mas o fóton real possui apenas componente transversal. Portanto, neste caso, apenas a função de "overlap" de polarização transversal $\left(\Psi_{\gamma}^{*} \Psi_{\gamma^{*}}\right)_{T}$ contribui para o processo. Para um dado sabor $f$ de quark, esta função é dada por [8]:

$$
\left(\Psi_{\gamma}^{*} \Psi_{\gamma^{*}}\right)_{T}^{f}=\frac{2 N_{c}}{\pi} \alpha_{e m} e_{f}^{2}\left\{\left[z^{2}+(1-z)^{2}\right] \epsilon K_{1}(\epsilon \rho) m_{f} K_{1}\left(m_{f} \rho\right)+m_{f}^{2} K_{0}(\epsilon \rho) K_{0}\left(m_{f} \rho\right)\right\}
$$

onde $\epsilon^{2}=z(1-z) Q^{2}+m_{f}^{2}, m_{f}$ é a massa do quark, $\alpha_{e m}$ é a constante de acoplamento eletromagnético, $e_{f}$ é a carga fracionária do quark e $N_{c}=3$. Esta expressão assume que a virtualidade do fóton que entra é $Q_{1}^{2}=Q^{2}$ enquanto que a virtualidade do fóton que sai é $Q_{2}^{2}=0$.

Quando temos um méson vetorial no estado final, $E=V$, as funções de overlap transversal e longitudinal são dadas respectivamente por [22]:

$$
\left(\Psi_{V}^{*} \Psi_{\gamma^{*}}\right)_{T}=\hat{e}_{f} e \frac{N_{c}}{\pi z(1-z)}\left\{m_{f}^{2} K_{0}(\epsilon r) \phi_{T}(r, z)-\left[z^{2}+(1-z)^{2}\right] \epsilon K_{1}(\epsilon r) \partial_{r} \phi_{T}(r, z)\right\}
$$

e:

$$
\left(\Psi_{V}^{*} \Psi_{\gamma^{*}}\right)_{L}=\hat{e}_{f} e \frac{N_{c}}{\pi} 2 Q z(1-z) K_{0}(\epsilon r)\left[M_{V} \phi_{L}(r, z)+\frac{m_{f}^{2}-\nabla_{r}^{2}}{M_{V} z(1-z)} \phi_{L}(r, z)\right]
$$

onde $\nabla_{r}^{2} \equiv(1 / r) \partial_{r}+\partial_{r}^{2}$ e $M_{V}$ é a massa do méson. A carga efetiva $\hat{e}_{f}=2 / 3$, $1 / 3$ ou $1 / \sqrt{2}$, para os mésons $J / \Psi, \phi$ e $\rho$, respectivamente. As funções de onda 
associadas ao fóton são bem conhecidas na literatura, e é delas que vêm as funções de Bessel modificadas, $K_{0}$ e $K_{1}$, presentes nas expressões (2.11) e (2.12). Por outro lado, existem diferentes convenções para as funções de onda dos mésons vetoriais. Em nossos cálculos nós usaremos o modelo Gauss-LC [24]:

$$
\begin{gathered}
\phi_{T}(r, z)=N_{T}[z(1-z)]^{2} \exp \left(-r^{2} / 2 R_{T}^{2}\right), \\
\phi_{L}(r, z)=N_{L} z(1-z) \exp \left(-r^{2} / 2 R_{L}^{2}\right) .
\end{gathered}
$$

A motivação para esta escolha é sua simplicidade e o fato de que os resultados não são muito sensíveis a diferenças entre os modelos, como foi mostrado em [24]. Os valores dos parâmetros deste modelo estão na tabela 4.1 .

Voltando ao processo (2.7), se o núcleo espalha inelasticamente, tal que $A^{*} \neq A$, o processo é chamado de produção incoerente da partícula $E$. Nesse caso, nós temos um sistema $X$ de partículas criadas, $A^{*}=X$, as quais são associadas à quebra do núcleo $A$. A seção de choque de produção incoerente da partícula $E$ é dada por [22]:

$$
\sigma^{i n c}\left(\gamma^{*} A \rightarrow E X\right)=\frac{|\mathcal{I} m \mathcal{A}(s, t=0)|^{2}}{16 \pi B_{E}}
$$

onde em altas energias [23]:

$$
|\mathcal{I} m \mathcal{A}|^{2}=\int d^{2} \vec{b} T_{A}(\vec{b})\left\langle\sigma_{\text {dip }} e^{-\frac{1}{2} \sigma_{\text {dip }} T_{A}(\vec{b})}\right\rangle^{2}
$$

sendo:

$$
\left\langle\sigma_{\text {dip }} e^{-\frac{1}{2} \sigma_{d i p} T_{A}(\vec{b})}\right\rangle=\int d^{2} \vec{\rho} \int d z \Psi_{E}^{*}(\vec{\rho}, z)\left[\sigma_{d i p} e^{-\frac{1}{2} \sigma_{d i p} T_{A}(\vec{b})}\right] \Psi_{\gamma^{*}}\left(\vec{\rho}, z, Q^{2}\right)
$$

$T_{A}(\vec{b})$ é a função de perfil nuclear, que descreve a distribuição dos núcleons na área transversal do núcleo e é dada pela Eq. (3.25). A seção de choque dipolo-próton, $\sigma_{d i p}$, é determinada através da Eq. (2.3) e os modelos que usaremos para a amplitude de espalhamento dipolo-próton $\mathcal{N}$, assim como para a amplitude de espalhamento 

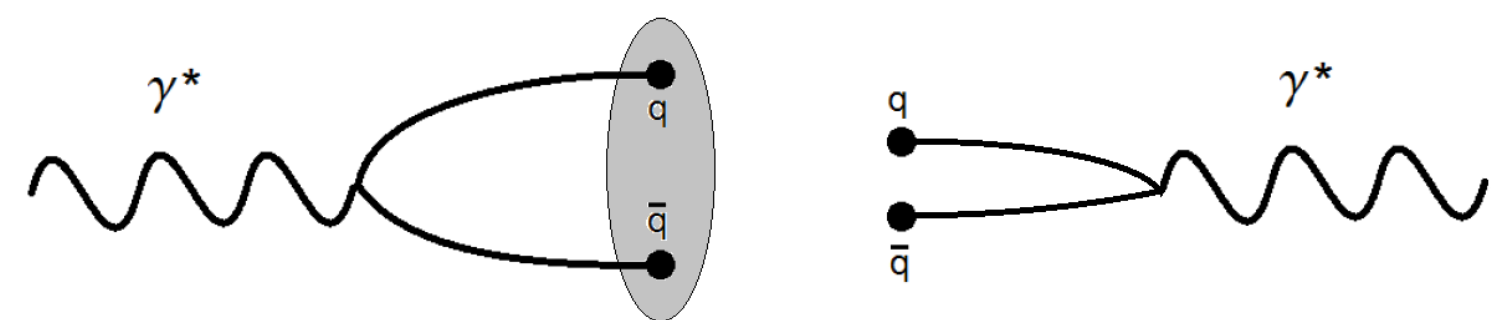

Figura 2.2: Diagrama ilustrando a interação entre dois fótons no formalismo de dipolo de cor. A área acinzentada representa o campo gluônico de um dos dipolos.

dipolo-núcleo $\mathcal{N}^{A}$, serão apresentados no capítulo 3.

Nosso trabalho sobre a produção exclusiva de mésons vetoriais e de fótons em processos de DDIS nuclear será apresentado no capítulo 4.

\subsubsection{Espalhamento fóton-fóton}

Na Ref. [5] estudamos o espalhamento fóton-fóton no formalismo de dipolos de cor. Em eletrodinâmica quântica (QED) dois fótons interagem através do "diagrama de caixa", que representa a flutuação destes fótons em pares elétron - pósitron. Em QCD acontece algo muito parecido. Na nossa abordagem os fótons flutuam em dipolos de cor e estes interagem um com o outro (veja Fig. 2.2). Isso implica que a seção de choque fóton-fóton, no formalismo de dipolo de cor, deverá conter dois termos de função de onda, e não apenas um como no caso do DIS (veja Eq. 2.1). Um dos termos de função de onda representa a probabilidade do fóton 1 flutuar no dipolo 1, enquanto o outro termo representa a probabilidade do fóton 2 flutuar no dipolo 2. De fato, a seção de choque fóton-fóton no formalismo de dipolos de cor é dada por:

$\sigma_{i j}\left(W^{2}, Q_{1}^{2}, Q_{2}^{2}\right)=\sum_{a, b=1}^{N_{f}} \int d z_{1} \int d^{2} \vec{\rho}_{1}\left|\Psi_{i}^{a}\left(z_{1}, \vec{\rho}_{1}\right)\right|^{2} \int d z_{2} \int d^{2} \vec{\rho}_{2}\left|\Psi_{j}^{b}\left(z_{2}, \vec{\rho}_{2}\right)\right|^{2} \sigma_{a, b}^{d d}\left(\vec{\rho}_{1}, \vec{\rho}_{2}, Y\right)$

onde $W^{2}$ é o quadrado da energia no centro de massa da colisão, $Q_{1}^{2}$ e $Q_{2}^{2}$ são as virtualidades dos fótons 1 e 2 envolvidos, $Y \approx \ln \left(W^{2} / Q_{1} Q_{2}\right)$ é a rapidez relativa, $\vec{\rho}_{1}$ $\left(\vec{\rho}_{2}\right)$ é o raio do dipolo $1(2)$ e $z_{1}\left(z_{2}\right)$ é a fração do momento do fóton 1 (2) carregada 
pelo quark presente no dipolo 1 (2), analogamente ao que já vimos no caso do DIS. Os índices $i$ e $j$ indicam os estados de polarização dos fótons ( $T$ ou $L)$. As funções de onda $\left|\Psi_{T}^{f}(z, \rho)\right|^{2}$ e $\left|\Psi_{L}^{f}(z, \rho)\right|^{2}$, para um dado sabor $f$ de quark, são dadas por:

$$
\begin{aligned}
\left|\Psi_{L}^{f}(z, \rho)\right|^{2} & =\frac{6 \alpha_{e m}}{4 \pi^{2}} e_{f}^{2}\left[4 Q^{2} z^{2}(1-z)^{2} K_{0}^{2}\left(\epsilon_{f} \rho\right)\right] \\
\left|\Psi_{T}^{f}(z, \rho)\right|^{2} & =\frac{6 \alpha_{e m}}{4 \pi^{2}} e_{f}^{2}\left\{\left[z^{2}+(1-z)^{2}\right] \epsilon_{f}^{2} K_{1}^{2}\left(\epsilon_{f} \rho\right)+m_{f}^{2} K_{0}^{2}\left(\epsilon_{f} \rho\right)\right\}
\end{aligned}
$$

onde $\left(\epsilon_{f}\right)^{2}=z(1-z) Q^{2}+m_{f}^{2}$, $e_{f}$ e $m_{f}$ são respectivamente a carga fracionária e a massa do quark de sabor $f$ e $K_{0}$ e $K_{1}$ são as funções de Bessel modificadas.

O termo $\sigma_{a, b}^{d d}\left(\vec{\rho}_{1}, \vec{\rho}_{2}, Y\right)$, presente em (2.18), é a seção de choque dipolo-dipolo, e o índice $a(b)$ especifica o sabor do quark contido no dipolo 1 (2).

Nossos resultados sobre o espalhamento fóton-fóton no formalismo de dipolo de cor serão apresentados no capítulo 5 .

\subsubsection{Produção de charme em colisões $p A$}

Na Ref. [6] estudamos a produção de quarks pesados em colisões próton-núcleo $(p A)$.

A interação forte é intermediada pela troca de glúons. O formalismo de dipolo de cor implica que alguns destes glúons irão flutuar em pares $q \bar{q}$. No entanto, os glúons não são partículas "brancas" como os fótons. Cada glúon carrega consigo uma carga de $\operatorname{cor} c_{i}$ e uma anticarga de cor $\bar{c}_{j}$. Aqui, $c_{i}$ representa as 3 possíveis cargas de cor, ou seja, vermelho $\left(c_{1}\right)$, azul $\left(c_{2}\right)$ e verde $\left(c_{3}\right)$, e $\bar{c}_{j}$ são as anticores correspondentes. Para que haja a conservação da carga de cor, quando o glúon se abrir num par $q \bar{q}$, o quark irá carregar a cor $c_{i}$ e o antiquark irá carregar a anticor $\bar{c}_{j}$. O par, portanto, não será um singleto de cor, mas sim um octeto. Esse fato torna a aplicação do formalismo de dipolo de cor em processos $p A$ um pouco mais complicada do que em processos de DIS, já que o fóton virtual não carrega carga de cor, e assim sua flutuação $q \bar{q}$ encontra-se num estado singleto.

O par $q \bar{q}$ no qual o glúon flutua é o próprio par $q \bar{q}$ que estamos interessados em 

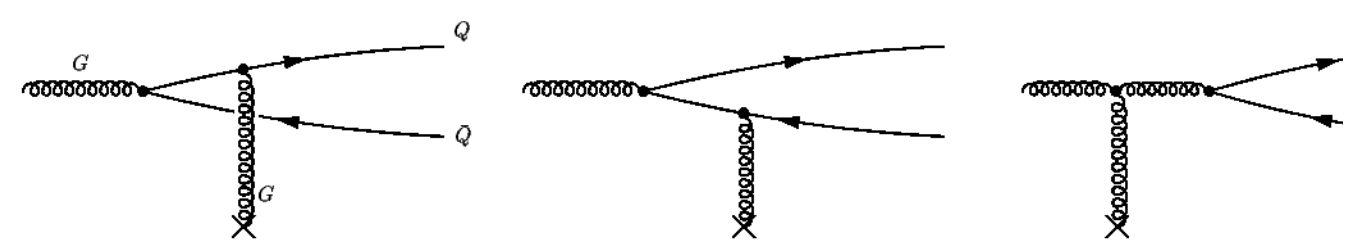

Figura 2.3: Os três gráficos de mais baixa ordem, no formalismo de dipolo de cor, que contribuem para o a produção de quarks pesados em colisões hádron-hádron. Extraído de [25].

encontrar no estado final da colisão. Para que a hadronização do par ocorra, i.e., para que ele se torne um singleto de cor, é preciso que pelo menos um glúon do alvo seja absorvido por ele. No caso onde um único glúon é absorvido, o mesmo deve conter as cores $\bar{c}_{i}$ e $c_{j}$ para que o par $q \bar{q}$ torne-se branco. Os diagramas de mais baixa ordem contribuindo para esse processo são aqueles mostrados na Fig. 2.3. Os dois primeiros gráficos mostram a situação onde um glúon do alvo é absorvido pelo quark ou pelo antiquark, e o terceiro gráfico mostra a situação onde um glúon do alvo é absorvido pelo glúon que foi emitido pelo projétil antes que este último flutue no par.

Geralmente, quando analisamos um processo de colisão $h_{1} h_{2}$ está implícito que o hádron $h_{2}$ é o alvo enquanto que o hádron $h_{1}$ é o projétil, e que a análise está sendo feita no referencial de repouso de $h_{2}$. Conforme será discutido na Seção 6.1, nas colisões $p A$ a troca do projétil $p$ pelo alvo $A$ (colisões $A p$ ) tem uma conseqüência particularmente interessante na forma como é feita a análise do processo. Enquanto as colisões $p A$ são ideais para estudar saturação, as colisões $A p$ podem ser usadas para estudar o efeito de "shadowing".

No que se segue, serão apresentadas as fórmulas que usamos nos cálculos de produção de charme. Como nossos cálculos foram feitos para processos $p p, p A$ e $A p$, as fórmulas serão apresentadas considerando a colisão de dois hádrons genéricos $h_{1}$ e $h_{2}$.

A seção de choque total $h_{1} h_{2} \rightarrow Q \bar{Q} X$ é dada por [25]:

$$
\sigma_{t o t}\left(h_{1} h_{2} \rightarrow\{Q \bar{Q}\} X\right)=2 \int_{0}^{-\ln \left(2 m_{Q} / \sqrt{s}\right)} d y x_{1} G_{h_{1}}\left(x_{1}, \mu_{F}\right) \sigma\left(G h_{2} \rightarrow\{Q \bar{Q}\} X\right)
$$

Nesta equação, $\sigma\left(G h_{2} \rightarrow\{Q \bar{Q}\} X\right)$ é a seção de choque de colisão de um glúon (emitido 
pelo projétil $\left.h_{1}\right)$ com o alvo $h_{2}$. A função $x_{1} G_{h_{1}}\left(x_{1}, \mu_{F}\right)$ representa a distribuição de glúons do projétil. Quanto mais glúons o projétil tiver, maior será a quantidade de glúons que ele emitirá. A variável y é a rapidez do par $Q \bar{Q}$, e $\mu_{F}$ é a escala de fatorização, que nós escolhemos $\mu_{F}=2 m_{Q}$.

A seção de choque $G h_{2} \rightarrow Q \bar{Q} X$, no formalismo de dipolo de cor (veja Fig. 2.3), é dada por [25]:

$$
\sigma\left(G h_{2} \rightarrow\{Q \bar{Q}\} X\right)=\int_{0}^{1} d \alpha \int d^{2} \rho\left|\Psi_{G \rightarrow Q \bar{Q}}(\alpha, \rho)\right|^{2} \sigma_{Q \bar{Q} G}^{h_{2}}(\alpha, \rho),
$$

onde $\sigma_{Q \bar{Q} G}^{h_{2}}$ é a seção de choque de um sistema quark-antiquark-glúon neutro de cor com o alvo $h_{2}, \alpha(\bar{\alpha}=1-\alpha)$ é a fração do momento do glúon carregada pelo quark (antiquark) e $\rho$ é a separação transversal entre o centro do par $Q \bar{Q}$ e o glúon.

A derivação da seção de choque $\sigma_{Q \bar{Q} G}^{h_{2}}(\alpha, \rho)$ pode ser encontrada na Ref. [26]. Os autores desta referência levaram em conta que o par $Q \bar{Q}$ pode ser criado, à partir da flutuação de um glúon, tanto no estado singleto como também no estado octeto de cor, e a seguinte expressão foi obtida:

$$
\sigma_{Q \bar{Q} G}^{h_{2}}(\alpha, \rho)=\frac{9}{8}\left[\sigma_{q \bar{q}}(\alpha \rho)+\sigma_{q \bar{q}}(\bar{\alpha} \rho)\right]-\frac{1}{8} \sigma_{q \bar{q}}(\rho)
$$

onde $\sigma_{q \bar{q}}(r)$ é a seção de choque de colisão de um par $q \bar{q}$ singleto de cor, com raio de separação $r$, contra um alvo $h_{2}$.

A função de onda do glúon no cone de luz, que representa a densidade de probabilidade da transição $G \rightarrow Q \bar{Q}$, que aparece na Eq. (2.22), é parecida com a função de onda do fóton, que descreve a transição $\gamma \rightarrow q \bar{q}$, e é dada por [25]:

$$
\left|\Psi_{G \rightarrow Q \bar{Q}}(\alpha, \rho)\right|^{2}=\frac{\alpha_{s}\left(\mu_{R}\right)}{(2 \pi)^{2}}\left\{m_{Q}^{2} K_{0}^{2}\left(m_{Q} \rho\right)+\left[\alpha^{2}+\bar{\alpha}^{2}\right] m_{Q}^{2} K_{1}^{2}\left(m_{Q} \rho\right)\right\},
$$


onde $\alpha_{s}\left(\mu_{R}\right)$ é a constante de acoplamento, que por sua vez é dada por:

$$
\alpha_{s}\left(\mu_{R}\right)=\frac{4 \pi}{\left(11-\frac{2}{3} N_{f}\right) \ln \left(\frac{\mu_{R}^{2}}{(200 M e V)^{2}}\right)},
$$

sendo $\mu_{R}$ a escala de renormalização, que nós assumiremos ser igual à massa do quark pesado. Além da seção de choque total de produção, Eq. (2.21), nós calculamos também a distribuição na rapidez $y$ :

$$
\frac{d \sigma\left(h_{1} h_{2} \rightarrow\{Q \bar{Q}\} X\right)}{d y}=x_{1} G_{h_{1}}\left(x_{1}, \mu_{F}\right) \sigma\left(G h_{2} \rightarrow\{Q \bar{Q}\} X\right)
$$

Esta equação é simplesmente a derivada da Eq. (2.21) com relação a $y$. 


\section{Capítulo 3}

\section{Modelos para a seção de choque dipolo-hádron}

O capítulo anterior foi iniciado com uma introdução ao formalismo de dipolo de cor e a sua aplicação mais simples, que é o processo de DIS. Logo a seguir na seção 2.2, foram apresentados os três processos que são tratados nesta tese. Todos eles fazem uso do formalismo de dipolo de cor. No entanto, nenhum modelo foi apresentado para a seção de choque dipolo-hádron, que aparece em todas as fórmulas. Este capítulo mostrará os modelos que usamos para a seção de choque de interação dipolo-hádron. Esta grandeza é fortemente dependente da dinâmica da QCD em altas energias.

\subsection{A Dinâmica Linear da QCD}

As equações de DGLAP são equações de evolução lineares nas distribuições partônicas (veja Seção 1.2.2). Em particular, a equação DGLAP que determina a distribuição de glúons $x G\left(x, Q^{2}\right)$ é linear nesta distribuição. Portanto, quando algum processo é calculado usando as soluções das equações de DGLAP para as distribuições partônicas, nós dizemos que esse processo é regido pela dinâmica linear da $Q C D$.

A seguir veremos um modelo de Física Linear para a seção de choque dipolo-próton. 


\subsubsection{O Modelo CT}

Na Ref. [27] foi proposta a seguinte expressão para a seção de choque dipolo-próton $\left(\sigma_{q \bar{q}}\right)$ na aproximação logarítmica dominante:

$$
\sigma_{q \bar{q}}\left(x, \rho^{2}\right)=\frac{\pi^{2}}{3} \rho^{2} \alpha_{s}\left[x G_{p}\left(x, 10 / \rho^{2}\right)\right]
$$

onde $\rho$ é o raio de separação do dipolo e $\alpha_{s}$ é a constante de acoplamento forte. Note que, nesta expressão, a variável $Q^{2}$ na distribuição $x G_{p}\left(x, Q^{2}\right)$ foi substituída por $10 / \rho^{2}$. De fato, conforme veremos mais adiante neste capítulo, numa primeira aproximação o raio ao quadrado $\rho^{2}$ de separação do dipolo é inversamente proporcional à virtualidade $Q^{2}$ do fóton virtual que o gerou, i.e., $\rho^{2} \propto 1 / Q^{2}$.

Uma observação importante a respeito da seção de choque (3.1) é que ela é diretamente proporcional a $\rho^{2}$. Isso implica que, quando o raio de separação do dipolo vai a zero, a seção de choque de interação do dipolo com o próton também vai a zero, e o dipolo passa pelo próton sem interagir com ele. Essa propriedade é chamada de "Transparência de Cor".

Este modelo para $\sigma_{q \bar{q}}$, em conjunto com a parametrização GRV98 para a distribuição de glúons no próton [13], será chamado nesta tese de "Modelo CT", onde CT é a abreviação da expressão "Color Transparency", ou transparência de cor. O Modelo CT será usado para fazer as predições da física linear nos processos $p A$. Os resultados serão apresentados no Capítulo 6.

\subsubsection{Generalização Nuclear do Modelo CT}

A generalização nuclear da Eq. (3.1), para calcular a seção de choque dipolo-núcleo $\sigma_{q \bar{q}}^{A}\left(x, \rho^{2}\right)$, é feita simplesmente substituindo a distribuição de glúons do próton $x G_{p}\left(x, Q^{2}\right)$ pela distribuição de glúons nuclear $x G_{A}\left(x, Q^{2}\right)$, para um dado núcleo com número de 
massa $A$ :

$$
\sigma_{q \bar{q}}^{A}\left(x, \rho^{2}\right)=\frac{\pi^{2}}{3} \rho^{2} \alpha_{s}\left[x G_{A}\left(x, 10 / \rho^{2}\right)\right]
$$

A distribuição nuclear de glúons está relacionada à distribuição gluônica de um próton através de um fator de modificação nuclear $R_{g}\left(x, Q^{2}\right)$ (veja Seção 1.3.2):

$$
x G_{A}\left(x, Q^{2}\right)=A R_{g}^{A}\left(x, Q^{2}\right) x G_{p}\left(x, Q^{2}\right) .
$$

\subsection{A Dinâmica Não-Linear da QCD}

Na seção 1.2.3 discutimos o comportamento das equações de DGLAP no regime de pequeno $x$ e apresentamos a Eq. (1.23) para a distribuição de glúons nesse regime cinemático. Olhando para a Eq. (1.23) vemos que, quando diminuímos $x$, a quantidade de glúons $x g\left(x, Q^{2}\right)$ aumenta. Se $x \rightarrow 0, x g \rightarrow \infty$. O mesmo vale quando aumentamos o valor da variável $Q^{2}$, sendo que se $Q^{2} \rightarrow \infty, x g \rightarrow \infty$.

Conforme foi discutido na Ref. [7], esse crescimento da distribuição de glúons pode ser entendido como um efeito cascata, onde os glúons presentes emitem novos glúons, que por sua vez também emitem glúons. Esse processo, onde glúons emitem glúons, é uma característica especial da QCD, que prediz que os glúons carregam carga de cor, e por isso eles interagem fortemente uns com os outros.

O crescimento ilimitado da distribuição de glúons com a diminuição de $x$ é problemático, e leva à violação da unitaridade. Para solucionar esse problema, foi proposta a idéia de "saturação da distribuição de glúons". Essa idéia consiste em considerar que, quando a densidade de glúons num hádron é muito alta, a quantidade de processos de recombinação, $g g \rightarrow g$, se torna tão grande que, em algum momento, o número de recombinações se iguala ao número de emissões, $g \rightarrow g g$. Quando isso ocorre, a distribuição de glúons satura, ou seja, a quantidade destas partículas presente no hádron para de crescer com o aumento de $Q^{2}$ ou a diminuição de $x$. 
Conforme discutido na Ref. [7], um trabalho pioneiro neste sentido foi proposto em 1983, por Gribov, Levin e Ryskin, na Ref. [28]. Estes autores propuseram a seguinte equação não-linear de evolução para a distribuição de glúons [7]:

$$
Q^{2} \frac{\partial^{2} x g\left(x, Q^{2}\right)}{\partial \ln (1 / x) \partial Q^{2}}=\frac{\alpha_{S} N_{c}}{\pi} x g\left(x, Q^{2}\right)-\frac{4 \alpha_{S}^{2} N_{c}}{3 C_{F} R^{2}} \frac{1}{Q^{2}}\left[x g\left(x, Q^{2}\right)\right]^{2}
$$

Observe que o termo não-linear desta distribuição possui sinal negativo. Este termo representa os processos de recombinação. Quando a densidade de glúons é pequena, o primeiro termo, linear em $x g$, é o termo dominante. À medida em que a distribuição $x g$ aumenta, o segundo termo vai se tornando cada vez mais importante, até que em um determinado momento os dois termos se tornam iguais, e o lado direito da Eq. (3.4) se anula, implicando que:

$$
Q^{2} \frac{\partial^{2} x g\left(x, Q^{2}\right)}{\partial \ln (1 / x) \partial Q^{2}}=0
$$

ou seja, nesse ponto ocorreu saturação, e $x g$ não cresce mais quando aumentamos $1 / x$ ou $Q^{2}$. O valor de $Q^{2}$ no qual isso ocorre $\left(Q_{s}^{2}\right)$ é chamado de "escala de saturação", e na teoria de Gribov, Levin e Ryskin é dado por:

$$
Q_{s}^{2}=\frac{4 \pi \alpha_{s}}{3 C_{F} R^{2}} x g\left(x, Q_{s}^{2}\right)
$$

Fazendo $Q^{2}=Q_{s}^{2}$ na Eq. (3.4) obtemos a Eq. (3.5).

\subsubsection{O Color Glass Condensate - CGC}

O trabalho de Gribov, Levin e Ryskin foi pioneiro na descrição da saturação de glúons. No entanto, um grande avanço ocorreu nesta área desde então, e teorias mais sofisticadas foram surgindo (veja a Ref. [7] e suas referências internas).

Uma teoria que teve grande aceitação na literatura é a teoria do "condensado de vidro colorido" - Color Glass Condensate (CGC) - proposta na Ref. [29]. 


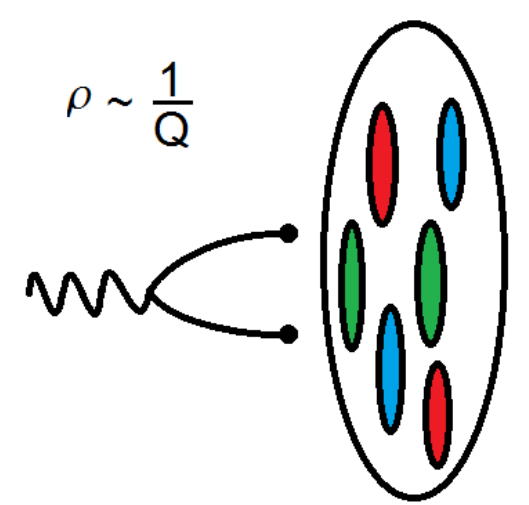

Figura 3.1: Resolução com a qual os glúons são "vistos" pelo dipolo.

O "condensado de vidro colorido" (CGC) tem esse nome por três razões. Primeiramente, ele é "colorido" porque ele é composto de glúons, e estes possuem carga de cor. Segundo, ele é um condensado porque a densidade de glúons é muito grande. Esta característica faz com que o campo gluônico tenha comportamentos clássicos. E terceiro, ele é um "vidro" porque os intervalos de tempo que caracterizam os seus processos internos sofrem uma forte dilatação, decorrente das Transformações de Lorentz. Dessa forma, qualquer mudança na estrutura do CGC ocorre lentamente.

Esta teoria dá origem a uma hierarquia infinita de equações de evolução acopladas, as chamadas Equações de JIMWLK [30]. Na aproximação de campo médio, a primeira destas equações se desacopla, é a chamada Equação de Balitsky-Kovchegov, ou simplesmente Equação de BK, a qual será apresentada na Seção 3.3.1.

\subsubsection{Uma visão geométrica da escala de saturação}

Conforme discutido na Ref. [7], é possível fazer uma análise geométrica, com argumentos clássicos, de como a saturação de glúons acontece. Para isso precisamos considerar duas características geométricas associadas aos glúons presentes no alvo hadrônico. Uma delas é a resolução, ou seja, o tamanho de cada glúon "visto" pelo dipolo, e a outra é a densidade de glúons no alvo.

A resolução depende do raio $\rho$ de separação do dipolo. Do "ponto de vista" do dipolo, o glúon ocupará uma área aproximadamente igual à sua (veja Fig. 3.1). Já a 
densidade de glúons depende tanto de $Q^{2}$ quanto da energia do sistema. Por exemplo, quando fixamos $Q^{2}$ e aumentamos a energia, a densidade de glúons aumenta (veja Fig. $3.2)$.

Nesta imagem clássica, a saturação ocorre quando a quantidade de glúons presentes no alvo for suficiente para preencher toda a área transversal do hádron. Quando isso acontecer, os glúons começarão a se sobrepôr uns aos outros, e os processos de recombinação serão mais frequentes, de tal forma que a quantidade de glúons sendo aniquilados se torna igual à quantidade de glúons sendo criados.

\section{A "escala de saturação"}

Usando essa imagem clássica, podemos encontrar uma expressão para a chamada "escala de saturação". Esta escala, chamada de " $Q_{s}$ " na literatura, separa o regime cinemático onde predomina a física linear do regime onde os efeitos de saturação tornam-se importantes.

Conforme dito anteriormente, a seção de choque $\sigma_{g}$ do glúon é da ordem da área ocupada pelo dipolo, i.e., $\sigma_{g} \sim \alpha_{s} \pi \rho^{2}$, onde $\alpha_{s}\left(Q^{2}\right)$ é a constante de acoplamento forte. O raio $\rho$ de separação do dipolo é inversamente proporcional à raiz quadrada da virtualidade $Q^{2}$ do fóton que deu origem a ele [7]:

$$
\rho \propto \frac{1}{\sqrt{Q^{2}}} .
$$

Isso nos permite expressar a seção de choque dipolo-glúon em termos de $Q^{2}[7]$ :

$$
\sigma_{g} \sim \alpha_{s}\left(Q^{2}\right) \frac{\pi}{Q^{2}}
$$

A saturação ocorre quando a soma das áreas individuais $\sigma_{g}$ dos glúons for igual à área $S_{A}$ do alvo, ou seja:

$$
S_{A}=N_{g}^{A} \sigma_{g}\left(Q_{s}^{2}\right) \sim N_{g}^{A} \alpha_{s} \frac{\pi}{Q_{s}^{2}}
$$

onde $N_{g}^{A}$ é o número de glúons presentes no alvo. Quando o alvo é um núcleo, $S_{A}$ 


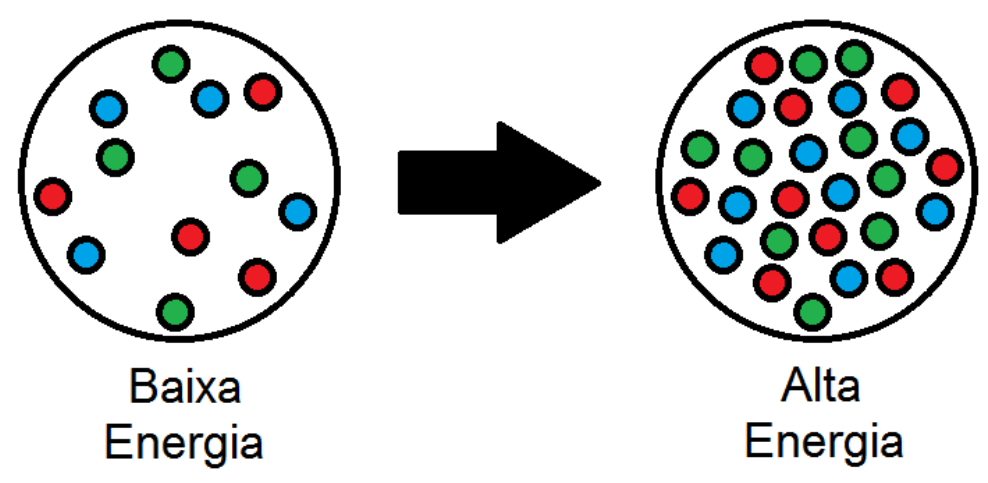

Figura 3.2: Aumento da densidade de glúons com a energia.

representa a área transversal do núcleo $A$ e o número $N_{g}^{A}$ usado na Eq. (3.9) é o número total de glúons contido no volume do núcleo $A$. Isso porque, devido à forte contração de Lorentz no comprimento longitudinal do núcleo, este ficará muito fino, e será praticamente um objeto bidimensional. Assim, todos os glúons presentes no núcleo estarão contidos num mesmo plano transversal de espessura desprezível. Invertendo a Eq. (3.9) para $Q_{s}^{2}$ obtemos:

$$
Q_{s}^{2}=\frac{\alpha_{s} N_{g}^{A} \pi}{S_{A}} .
$$

Usando $N_{g}^{A} \sim A x g\left(x, Q^{2}\right)$, onde $x g\left(x, Q^{2}\right)$ é a distribuição de glúons em um núcleon (próton ou nêutron), obtemos a seguinte expressão para a escala de saturação $Q_{s}$ em um núcleo com número de massa $A$ :

$$
Q_{s}^{2}=\frac{\alpha_{s} N_{g}^{A} \pi}{S_{A}} \sim \alpha_{s} \frac{A x g\left(x, Q^{2}\right)}{A^{2 / 3}} \sim A^{1 / 3} \alpha_{s} x g\left(x, Q^{2}\right)
$$

A "escala de saturação" $Q_{s}$ separa o regime linear do regime de saturação. Quando $Q^{2}>Q_{s}^{2}$, a distribuição de glúons encontra-se no regime linear, i.e., no regime onde os efeitos não-lineares da QCD são desprezíveis. Por outro lado, quando $Q^{2}<Q_{s}^{2}$, os efeitos não-lineares da QCD, responsáveis pela ocorrência de saturação, tornam-se importantes e não podem ser desprezados.

A escala de saturação dada pela expressão (3.11) é apenas uma primeira aproximação, obtida com argumentos geométricos. Alguns fatores multiplicativos constantes 
foram ignorados em sua determinação. O resultado mais importante desta expressão é que ela nos indica que a escala de saturação de um núcleo $A$ é dada em termos da escala de saturação de um próton simplesmente fazendo uma reescala desta última, ou seja, simplesmente multiplicando pelo fator $A^{1 / 3}$.

\subsection{Modelos de saturação}

Nesta seção apresentamos os modelos de saturação utilizados nos nossos cálculos. Na Seção 3.2 apresentamos a Eq. (3.4), que foi a primeira equação não-linear proposta para descrever o comportamento da distribuição de glúons. Outros modelos mais sofisticados foram surgindo em seguida. Os modelos mais recentes de saturação não são modelos para a distribuição de glúons $x g\left(x, Q^{2}\right)$, como a Eq. (3.4), mas são modelos para a amplitude $\mathcal{N}$ de espalhamento dipolo-hádron.

Conforme discutido na Seção 2.1.2, no formalismo de dipolo de cor a seção de choque dipolo-hádron $\left(\sigma_{d i p}\right)$ aparece como a transformada de Fourier da distribuição de glúons não integrada em $k_{T}$, sendo que o momento transversal $k_{T}$ é a variável de Fourier conjugada ao tamanho $\rho$ do dipolo. A seção de choque $\sigma_{d i p}$, por sua vez, é determinada como a integral no parâmetro de impacto da amplitude $\mathcal{N}$ de espalhamento dipolohádron (veja Seção 2.1.1). Os modelos de saturação que serão apresentados à seguir são modelos para $\mathcal{N}$.

\subsubsection{A equação de Balitsky-Kovchegov (BK)}

A equação não-linear mais popular hoje na literatura para descrever a dinâmica da QCD em altas energias é a Equação de Balitsky-Kovchegov, ou simplesmente "Equação de BK", que é dada por [31]:

$$
\begin{aligned}
\frac{\partial \mathcal{N}(\rho, Y)}{\partial Y}= & \int \frac{d^{2} \vec{z}}{2 \pi} K\left(\vec{\rho}, \overrightarrow{\rho_{1}}, \overrightarrow{\rho_{2}}\right)\left[\mathcal{N}\left(\rho_{1}, Y\right)+\mathcal{N}\left(\rho_{2}, Y\right)\right. \\
& \left.-\mathcal{N}(\rho, Y)-\mathcal{N}\left(\rho_{1}, Y\right) \mathcal{N}\left(\rho_{2}, Y\right)\right]
\end{aligned}
$$



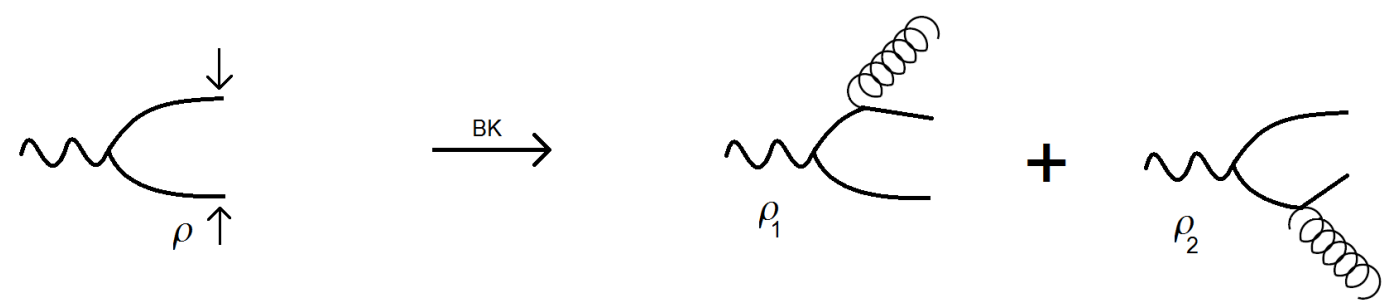

Figura 3.3: Representação da evolução feita pela Equação de BK sobre o par $q \bar{q}$, cujo tamanho inicial é $\rho$.

O "kernel" desta equação é dado por:

$$
\begin{aligned}
K\left(\vec{\rho}, \overrightarrow{\rho_{1}}, \overrightarrow{\rho_{2}}\right) & =\bar{\alpha}_{s} \frac{\rho^{2}}{\rho_{1}^{2} \rho_{2}^{2}} \\
\bar{\alpha}_{s} & =\frac{\alpha_{s} N_{c}}{\pi} .
\end{aligned}
$$

Como podemos ver, a Equação de BK evolui a amplitude $\mathcal{N}$ de espalhamento dipolohádron na rapidez $Y=\ln \left(x_{0} / x\right)$, onde $x$ é a variável de Bjorken e $x_{0}$ é um valor inicial constante para esta variável.

Basicamente, o que a Equação de BK faz é considerar a probabilidade de o quark (ou o antiquark) emitir um glúon antes de interagir com o alvo (veja Fig. 3.3). Se a emissão do glúon ocorrer, o tamanho do dipolo não será mais $\rho$. Se o quark (o antiquark) emitir um glúon, a posição transversal do quark (do antiquark) vai mudar, e o novo raio de separação do dipolo será $\rho_{1}\left(\rho_{2}\right)$. O vetor $\vec{z}$ de integração na Equação de BK representa a nova posição transversal do quark ou do antiquark, que emitiu o glúon, após a emissão.

O kernel da equação, $K\left(\vec{\rho}, \overrightarrow{\rho_{1}}, \overrightarrow{\rho_{2}}\right)$, é interpretado como a probabilidade de um glúon ser emitido pelo dipolo, e como podemos ver olhando a Eq. (3.12), duas novas amplitudes de espalhamento dipolo-hádron surgem após a emissão, uma considerando o novo tamanho $\rho_{1}$ do dipolo e a outra considerando o novo tamanho $\rho_{2}$.

O termo não-linear da Equação de BK assegura que a unitaridade seja satisfeita, ou seja, ele assegura que: $|\mathcal{N}(\rho, Y)| \leq 1$. Note que a Equação de BK não depende do 
parâmetro de impacto $\vec{b}$. De fato, a dependência de $\mathcal{N}$ com $\vec{b}$ é muito difícil de ser calculada.

\subsubsection{Os modelos fenomenológicos}

A Equação de BK não tem uma solução analítica conhecida. Por conta disso, vários modelos fenomenológicos para a amplitude $\mathcal{N}(\rho, Y)$ têm sido usados na literatura ao longo dos anos. Estes modelos procuram englobar as principais propriedades esperadas para $\mathcal{N}$. Duas destas propriedades dizem respeito ao comportamento de $\mathcal{N}$ nos regimes de pequeno e grande tamanhos de dipolo. O tamanho do dipolo é comparado com o inverso da escala de saturação $Q_{s}$, e as seguintes características são esperadas para $\mathcal{N}$ :

1. Transparência de cor: $\quad$ para $\quad \rho \ll 1 / Q_{s} \quad \rightarrow \quad \mathcal{N} \propto \rho^{2}$

2. Saturação: $\quad$ para $\quad \rho \gg 1 / Q_{s} \quad \rightarrow \quad \mathcal{N} \approx 1$

A "transparência de cor" implica que quando o tamanho do dipolo é muito pequeno a interação dele com o alvo hadrônico é muito fraca, sendo que no limite $\rho=0$ não há nenhuma interação. Já a propriedade de que para dipolos muito grandes $\mathcal{N} \rightarrow 1$ é uma conseqüência da saturação, e é esta propriedade que garante que $\mathcal{N}$ pode ser interpretado como uma amplitude de probabilidade de que a interação ocorra.

\subsubsection{O modelo de GBW}

Na Ref. [32], Golec-Biernart e Wüsthoff (GBW) propuseram o seguinte modelo fenomenológico para a amplitude de interação do dipolo com um próton:

$$
\mathcal{N}(x, \rho)=\left[1-\exp \left(-\frac{\left[Q_{\mathrm{s}}(x) \rho\right]^{2}}{4}\right)\right]
$$

com:

$$
Q_{s}^{2}(x)=Q_{0}^{2}\left(\frac{x_{0}}{\tilde{x}}\right)^{\lambda} \quad ; \quad \tilde{x}=x\left(1+\frac{4 m_{f}^{2}}{Q^{2}}\right)
$$


Alguns dos parâmetros deste modelo foram fixados:

$$
Q_{0}^{2}=1 \mathrm{GeV}^{2} \quad ; \quad m_{u} \approx m_{d} \approx m_{s} \approx 0,14 \mathrm{GeV}
$$

Já os parâmetros $\sigma_{0}, \lambda$ e $x_{0}$ foram considerados livres, e foram escolhidos de forma que o modelo descrevesse os dados experimentais de HERA disponíveis na época (1999). No caso onde foram considerados três sabores de quarks $(u, d, s)$ obtiveram:

$$
\sigma_{0}=23,03 \mathrm{mb} \quad ; \quad \lambda=0,288 \quad ; \quad x_{0}=3,04 \times 10^{-4} \quad .
$$

Observando a Eq. (3.14) podemos notar que quando $Q_{s}^{2}(x) \rho^{2} \ll 1$ este modelo satisfaz a primeira propriedade requerida para $\mathcal{N}$, i.e., a transparência de cor: $\mathcal{N}(\rho) \propto$ $\rho^{2}$. Para verificar isto basta expandir a exponencial e reter apenas os dois primeiros termos da expansão. Na região $Q_{s}^{2}(x) \rho^{2} \gg 1$ a exponencial assume valores próximos de zero, e com isso a segunda condição para $\mathcal{N}$ também é satisfeita pelo modelo de GBW, i.e., para dipolos muito grandes temos: $\mathcal{N} \approx 1$.

O modelo de GBW apresenta as duas propriedades citadas na seção anterior. Entretanto, este modelo foi proposto em 1999. Embora a parametrização de GBW descreva bem os dados de HERA desta época, isso não ocorre para os novos dados, que possuem uma precisão maior.

\subsubsection{O modelo IIM-S}

Embora uma solução analítica exata não seja conhecida para a Equação de BK, existem na literatura soluções analíticas para ela que são válidas apenas em certas regiões cinemáticas. Na Ref. [33] foi proposto um modelo que interpola suavemente duas soluções analíticas da Equação de BK, uma delas válida para pequenos tamanhos de dipolo e a outra válida para grandes tamanhos de dipolo. A parametrização proposta 
na Ref. [33] foi:

$$
\mathcal{N}(x, \rho)= \begin{cases}\mathcal{N}_{0}\left(\frac{\rho Q_{s}}{2}\right)^{2\left(\gamma_{s}+\frac{\ln \left(2 / \rho Q_{s}\right)}{\kappa \lambda Y}\right)}, & \text { para } \rho Q_{s}(x) \leq 2 \\ 1-\exp ^{-a \ln ^{2}\left(b \rho Q_{s}\right)} & , \text { para } \rho Q_{s}(x)>2\end{cases}
$$

Os coeficientes $a$ e $b$ foram determinados impondo a condição de que $\mathcal{N}(x, \rho)$ e sua derivada com relação a $\rho Q_{s}$ fossem contínuas em $\rho Q_{s}=2$. A escala de saturação é dada por:

$$
Q_{s}(x)=\left(\frac{x_{0}}{x}\right)^{\lambda}
$$

Nós chamaremos este modelo de IIM. O modelo IIM-S, proposto em [34], é uma melhoria do modelo IIM. No IIM-S a amplitude de espalhamento é dada por (3.18), fixando os parâmetros $\kappa=9,9, Q_{0}^{2}=1,0 \mathrm{GeV}^{2}$ e $\mathcal{N}_{0}=0,7$, e determinando os parâmetros livres à partir de um fit aos dados mais recentes de H1 e de ZEUS. São eles: $\gamma_{s}=0,6194, \lambda=0,2545, x_{0}=0,2131 \times 10^{-4}$ e $\sigma_{0}=26,24 \mathrm{mb}$.

\subsubsection{O modelo b-CGC}

O modelo b-CGC, proposto na Ref. [35], é uma modificação do modelo IIM que introduz uma dependência no parâmetro de impacto $\bar{b}$ para a colisão dipolo-próton. No b-CGC temos:

$$
\sigma_{d i p}\left(x, \rho^{2}\right) \equiv \int d^{2} \bar{b} \frac{d \sigma_{d i p}}{d^{2} \bar{b}} \quad ; \quad \frac{d \sigma_{d i p}}{d^{2} \bar{b}}=2 \mathcal{N}(x, \rho, \bar{b})
$$

onde:

$$
\mathcal{N}(x, \rho, \bar{b})= \begin{cases}\mathcal{N}_{0}\left(\frac{\rho Q_{s, p}}{2}\right)^{2\left(\gamma_{s}+\frac{\ln \left(2 / \rho Q_{s, p}\right)}{\kappa \lambda Y}\right)}, & \text { para } \rho Q_{s, p} \leq 2 \\ 1-\exp ^{-a \ln ^{2}\left(b \rho Q_{s, p}\right)} & , \text { para } \rho Q_{s, p}>2\end{cases}
$$


Veja que, no modelo b-CGC, a parametrização para $\mathcal{N}$ é idêntica àquela do modelo IIM. Porém, agora temos $Q_{s, p}(x, \bar{b})$ no lugar de $Q_{s}(x)$, ou seja, a escala de saturação do próton passa a depender do parâmetro de impacto dipolo-próton, sendo dada por:

$$
Q_{s, p}(x, \bar{b})=\left(\frac{x_{0}}{x}\right)^{\frac{\lambda}{2}}\left[\exp \left(-\frac{\bar{b}^{2}}{2 B_{C G C}}\right)\right]^{\frac{1}{2 \gamma_{s}}}
$$

Os parâmetros do modelo b-CGC foram ajustados para descrever os dados mais recentes de HERA da função de estrutura $F_{2}$ [36]. O conjunto de parâmetros que utilizamos em nossos cálculos é o da segunda linha da tabela II de [36]: $\gamma_{s}=0,46$, $B_{C G C}=7,5 \mathrm{GeV}^{-2}, \mathcal{N}_{0}=0,558, x_{0}=1,84 \times 10^{-6}$ e $\lambda=0,119$. O parâmetro $\kappa$ foi fixado: $\kappa=9,9$.

\subsubsection{O modelo rcBK}

Até o início de 2009, os modelos b-CGC e IIM-S eram os modelos mais sofisticados dentre aqueles disponíveis na literatura. Entretanto, em 2009 foi disponibilizado um código FORTRAN que calcula a solução numérica da equação de BK com correções em "next-to-leading order" (NLO) e que considera a constante de acoplamento variável [37]. Este modelo é chamado na literatura simplesmente de "rcBK", onde "rc" é a abreviação da expressão "running coupling", ou "acoplamento variável" na tradução direta. Desde que foi proposto, o modelo rcBK tornou-se o mais aceito.

A equação de BK apenas evolui a amplitude $\mathcal{N}$ na rapidez $Y$. Para obter a solução numérica rcBK devemos fornecer a condição inicial, que pode ser extraída, por exemplo, de algum modelo fenomenológico. Nós verificamos que a solução numérica rcBK não se mostra muito sensível à escolha de diferentes condições iniciais. Em nossos cálculos nós escolhemos usar a condição inicial dada pelo modelo de GBW.

A Fig. 3.4 compara as predições do modelo rcBK com as predições do modelo IIM-S para o comportamento de $\mathcal{N}$ como função do tamanho do dipolo ao quadrado. Os cálculos foram feitos para dois valores de $x: x=10^{-3}$ e $x=10^{-6}$. Como podemos ver, o modelo rcBK prediz que o regime de saturação é alcançado mais lentamente do 

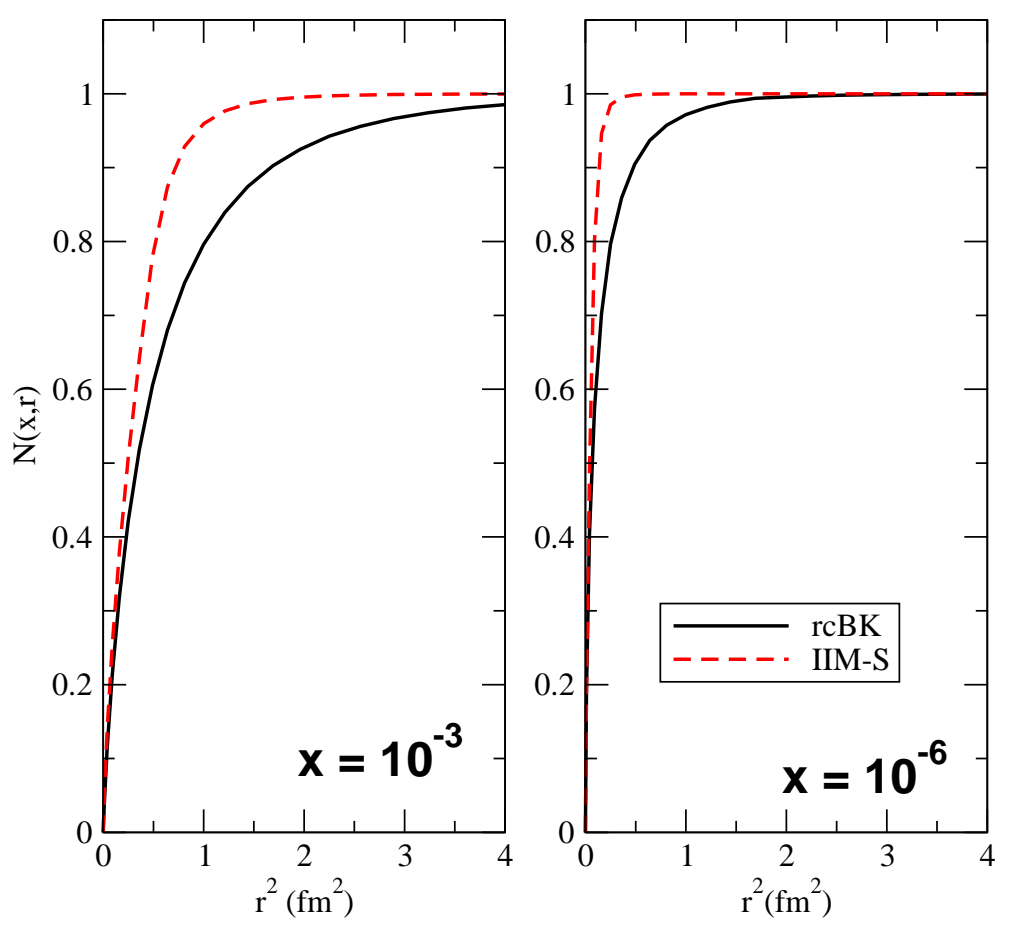

Figura 3.4: Comportamento das amplitudes de espalhamento rcBK (linha sólida) e IIM-S (linha tracejada) com a separação $r$ do par $q \bar{q}$ para diferentes valores de $x$ : (a) $x=10^{-3}$ e (b) $x=10^{-6}$.

que prediz o modelo IIM-S.

\subsection{Generalização nuclear dos modelos de saturação}

Os modelos apresentados na seção anterior são modelos para a amplitude de espalhamento dipolo-núcleon, sendo que o núcleon pode ser um próton ou um nêutron. Quando o alvo for um núcleo com número de massa $A$ arbitrário, ou seja, quando o processo de interesse for o espalhamento dipolo-núcleo, é preciso estender os modelos da seção anterior para o caso nuclear. Na próxima seção vamos apresentar o modelo mais utilizado, que é o de Glauber-Mueller. 


\subsubsection{O Modelo de Glauber-Mueller}

A seção de choque dipolo-núcleo $\left(\sigma_{\text {dip }}^{A}\right)$, assim como a seção de choque dipolo-núcleon (Eq. 2.3), é escrita como a integral da amplitude de espalhamento $\left(\mathcal{N}^{A}\right)$ no parâmetro de impacto $(\vec{b})$, sendo dada por:

$$
\sigma_{\text {dip }}^{A}(x, \vec{\rho})=2 \int d^{2} \vec{b} \mathcal{N}^{A}(x, \vec{\rho}, \vec{b})
$$

Em 2002, Armesto [38] propôs o uso do modelo de Glauber-Mueller para parametrizar a amplitude de espalhamento dipolo-núcleo. Na parametrização proposta em [38], a amplitude de espalhamento dipolo-núcleo, que é o integrando da Eq. (3.23), é determinada pela seguinte expressão:

$$
\mathcal{N}^{A}(x, \rho, b)=1-\exp \left[-\frac{1}{2} T_{A}(b) \sigma_{d i p}\left(x, \rho^{2}\right)\right]
$$

onde $\sigma_{d i p}$ é a seção de choque de interação dipolo-núcleon e a função de perfil nuclear $T_{A}(b)$, que descreve a distribuição dos núcleons na área transversal do núcleo, é obtida como:

$$
T_{A}(\vec{b})=\int d y \rho_{A}(\vec{b}, y)
$$

onde $\vec{y}$ é a direção do feixe e $\rho_{A}$ é uma função densidade que descreve a distribuição dos núcleons no núcleo. A função de perfil nuclear que usamos em nossos cálculos foi obtida assumindo a distribuição de Woods-Saxon para $\rho_{A}$, que é uma distribuição padrão.

Da forma como $T_{A}(b)$ aparece na expressão (3.24), está implícito que a integral desta função no parâmetro de impacto está normalizada a $A$, i.e.:

$$
\int d^{2} \vec{b} T_{A}(\vec{b})=A
$$

onde $A$ é o número de massa do núcleo considerado. Há autores que convencionam normalizar a função de perfil nuclear a 1. Neste caso, é preciso fazer a substituição 
$T_{A}(b) \rightarrow A T_{A}(b)$ em (3.24).

Esta generalização nuclear mostrou-se capaz de descrever os poucos dados experimentais disponíveis sobre a função de estrutura nuclear na região de $x$ pequeno $\left(x<10^{-2}\right)$, que é a região cinemática de interesse desta tese.

Veja que a estrutura desta fórmula é bastante parecida com aquela do modelo de GBW, a Eq. (3.14), ou seja, ambas possuem a forma "unidade menos a exponencial de um termo". Esta maneira de escrever a amplitude de espalhamento é possível na chamada "aproximação eikonal", que supõe que a energia do projétil é muito maior do que a energia de interação com o alvo, tal que a trajetória do projétil sofre apenas um pequeno desvio após a interação.

Uma última observação é que, embora a parametrização (3.23) apresente uma dependência no parâmetro de impacto $b$ entre o dipolo e o núcleo, a seção de choque dipolo-núcleon, que aparece no expoente, não precisa necessariamente depender do parâmetro de impacto entre o dipolo e o núcleon considerado. De fato, em [38] o autor assumiu $\sigma_{\text {dip }}$ como sendo dado pelo modelo de GBW, descrito na seção 3.3.3, que não possui tal dependência.

\subsection{Generalização nuclear da escala de saturação}

A expressão para a escala de saturação do próton:

$$
Q_{s}^{2}(x)=\left(\frac{x_{0}}{x}\right)^{\lambda}
$$

surgiu como um modelo fenomenológico, mas é possível derivar esta expressão da Equação de BK tomando o limite de $x$ muito pequeno (veja, por exemplo, Ref. [7]). Na Ref. [32] foi encontrado $\lambda \approx 0,3$ através de um ajuste aos dados de colisões $e p$ do HERA.

Uma generalização nuclear desta escala de saturação pode ser feita usando o resultado obtido na Eq. (3.11), ou seja, multiplicando a Eq. (3.27) por um fator $A^{1 / 3}$. 
Com isso, a escala de saturação em um núcleo com número de massa $A$ é dada por:

$$
Q_{s}^{2}(x)=A^{1 / 3}\left(\frac{x_{0}}{x}\right)^{\lambda}
$$

Embora a Eq. (3.11) tenha sido obtida de um modelo bastante simples, baseado em argumentos geométricos, esta generalização nuclear para a escala de saturação pode ser usada como uma primeira aproximação, já que uma parametrização mais sofisticada é desconhecida.

\subsubsection{Por que um núcleo $A$ como alvo?}

Substituindo a expressão (1.3) para $x$ na expressão (3.28) para $Q_{s}^{2}$ e usando $\lambda \approx 0,3$ obtemos:

$$
Q_{s}^{2}(x)=A^{1 / 3}\left(x_{0}\right)^{0,3}\left(\frac{W^{2}}{Q^{2}}\right)^{0,3} .
$$

Consideremos um valor fixo $Q_{s}^{2}=K_{0}^{2}$ para a escala de saturação. Quando tivermos um próton como alvo $(A=1)$ será preciso que a energia total do sistema assuma um certo valor $W=W_{0}$ para que a escala de saturação $Q_{s}^{2}=K_{0}^{2}$ seja atingida, ou seja:

$$
K_{0}^{2}=\left(x_{0}\right)^{0,3}\left(\frac{W_{0}^{2}}{Q^{2}}\right)^{0,3}
$$

Se trocarmos o próton por um núcleo de chumbo $(A=208)$, e mantivermos o mesmo valor para a virtualidade $Q^{2}$, após algumas manipulações algébricas verificamos que, a mesma escala de saturação $Q_{s}^{2}=K_{0}^{2}$ é atingida com uma energia 20 vezes menor do que quando o alvo é um próton, i.e.:

$$
K_{0}^{2} \approx 208^{1 / 3}\left(x_{0}\right)^{0,3}\left(\frac{\left(\frac{W_{0}}{20}\right)^{2}}{Q^{2}}\right)^{0,3}
$$

Portanto, os efeitos de saturação em um núcleo, em comparação com um próton, são ampliados. Esse fato implica que é mais fácil detectar sinais de saturação quando temos um núcleo pesado como alvo. 


\section{Capítulo 4}

\section{Processos exclusivos em colisões}

\section{elétron-íon}

Em [22] foram estimadas as seções de choque coerente e incoerente para a produção exclusiva de $\rho$ e $J / \Psi$ em colisões $e A$. Os autores de [22] usaram dois modelos fenomenológicos de saturação para calcular a seção de choque dipolo-próton $\sigma_{d i p}$ : GBW e b-CGC.

Até 2009 o b-CGC era um dos modelos mais sofisticados dentre aqueles disponíveis na literatura. Entretanto, conforme foi citado na seção 3.3.6, em 2009 surgiu o modelo "rcBK" [37], que é a solução numérica da Equação de BK com acoplamento variável.

Desde que foi proposto, o uso do modelo rcBK tornou-se praticamente unânime nos cálculos das seções de choque dipolo-próton. Assim, nós consideramos importante compararmos as predições do modelo rcBK com aquelas do modelo b-CGC para verificarmos se são discrepantes. Em [4] nós refizemos os cálculos da Ref. [22] usando o modelo rcBK e comparamos suas predições com aquelas do modelo b-CGC. Além dos mésons $\rho$ e $J / \Psi$, considerados em [22], nesse novo trabalho nós calculamos também a produção de mésons $\phi$ e de fótons em processos $e A$.

Os três mésons vetoriais citados, $\rho, \phi$ e $J / \Psi$, possuem spin total 1 e paridade ímpar. O méson $J / \Psi$ é um dos estados do charmonium, sendo composto de um par 


\begin{tabular}{cccc|cccc}
\hline \hline Meson & $M_{V} / \mathrm{GeV}$ & $f_{V}$ & $m_{f} / \mathrm{GeV}$ & $N_{T}$ & $R_{T}^{2} / \mathrm{GeV}^{-2}$ & $N_{L}$ & $R_{L}^{2} / \mathrm{GeV}^{-2}$ \\
\hline$J / \psi$ & 3.097 & 0.274 & 1.4 & 1.23 & 6.5 & 0.83 & 3.0 \\
$\phi$ & 1.019 & 0.076 & 0.14 & 4.75 & 16.0 & 1.41 & 9.7 \\
$\rho$ & 0.776 & 0.156 & 0.14 & 4.47 & 21.9 & 1.79 & 10.4 \\
\hline \hline \multicolumn{7}{c}{ Tabela 4.1: Parâmetros do modelo Gauss-LC. }
\end{tabular}

charme-anticharme $(c \bar{c})$. Já o méson $\phi$ é composto de um par estanho-antiestranho $(s \bar{s})$ e o méson $\rho$ é uma mistura sem sabor de quarks $u$ e $d$.

Nós consideramos, em nossos cálculos, dois diferentes alvos nucleares: o cálcio $(A=40)$ e o chumbo $(A=208)$.

As fórmulas que usamos em nossos cálculos estão na seção 2.2.1. Os parâmetros do modelo Gauss-LC, dado pelas Eqs. (2.13) e (2.14), que nós usamos para as funções de onda dos mésons vetoriais, estão na tabela 4.1. No cálculo da seção de choque coerente, Eq. (2.9), nós usamos o modelo de Glauber-Mueller, descrito na seção 3.4.1, para a amplitude de espalhamento dipolo-núcleo $\mathcal{N}^{A}$. Além disso, no cálculo da seção de choque incoerente é preciso escolher uma parametrização para $B_{E}$, que aparece na Eq. (2.15). Para a produção de mésons vetoriais nós usamos:

$$
B_{V}\left(Q^{2}\right)=0,60\left[\frac{14}{\left(Q^{2}+M_{V}^{2}\right)^{0,26}}+1\right]
$$

obtido de um fit de dados experimentais [39]. Para o DVCS, ou seja, para a produção de fótons, nós tomamos a parametrização da Ref. [40]:

$$
B_{\gamma}\left(Q^{2}\right)=a\left[1-b \log \left(\frac{Q^{2}}{Q_{0}^{2}}\right)\right]
$$

$\operatorname{com} a=6,98 \pm 0,54 \mathrm{GeV}^{2}, b=0,12 \pm 0,03$ e $Q_{0}^{2}=2 G e V^{2}$

\subsection{Resultados}

Nossos resultados são mostrados nas Figs. 4.1, 4.2, 4.3 e 4.4. Cada figura contém quatro gráficos, sendo que cada gráfico corresponde a um estado final exclusivo diferente. 


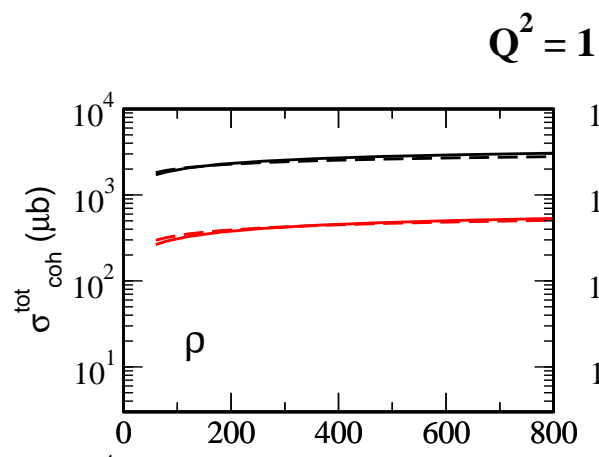

$Q^{2}=1 \mathrm{GeV}^{2}$
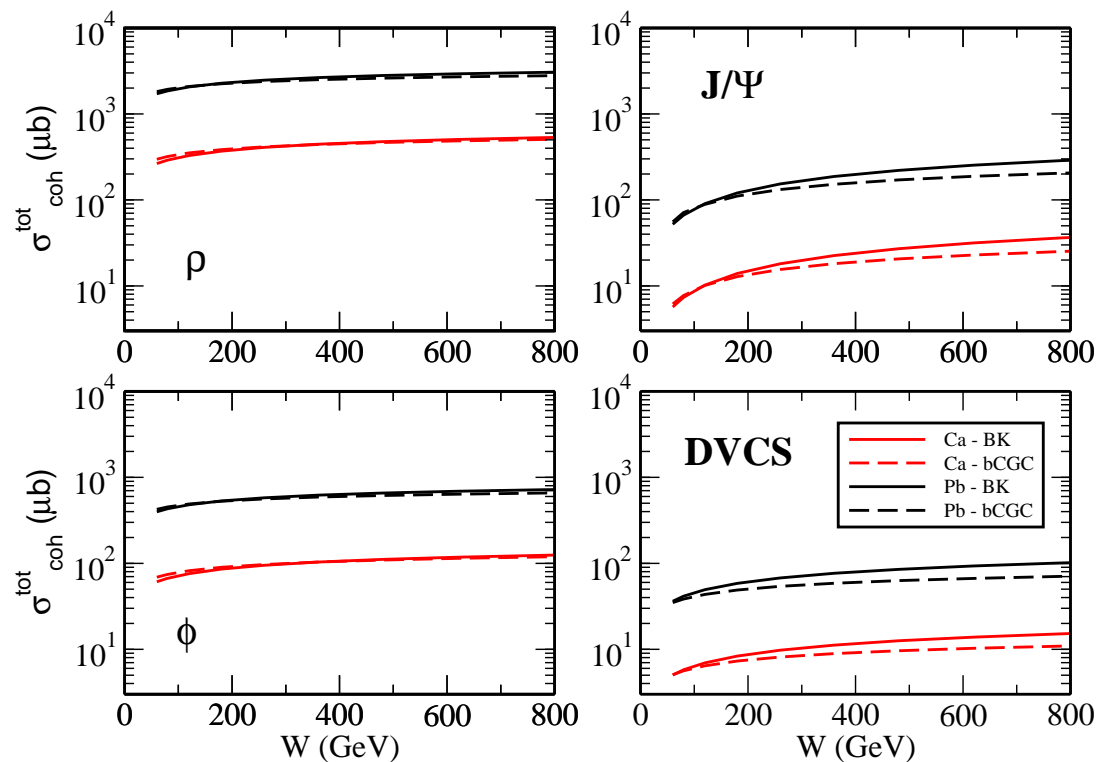

Figura 4.1: Seção de choque coerente em função da energia para diferentes estados finais exclusivos e $Q^{2}=1 \mathrm{GeV}^{2}$.

As Figs. 4.1 e 4.2 mostram nossos resultados para as seções de choque coerentes. Na Fig. 4.1 as curvas são mostradas como funções da energia $W$ do sistema $\gamma^{*} A$ para um valor fixo $\left(Q^{2}=1 \mathrm{GeV}^{2}\right)$ da virtualidade. Na Fig. 4.2 nós fixamos a energia $W=500 \mathrm{GeV}$ e as curvas são mostradas como funções da virtualidade $Q^{2}$ do fóton. As Figs. 4.3 e 4.4 são os correspondentes análogos das Figs. 4.1 e 4.2, só que para as seções de choque incoerentes. Em cada gráfico, as duas curvas superiores de cor preta correspondem aos processos onde temos um núcleo de chumbo como alvo. Já as duas curvas inferiores de cor vermelha correspondem aos processos onde o alvo é um núcleo de cálcio. Esse resultado, mostrando que a seção de choque do chumbo é bem maior do que a do cálcio já era esperado, pois um núcleo de chumbo $(A=208)$ é bem maior do que um núcleo de cálcio $(A=40)$.

Em todos os gráficos vemos que, como já era de se esperar, as seções de choque crescem com $W$ e diminuem com $Q^{2}$. O primeiro fato é uma consequência do aumento do número de glúons no alvo quando a energia é aumentada, o que faz com que a seção de choque fique maior. A diminuição da seção de choque com $Q^{2}$ ocorre porque 

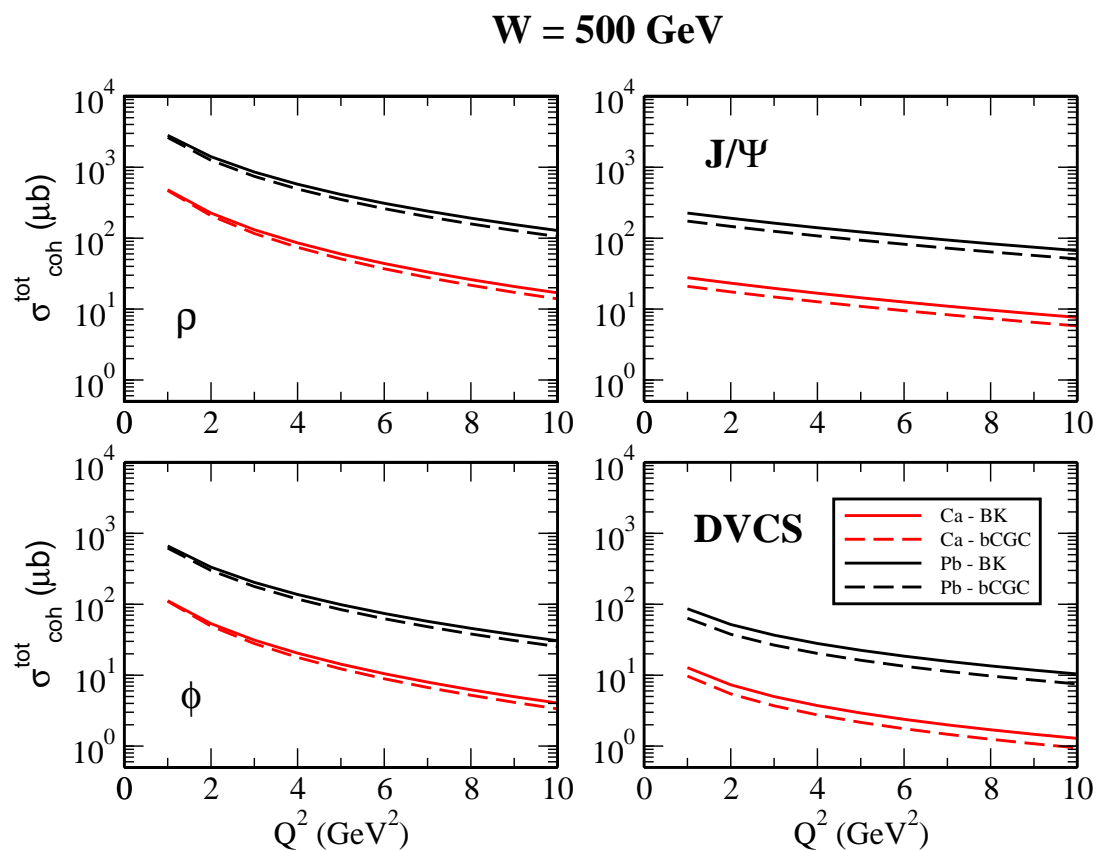

Figura 4.2: Seção de choque coerente em função da virtualidade para diferentes estados finais exclusivos e $W=500 \mathrm{GeV}$.

quando a virtualidade aumenta, tanto o dipolo proveniente do fóton quanto o estado final tornam-se mais compactos (como mostram suas funções de onda) e o dipolo projétil "enxerga menos" o alvo, atravessando-o sem interagir com ele. O alvo se afasta cada vez mais do regime de saturação, tornando-se diluído, e o fenômeno de transparência de cor começa a ser observado.

Outra observação que podemos fazer é que, pelo menos para os dois modelos considerados (b-CGC e rcBK), os resultados não dependem fortemente da seção de choque de dipolo escolhida. Em particular, para pequeno $Q^{2}$ e pequeno $W$ as seções de choque de produção obtidas com b-CGC ou rcBK são indistinguíveis. Isto ocorre porque, nesta região cinemática, as próprias seções de choque de dipolo tendem a coincidir. Esta "coincidência" se deve ao fato de que ambas as seções de choque de dipolo foram ajustadas para descrever os dados de DIS, dados estes que estão disponíveis apenas nesta região cinemática. Outra característica observada é a diminuição das seções de choque de produção com o aumento da massa do méson vetorial considerado. Certamente, quanto maior a massa do méson, maior a energia necessária para produzí-lo, o 

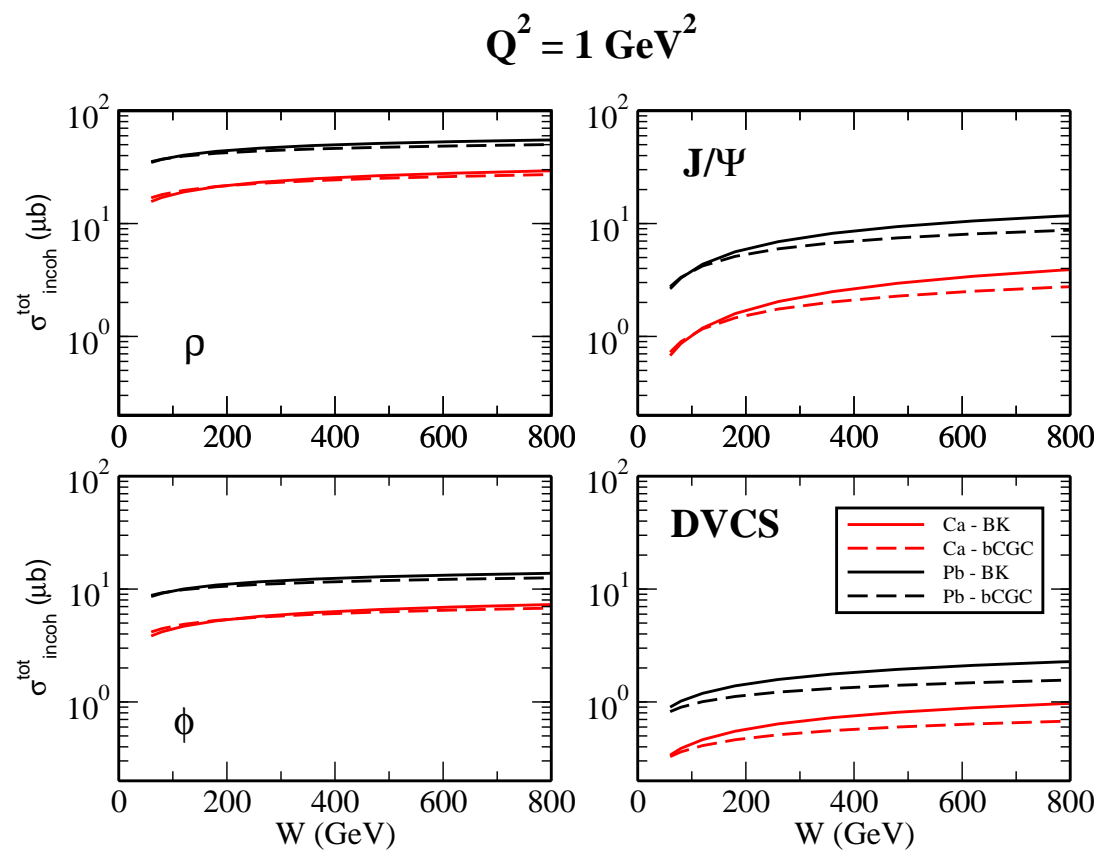

Figura 4.3: Seção de choque incoerente em função da energia para diferentes estados finais exclusivos e $Q^{2}=1 \mathrm{GeV}^{2}$.

que torna o número de eventos de produção observado menor.

Em todos os casos nós vemos que os resultados obtidos com rcBK são maiores do que aqueles obtidos com o b-CGC. É interessante notar que a diferença entre as predições destes dois modelos aumenta quando consideramos mésons vetoriais mais pesados. A explicação para isso é que quando $r$ é pequeno a seção de choque de dipolo rcBK é sempre maior do que a b-CGC, enquanto que para $r$ grande as duas seções de choque se aproximam uma da outra. Por outro lado, as funções de overlap dos mésons vetoriais, como função de $r$, possuem picos em diferentes localizações. Quanto maior é a massa do méson menor é o valor de $r$ no qual o pico da função está localizado. Em particular, a função de overlap do $J / \Psi$ somente contribui significativamente para o integrando da seção de choque de produção (veja as Eqs. 2.8 e 2.9) na região onde $r$ é pequeno, região na qual rcBK está sempre acima do b-CGC.

Uma última observação é que os nossos resultados confirmam a dominância da seção de choque coerente, com uma pequena contribuição vinda de processos incoerentes, um resultado previamente encontrado em [22]. 

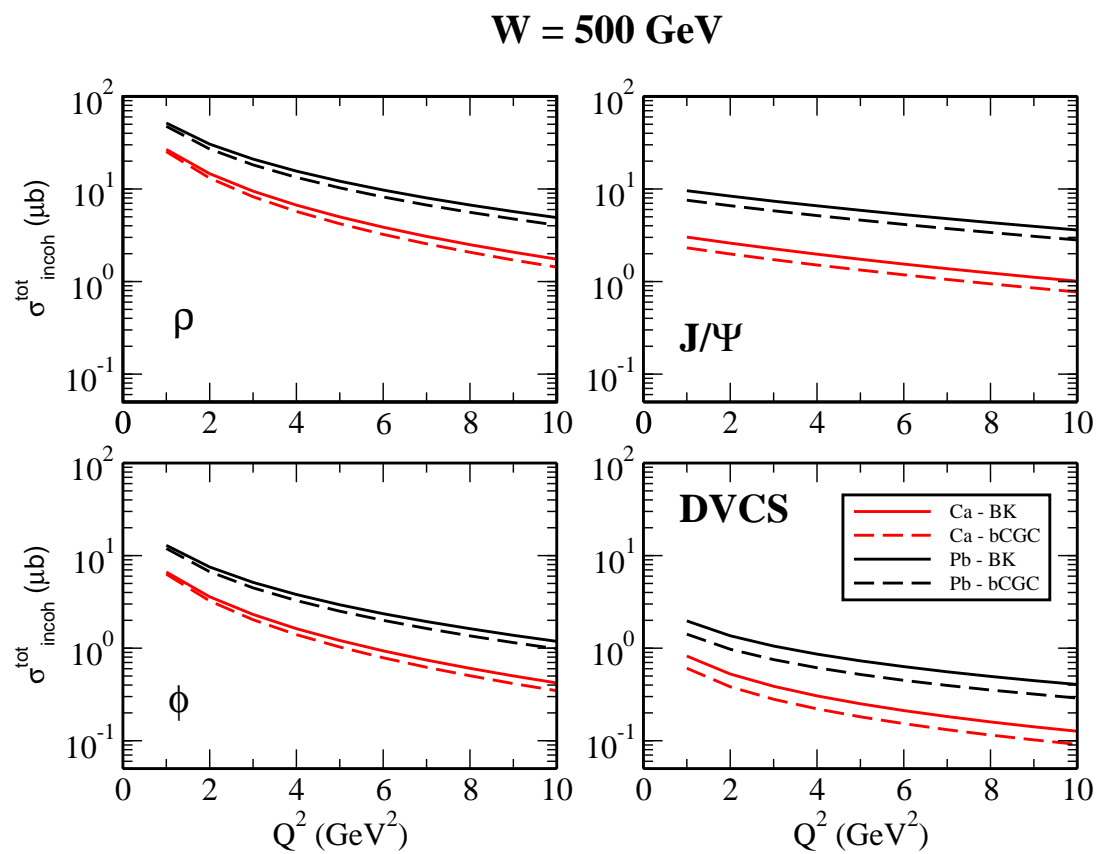

Figura 4.4: Seção de choque incoerente em função da virtualidade para diferentes estados finais exclusivos e $W=500 \mathrm{GeV}$.

\subsection{Conclusão}

Neste trabalho, utilizamos pela primeira vez o modelo rcBK para calcular as seções de choque de processos $e A$ mostradas nas figuras deste capítulo. Nosso objetivo foi verificar se as predições do modelo rcBK são muito diferentes daquelas do modelo b-CGC. Concluímos que o modelo rcBK prediz seções de choque maiores do que o modelo b-CGC. Como podemos ver, as predições de ambos os modelos são quase indistinguíveis para a produção dos mésons mais leves, o $\rho$ e o $\phi$. Por outro lado, a diferença se torna considerável para a produção exclusiva de $J / \Psi$ e para o DVCS nuclear. Isso significa que se os dados experimentais do LHeC e do futuro eRHIC, sobre estes dois últimos processos, forem suficientemente precisos, eles poderão, em princípio, ser usados para determinar dentre os modelos rcBK e b-CGC qual descreve melhor a seção de choque dipolo-próton. 


\section{Capítulo 5}

\section{Espalhamento fóton-fóton}

Neste capítulo apresentamos o trabalho publicado na Ref. [5] sobre o espalhamento fóton-fóton. Nosso objetivo é calcular a seção de choque de espalhamento fóton-fóton usando diferentes modelos de saturação. Vamos utilizar o formalismo de dipolo de cor (veja Seção 2.2.2), que implica que a seção de choque fóton-fóton é fatorizada da forma mostrada na Eq. (2.18). A seção de choque dipolo-dipolo, $\sigma_{a, b}^{d d}\left(\vec{\rho}_{1}, \overrightarrow{\rho_{2}}, Y\right)$, é o principal ingrediente para os cálculos (veja Eq. 2.18), e é nela que entram os efeitos não-lineares da QCD. Criar um modelo para $\sigma_{a, b}^{d d}\left(\vec{\rho}_{1}, \overrightarrow{\rho_{2}}, Y\right)$, que englobe efeitos de saturação, não é uma tarefa trivial. A idéia básica por trás dos modelos de saturação para $\sigma_{a, b}^{d d}$ é tratar um dos dipolos como se fosse um alvo hadrônico, por exemplo como se fosse um próton. Desta forma, a seção de choque dipolo-próton pode ser usada como um ponto de partida, e então são feitas algumas pequenas modificações nela para que se aproxime mais do caso dipolo-dipolo.

Até onde sabemos, só há um modelo de saturação disponível na literatura para $\sigma_{a, b}^{d d}$. Este modelo será apresentado na próxima seção e nós o chamaremos de "Modelo 1". Neste trabalho nós propomos um novo modelo de saturação para $\sigma_{a, b}^{d d}$. Nosso modelo também será apresentado na próxima seção e será chamado de "Modelo 2". 


\subsection{Modelos para a seção de choque dipolo-dipolo}

\section{Modelo 1}

Na Ref. [41] foi proposto o seguinte modelo para a seção de choque dipolo-dipolo $\sigma_{a, b}^{d d}$ :

$$
\sigma_{a, b}^{d d}\left(\vec{r}_{1}, \vec{r}_{2}, Y\right)=\sigma_{0}^{a, b} N\left(\vec{r}_{1}, \vec{r}_{2}, Y\right)
$$

com

$$
\sigma_{0}^{a, b}=\frac{2}{3} \sigma_{0}
$$

onde $\sigma_{0}$ é um parâmetro livre que foi fixado através de um fit aos dados de DIS do HERA. A expressão acima é uma adaptação para este contexto do antigo modelo aditivo de quarks, que relaciona a seção de choque próton-próton com a seção de choque méson-próton através do mesmo fator $2 / 3$. Este fator representa a razão entre o número de quarks no dipolo e o número de quarks no próton. Em outras palavras, nesse modelo foi assumido que o dipolo projétil interage com o dipolo alvo como se este último fosse um próton, a diferença estando apenas num fator constante associado ao número de quarks. Por isso pode-se usar o mesmo parâmetro $\sigma_{0}$ da seção de choque do DIS, só que multiplicado por um fator $(2 / 3)$ devido à diferença no número de quarks. Nesse modelo assume-se que:

$$
N\left(\vec{r}_{1}, \vec{r}_{2}, Y\right)=N\left(\vec{r}_{\mathrm{eff}}, Y=\ln \left(1 / \bar{x}_{a b}\right)\right)
$$

onde:

$$
r_{\mathrm{eff}}^{2}=\frac{r_{1}^{2} r_{2}^{2}}{r_{1}^{2}+r_{2}^{2}} \quad \text { e } \quad \bar{x}_{a b}=\frac{Q_{1}^{2}+Q_{2}^{2}+4 m_{a}^{2}+4 m_{b}^{2}}{W^{2}+Q_{1}^{2}+Q_{2}^{2}}
$$

O parâmetro livre deste modelo é a massa dos quarks leves, ou seja, os quarks $u, d$ e $s$, que têm aqui a mesma massa $\left(m_{u} \approx m_{d} \approx m_{s}\right)$. 


\section{Modelo 2}

No nosso modelo, o "dipolo alvo" será aquele que possuir o maior tamanho, i.e., será o dipolo de tamanho $R=\operatorname{Max}\left(r_{1}, r_{2}\right)$. Nós assumimos também que apenas o alcance $b<R$ contribui para a seção de choque dipolo-dipolo. Esta aproximação implica que estamos considerando que $\mathcal{N}$ é desprezível quando não há overlap entre os dipolos $(b>R)$. Portanto, nós propomos a seguinte expressão para a seção de choque dipolodipolo:

$$
\sigma^{d d}\left(\vec{r}_{1}, \vec{r}_{2}, Y\right)=2 N(\vec{r}, Y) \int_{0}^{R} d^{2} \vec{b}=2 \pi R^{2} N(\vec{r}, Y)
$$

onde $r=\operatorname{Min}\left(r_{1}, r_{2}\right)$. A forma explícita de $\sigma^{d d}$ nesse nosso modelo fica:

$$
\sigma^{d d}\left(\vec{r}_{1}, \vec{r}_{2}, Y\right)=2 \pi r_{1}^{2} N\left(r_{2}, Y_{2}\right) \Theta\left(r_{1}-r_{2}\right)+2 \pi r_{2}^{2} N\left(r_{1}, Y_{1}\right) \Theta\left(r_{2}-r_{1}\right)
$$

onde $\Theta\left(r_{i}-r_{j}\right)$ é a função de Heaviside (função degrau), e:

$$
Y_{j}=\ln \left(1 / x_{j}\right) \quad e \quad x_{j}=\frac{Q_{j}^{2}+4 m_{f}^{2}}{W^{2}+Q_{j}^{2}} .
$$

A principal vantagem do Modelo 2 em relação ao Modelo 1 é que no Modelo 2 a massa dos quarks leves não é um parâmetro livre, mas assume o mesmo valor que é usado nos cálculos de DIS. Por outro lado, no Modelo 2, devido à dependência quadrática de $\sigma^{d d}$ no tamanho do dipolo maior (veja Eq. 5.5), a contribuição de grandes valores de $r_{1} \mathrm{e}$ $r_{2}$ para a seção de choque total é bastante significativa. Para manter nossos cálculos no regime perturbativo, nós fizemos um corte na integral sobre os tamanhos $r_{1}$ e $r_{2}$ dos dipolos, impondo um valor máximo $r_{\max }$ para eles da ordem do inverso da escala de energia da QCD perturbativa $\left(\Lambda_{Q C D}\right)$. Em outras palavras, ao invés de integrar $r_{1}$ e $r_{2}$ de 0 até $\infty$ nós integramos de 0 até $r_{\max }=1 / \Lambda$, com $\Lambda \sim \Lambda_{Q C D}$. Esse valor para $r_{\max }$ corresponde a um raio máximo para o dipolo da ordem de $r_{\max } \sim 1 / \Lambda_{Q C D} \sim 1$ fm, ou $r_{\max } \sim 1 \times 10^{-13} \mathrm{~cm}$. 


\begin{tabular}{|c|c|c|c|}
\hline Modelo & $N(\vec{r}, Y)$ & $m(\mathrm{MeV})$ & $\Lambda(\mathrm{MeV})$ \\
\hline Modelo 1 & rcBK & 198 & - \\
& IIM-S & 205 & - \\
\hline Modelo 2 & rcBK & - & 210 \\
& IIM-S & - & 230 \\
\hline \multicolumn{3}{|c|}{ Tabela 5.1: Parâmetros usados nos cálculos. }
\end{tabular}

Ao invés de fixarmos $\Lambda=\Lambda_{Q C D}$, nós fizemos de $\Lambda$ o parâmetro livre do Modelo 2 . Nós determinamos o seu valor através de um ajuste aos dados experimentais disponíveis sobre colisões $\gamma \gamma$. Se o valor obtido para $\Lambda$ neste ajuste aos dados fosse muito diferente de $\Lambda_{Q C D}$, por exemplo se fosse muito menor, isso seria um indicativo de que há uma grande contribuição da QCD não-perturbativa para este processo, e que não é possível descrever os dados usando apenas a QCD perturbativa. No entanto, para nossa surpresa, conforme veremos à seguir o valor obtido para $\Lambda$ é bastante próximo do valor $\Lambda_{Q C D} \approx 217 \mathrm{MeV}$.

\subsection{Resultados}

Em nossos cálculos nós usamos os modelos 1 e 2 para a seção de choque fóton-fóton $\sigma^{d d}$. Nós usamos também dois modelos para a amplitude de espalhamento $N$. Com isso nós pudemos verificar se os resultados são muito dependentes do modelo usado para $N$. Os dois modelos que escolhemos para a amplitude $N$ são os modelos rcBK (veja Seção 3.3.6) e IIM-S (veja Seção 3.3.4). O rcBK é considerado o melhor modelo disponível atualmente e nós achamos importante comparar suas predições com as do modelo IIM-S, que era um dos melhores modelos disponíveis antes de surgir o rcBK.

A Fig. 5.1 mostra as nossas predições para a seção de choque total $\gamma \gamma$, i.e., a seção de choque de colisão de dois fótons reais. Nesta figura, $\operatorname{rcBK}(1)$ indica que estamos usando o Modelo 1 para $\sigma^{d d}$ e rcBK para a amplitude de espalhamento, e assim por diante. Os dados experimentais foram obtidos da Ref. [42], e os parâmetros livres dos modelos 1 e 2 foram determinados através do ajuste a estes dados, como mostra a figura. Os valores encontrados para estes parâmetros são mostrados na Tabela 5.1. 

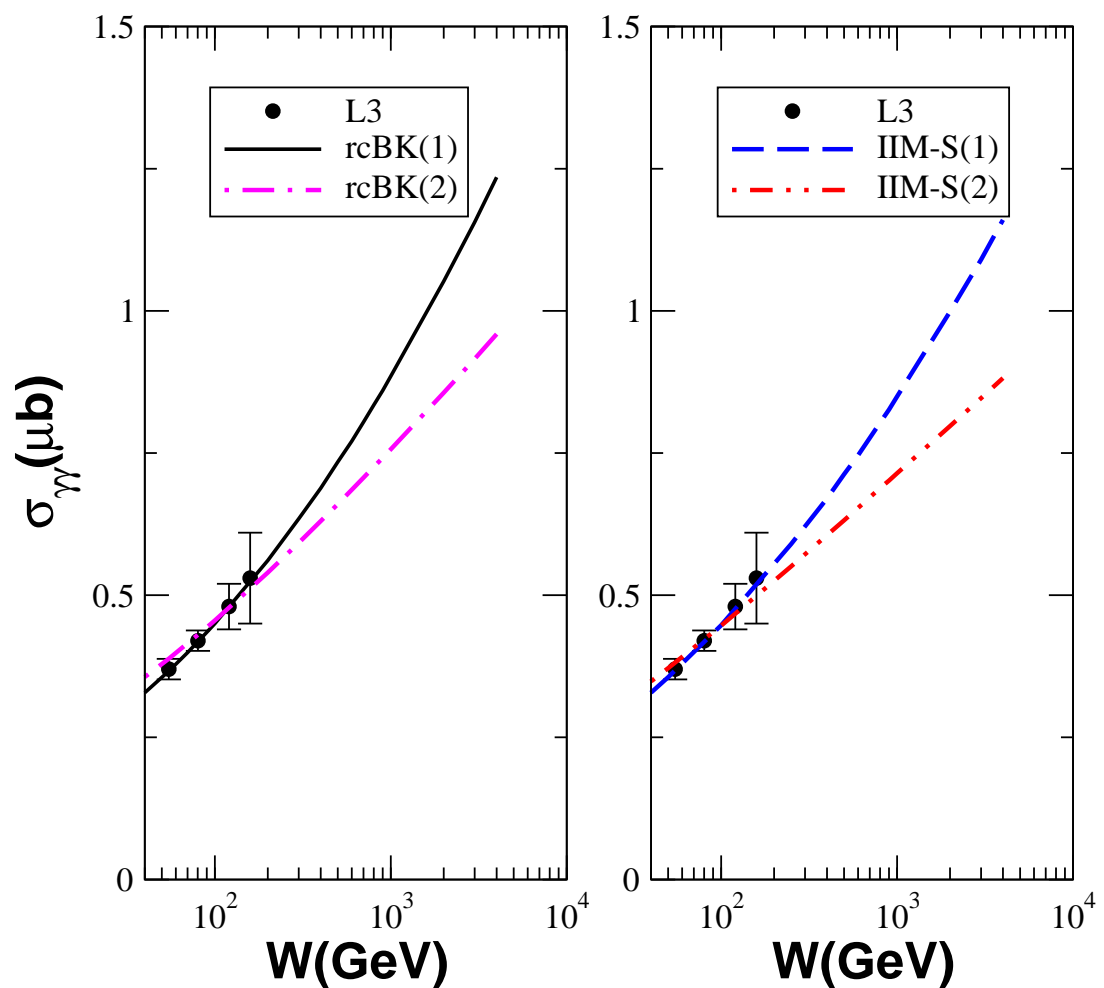

Figura 5.1: Seção de choque total $\gamma \gamma$, como função da energia $W$, usando os modelos 1 e 2, cada qual calculado com as amplitudes de espalhamento a) rcBK e b) IIM-S. Dados experimentais obtidos de [42].

Assim como aconteceu na referência [41], para descrever os dados experimentais sobre a seção de choque $\gamma \gamma$ usando o Modelo 1 nós tivemos que assumir valores para a massa dos quarks leves (veja Tabela 5.1) maiores do que o valor usado para elas na descrição dos dados de $F_{2}$ do HERA, onde foi usado $m_{u, d, s}=140 \mathrm{MeV}$. Por outro lado, o valor de $\Lambda=1 / r_{\max }$ usado para descrever os dados com o Modelo 2 é quase igual a $\Lambda_{Q C D} \approx 217 \mathrm{MeV}$, o que está de acordo com as nossas expectativas. Este resultado pode ser interpretado como um indicador de que o Modelo 2 captura as principais características da interação.

Na Fig. 5.1 podemos ver que as predições dos dois modelos na região $W>110 \mathrm{GeV}$, onde não há dados experimentais, tornam-se bastante diferentes. Em particular, para $W=3000 \mathrm{GeV}$ o Modelo 1 prediz um resultado $\approx 25 \%$ maior do que o Modelo 2 . Por último podemos notar que, escolhido um dos modelos, estas conclusões independem da amplitude de dipolo utilizada (rcBK ou IIM-S). 

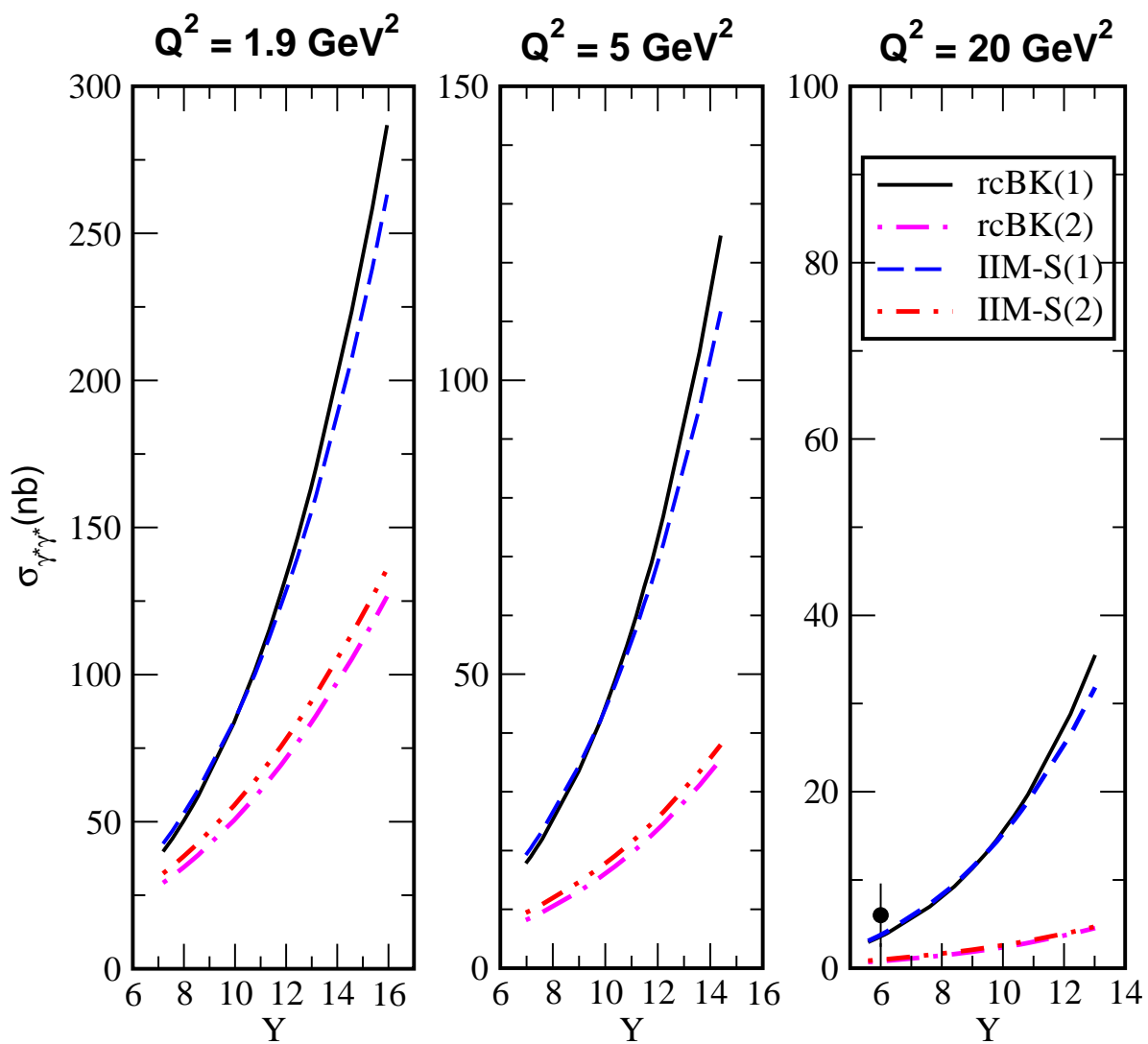

Figura 5.2: A seção de choque total $\gamma^{*} \gamma^{*}$ como função de $Y \equiv \ln \left(W^{2} / Q_{1} Q_{2}\right)$ para diferentes valores de $Q^{2}\left(Q^{2}=Q_{1}^{2}=Q_{2}^{2}\right)$.

Nós calculamos também a seção de choque fóton-fóton para outros dois casos. Primeiro nós consideramos o caso em que $Q_{1}^{2} \sim Q_{2}^{2}$, com $Q_{1,2}^{2}$ grandes. Nesta configuração os fótons são altamente virtuais. No segundo caso nós consideramos a situação onde $Q_{1}^{2}>>Q_{2}^{2}$. Ao assumirmos esta condição nós estamos estudando a estrutura do fóton virtual $\left(Q_{2}^{2}>0\right)$ ou a estrutura do fóton real $\left(Q_{2}^{2}=0\right)$. Por exemplo, a função de estrutura $F_{2}^{\gamma}\left(x, Q^{2}\right)$ do fóton real $\left(Q_{1}^{2}=Q^{2}, Q_{2}^{2}=0\right)$ está relacionada da seguinte maneira com a seção de choque total $\gamma^{*} \gamma$ :

$$
F_{2}^{\gamma}\left(x, Q^{2}\right)=\frac{Q^{2}}{4 \pi^{2} \alpha_{e m}}\left[\sigma_{T, T}\left(W^{2}, Q^{2}, Q_{2}^{2}=0\right)+\sigma_{L, T}\left(W^{2}, Q^{2}, Q_{2}^{2}=0\right)\right]
$$

Neste caso a variável de Bjorken é dada por: $x=Q_{1}^{2} / W^{2}$, onde $\left(Q_{i}^{2}=-q_{i}^{2}\right)$.

A Fig. 5.2 mostra os resultados dos nossos cálculos para a seção de choque total 

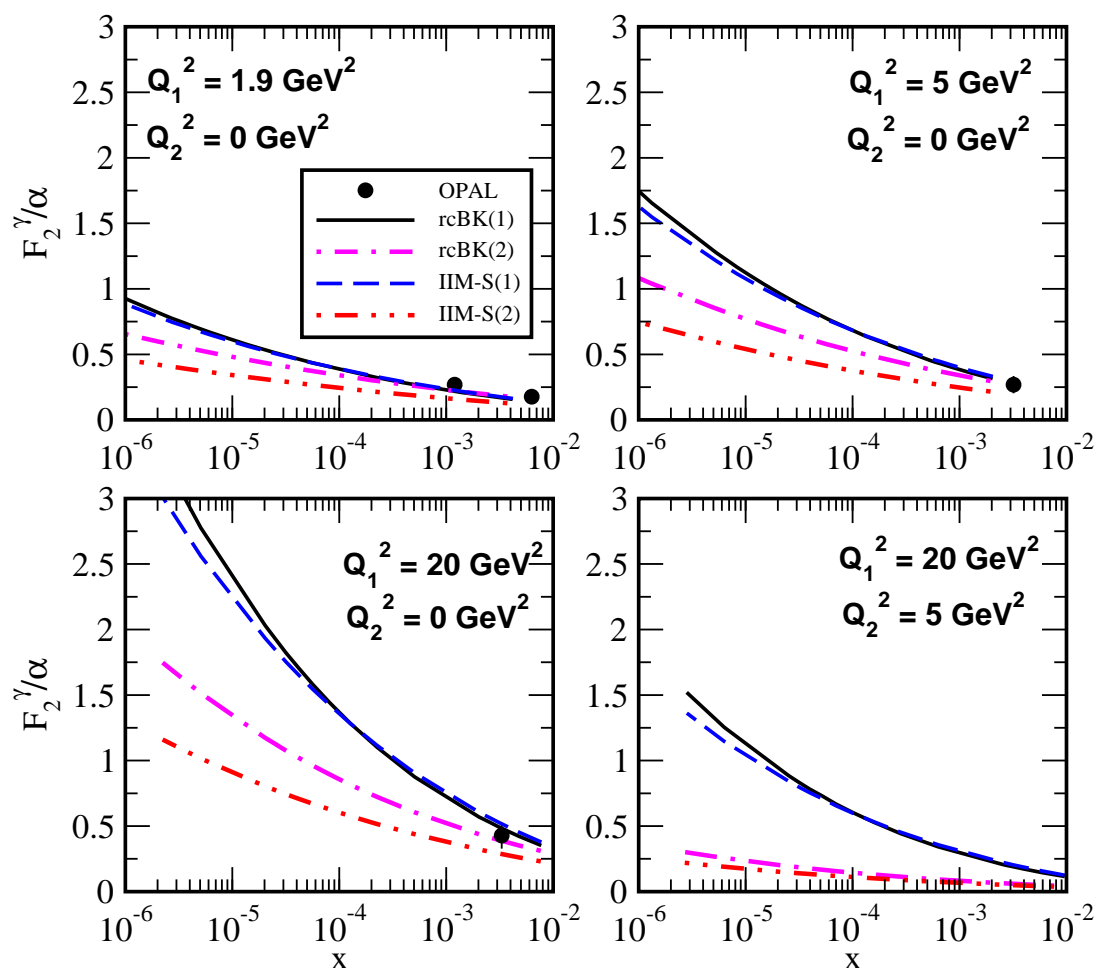

Figura 5.3: A função de estrutura $F_{2}^{\gamma}\left(x, Q^{2}\right)$ do fóton, como função de $x$, para diferentes valores das virtualidades $Q_{1}^{2}$ e $Q_{2}^{2}$.

$\gamma^{*} \gamma^{*}$ em função de $Y \equiv \ln \left(W^{2} / Q_{1} Q_{2}\right)$. Nós assumimos $Q_{1}^{2}=Q_{2}^{2}=Q^{2}$. Como podemos ver, as seções de choque aumentam com $Y$ e diminuem com $Q^{2}$. Além disso, como no caso anterior, percebemos que a principal diferença nos resultados está associada à escolha de $\sigma^{d d}$, sendo que o Modelo 1 prediz um crescimento mais acentuado da seção de choque com $Y$ do que o Modelo 2. Esta diferença aumenta para maiores virtualidades. Em particular, para $Y=10$ e $Q^{2}=20 \mathrm{GeV}^{2}$ as predições diferem por um fator $\approx 8$. Os resultados quase não mudam quando trocamos uma das amplitudes pela outra. O ponto experimental do terceiro gráfico foi obtido pela colaboração L3 [43].

Finalmente, na Fig. 5.3 nós apresentamos os nossos resultados para a função de estrutura $F_{2}^{\gamma}$ do fóton em função da variável $x$. No caso de um fóton virtual, a idéia básica é que outro fóton com virtualidade muito maior possa verificar sua estrutura e nos fornecer informações à respeito da mesma. Os cálculos da função de estrutura 
de um fóton virtual com virtualidade $Q^{2}=5 \mathrm{GeV}^{2}$ são mostrados no lado direito inferior da Fig. 5.3. Embora existam atualmente poucos dados experimentais para este observável, seu estudo experimental é factível em futuros colisores lineares. Para o fóton real, podemos dizer que os nossos cálculos descrevem bem os poucos dados experimentais disponíveis [44], visto que os parâmetros livres dos modelos 1 e 2 já foram fixados. Como podemos ver na Fig. 5.3, o Modelo 1 prediz um crescimento muito mais acentuado para $F_{2}^{\gamma}$ do que prediz o Modelo 2. Isto ocorre nos dois casos, quando diminuímos $x$ e quando aumentamos $Q_{1}^{2}$. Esse comportamento já havia sido observado nas figuras anteriores. A diferença é que, no caso de $F_{2}^{\gamma}$, como podemos ver, somente o Modelo 1 não é sensível à mudança da amplitude de dipolo usada. O Modelo 2 apresenta uma diferença considerável quando usamos rcBK ou IIM-S para a amplitude de dipolo. Isto torna o estudo de $F_{2}^{\gamma}$ uma importante fonte de informações sobre a dinâmica da QCD em altas energias.

\subsection{Conclusão}

Os cálculos apresentados neste capítulo podem ser considerados predições para observáveis de processos $\gamma \gamma$ que serão medidos no futuro "International Linear Collider" (ILC).

Inicialmente, o nosso objetivo era apenas calcular a seção de choque fóton-fóton, usando o Modelo 1 para a seção de choque dipolo-dipolo, e considerando dois diferentes modelos de saturação para comparar suas predições, os modelos rcBK e IIM-S. No entanto, durante o desenvolvimento deste trabalho, nós propusemos o Modelo 2, que tem a vantagem de manter o mesmo valor para a massa dos quarks leves usado nos cálculos de DIS. O fato de termos obtido o valor que esperávamos para o parâmetro livre $\Lambda$ desse nosso modelo, i.e., $\Lambda \approx \Lambda_{Q C D}$, nos encorajou a usá-lo em nossos cálculos subsequentes e comparar suas predições com aquelas do Modelo 1.

Nossos resultados indicam uma diferença considerável entre as predições dos Modelos 1 e 2 para todos os observáveis calculados. Por outro lado, as seções de choque 
mostraram-se pouco sensíveis à amplitude de espalhamento escolhida, rcBK ou IIM-S. Somente a função de estrutura, calculada com o Modelo 2, apresentou uma diferença considerável quando trocamos uma amplitude pela outra. Isso indica que, se os futuros dados experimentais sobre a seção de choque fóton-fóton mostrarem que o Modelo 2 descreve corretamente os dados, a medida da função de estrutura do fóton poderá nos indicar qual amplitude de espalhamento é a mais correta. 


\section{Capítulo 6}

\section{Produção de quarks pesados em colisões próton-núcleo}

Neste capítulo apresentamos o trabalho publicado na Ref. [6]. Nosso objetivo principal foi estudar a produção de charme em processos $p A$ nas energias do LHC, mas nós analisamos também a produção de bottom.

A produção de charme no LHC possui uma importante característica que a diferencia dos experimentos anteriores do mesmo tipo. Em contraste com os aceleradores anteriores, SPS, Tevatron e RHIC, onde a escala de saturação $Q_{s}$ era menor do que a escala típica de produção, $\mu=m_{Q}$, nas energias do LHC nós temos pela primeira vez o regime cinemático onde $Q_{s} \approx \mu$. Portanto, espera-se que os dados do LHC referentes a estas seções de choque apresentem uma modificação apreciável vinda de efeitos de saturação.

Este capítulo pode ser dividido em duas partes. Na primeira parte nós calculamos as seções de choque de produção de charme e de bottom usando diferentes modelos de saturação. Fazemos estes mesmos cálculos usando também um modelo da física linear, o modelo CT, apresentado na Seção 3.1. Com isso nós podemos comparar as predições da física de saturação com aquelas da física linear e verificar quais observáveis apresentam sinais mais evidentes de física de saturação. $\mathrm{Na}$ segunda parte deste 


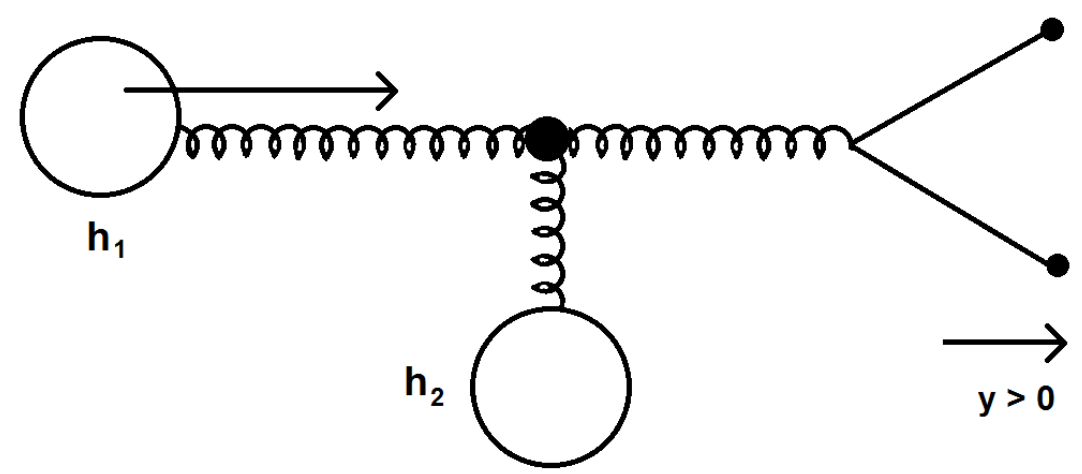

Figura 6.1: Esquematização da produção de quarks na região de grande rapidez $(y>0)$ nos processos $h_{1} h_{2}$.

capítulo nós fazemos uma análise quantitativa da magnitude do efeito de shadowing nuclear nas seções de choque de produção de charme e de bottom. Nós utilizamos duas parametrizações para a magnitude do shadowing (veja Seção 1.3.2), a parametrização nDS e a parametrização EPS09 [45]. Conforme pode ser visto na Fig. 1.3, as parametrizações nDS e EPS08 representam respectivamente os limites superior e inferior da região de incerteza teórica na magnitude do shadowing. Em nossa análise nós usamos EPS09, que é uma versão melhorada de EPS08, mas que também prediz fortes efeitos nucleares nas distribuições gluônicas.

\subsection{O referencial do CGC}

Quando analisamos os quarks produzidos na região de rapidez $y \gg 0$ (veja a Fig. 6.1) estamos automaticamente selecionando os glúons do projétil $\left(h_{1}\right)$ que carregam grande fração $x_{1}$ de seu momento longitudinal. Ao mesmo tempo, estamos selecionando os glúons do alvo $\left(h_{2}\right)$ que carregam uma pequena fração, $x_{2} \ll 1$, de seu momento. Isto ocorre porque a rapidez $y$ está relacionada a $x_{1}$ e a $x_{2}$ da seguinte forma:

$$
x_{1}=\frac{m_{Q}}{\sqrt{s}} e^{+y} \quad, \quad x_{2}=\frac{m_{Q}}{\sqrt{s}} e^{-y}
$$

onde $m_{Q}$ é a massa do quark produzido e $\sqrt{s}$ é a energia do sistema $h_{1} h_{2}$ no referencial do centro de massa. Fazendo algumas manipulações algébricas nestas duas fórmulas 
obtemos:

$$
y=\frac{1}{2} \ln \left(\frac{x_{1}}{x_{2}}\right) .
$$

Esta expressão nos mostra que $y \gg 0$ implica $x_{1} \gg x_{2}$.

Como o valor de $x_{1}$ associado ao glúon do projétil é grande, $x_{1} \approx 1$, no cálculo da produção de quarks a distribuição de glúons do projétil pode ser descrita pela física linear, ou seja, pode ser evoluída usando as equações DGLAP. Isto porque na região de grande $x$ (pequena densidade) os efeitos não lineares da QCD são desprezíveis. Por outro lado, como o valor de $x_{2}$ é pequeno, a densidade de glúons do alvo é grande, e os efeitos não lineares da QCD não podem ser desprezados nesta distribuição. Portanto, nos processos onde $h_{1}=p$ e $h_{2}=A$ nós podemos estudar o efeito de saturação na distribuição de glúons do núcleo $A$. Por outro lado, nos processos onde $h_{1}=A$ e $h_{2}=p$, a distribuição de glúons no núcleo $A$ pode ser descrita pela física linear, o que significa que esse tipo de processo é útil no estudo do efeito de shadowing.

\subsection{Efeitos de saturação na produção de charme e de bottom}

A seguir serão apresentados os resultados da nossa análise do efeito de saturação na produção de charme e de bottom. Como existem dados experimentais disponíveis sobre a produção desses quarks em colisões $p p$, nós calculamos primeiro as seções de choque de produção para este tipo de processo e comparamos os nossos cálculos com os dados. Em seguida nós calculamos as seções de choque de produção para processos $p A$. As fórmulas que usamos em nossos cálculos foram apresentadas na Seção 2.2.3. A seção de choque total de produção de quarks pesados em processos $p h_{2}$, onde o hádron $h_{2}$ pode ser um próton ou um núcleo, é dada pela Eq. (2.21), ou seja:

$$
\sigma_{t o t}\left(p h_{2} \rightarrow\{Q \bar{Q}\} X\right)=2 \int_{0}^{-\ln \left(2 m_{Q} / \sqrt{s}\right)} d y x_{1} G_{p}\left(x_{1}, \mu_{F}\right) \sigma\left(G h_{2} \rightarrow\{Q \bar{Q}\} X\right)
$$


e a distribuição de rapidez é dada por:

$$
\frac{d \sigma\left(p h_{2} \rightarrow\{Q \bar{Q}\} X\right)}{d y}=x_{1} G_{p}\left(x_{1}, \mu_{F}\right) \sigma\left(G h_{2} \rightarrow\{Q \bar{Q}\} X\right)
$$

A distribuição de glúons no próton, $x_{1} G_{p}\left(x_{1}, \mu_{F}\right)$, encontra-se num estado diluído, podendo ser descrita pela física linear. Nós usaremos a parametrização de GRV98 [13] para determiná-la. A seção de choque glúon-alvo, $\sigma\left(G h_{2} \rightarrow\{Q \bar{Q}\} X\right)$, é determinada pela Eq. (2.22). Para calculá-la é preciso escolher um modelo para a seção de choque $\sigma_{Q \bar{Q} G}^{h_{2}}$

\section{Modelos usados nos processos $p p$}

Quando o alvo for um próton $\left(h_{2}=p\right)$ nós usaremos a Eq. (2.23) para determinar $\sigma_{Q \bar{Q} G}^{h_{2}}$, ou seja:

$$
\sigma_{Q \bar{Q} G}^{p}(\alpha, \rho)=\frac{9}{8}\left[\sigma_{q \bar{q}}(\alpha \rho)+\sigma_{q \bar{q}}(\bar{\alpha} \rho)\right]-\frac{1}{8} \sigma_{q \bar{q}}(\rho)
$$

Como o nosso objetivo é comparar os resultados da física de saturação com aqueles da física linear, nós usamos dois modelos de saturação e um modelo da física linear para calcular $\sigma_{q \bar{q}}(r)$. O dois modelos de saturação que utilizamos foram os modelos GBW e rcBK, que são respectivamente o mais antigo e o mais recente. Ao comparar as previsões destes dois modelos, esperamos ter uma idéia da incerteza teórica, associada à imprecisão com que calculamos a seção de choque dipolo-núcleon. Nas legendas das figuras nós chamaremos as curvas obtidas com estes dois modelos pelos próprios nomes dos modelos, ou seja, rcBK e GBW. Para os cálculos da física linear, nós usamos o modelo CT para calcular $\sigma_{q \bar{q}}(r)$, que foi apresentado na Seção 3.1.1. Os resultados obtidos com esse modelo serão citados nas legendas simplesmente como "CT".

\section{Modelos usados nos processos $p A$}

Para calcular as seções de choque de produção de quarks em processos $p A$ é preciso generalizar $\sigma_{Q \bar{Q} G}^{p}$ para $\sigma_{Q \bar{Q} G}^{A}$. Nos cálculos da física linear esta generalização é imediata, 
e é dada por:

$$
\sigma_{Q \bar{Q} G}^{A}(\alpha, \rho)=\frac{9}{8}\left[\sigma_{q \bar{q}}^{A}(\alpha \rho)+\sigma_{q \bar{q}}^{A}(\bar{\alpha} \rho)\right]-\frac{1}{8} \sigma_{q \bar{q}}^{A}(\rho)
$$

Nós usamos o modelo CT generalizado (veja Seção 3.1.2) para calcular $\sigma_{q \bar{q}}^{A}(r)$, com o fator de modificação nuclear $R_{g}^{A}$ dado pela parametrização EPS09 [45]. Assim como nos processos $p p$, nos processos $p A$ os resultados obtidos com esse modelo serão citados nas legendas como "CT".

Nos cálculos da física de saturação, para fazer a generalização nuclear de $\sigma_{Q \bar{Q} G}^{p}$ nós usamos o modelo de Glauber-Mueller (veja Seção 3.4.1):

$$
\sigma_{Q \bar{Q} G}^{A}(\alpha, \rho)=2 \int d^{2} \vec{b}\left\{1-\exp \left[-\frac{1}{2} T_{A}(b) \sigma_{Q \bar{Q} G}^{p}(\alpha, \rho)\right]\right\},
$$

$\operatorname{com} \sigma_{Q \bar{Q} G}^{p}$ dado pela Eq. (6.5). Da mesma forma como nos processos $p p$, nos processos $p A$ nós também usamos dois modelos de saturação para $\sigma_{q \bar{q}}(r)$, os modelos rcBK e GBW. Nas legendas dos processos $p A$ os respectivos resultados são citados como "rcBK" e "GBW". Nesse caso, está implícito que nós usamos a generalização de GlauberMueller, Eq. (6.7), para determinar $\sigma_{Q \bar{Q} G}^{A}$.

Na referência $[46,47]$ foi proposta uma nova fórmula para a seção de choque $\sigma_{Q \bar{Q} G}^{A}$, baseada no formalismo do Color Glass Condensate. Esta é uma alternativa ao modelo de Glauber-Mueller. Os autores desta referência analisaram em detalhes o canal $G \rightarrow$ $q \bar{q}$ usando o formalismo do CGC, e obtiveram a seguinte expressão para $\sigma_{Q \bar{Q} G}^{A}$ :

$$
\sigma_{Q \bar{Q} G}^{A}(\alpha, \rho)=\int d^{2} \vec{b}\left\{\frac{9}{8}\left[1-e^{\left\{\left[-\sigma_{q \bar{q}}(\alpha \rho)-\sigma_{q \bar{q}}(\bar{\alpha} \rho)\right] T_{A}(b)\right\}}\right]-\frac{1}{8}\left[1-e^{\left\{-\sigma_{q \bar{q}}(\rho) T_{A}(b)\right\}}\right]\right\},
$$

onde a função de perfil nuclear, $T_{A}(b)$, é a mesma usada na Eq. (6.7). Nós estudamos a produção de charme e bottom em processos $p A$ incluindo também a expressão acima e comparamos as predições da Eq. (6.8) com aquelas obtidas usando a Eq. (6.7). Nos cálculos que fizemos com a Eq. (6.8) nós usamos apenas o modelo de GBW para determinar $\sigma_{q \bar{q}}(r)$. Uma análise mais detalhada das diferenças entre estas duas fórmulas para $\sigma_{Q \bar{Q} G}^{A}$ é deixada para um trabalho futuro. As predições obtidas usando 

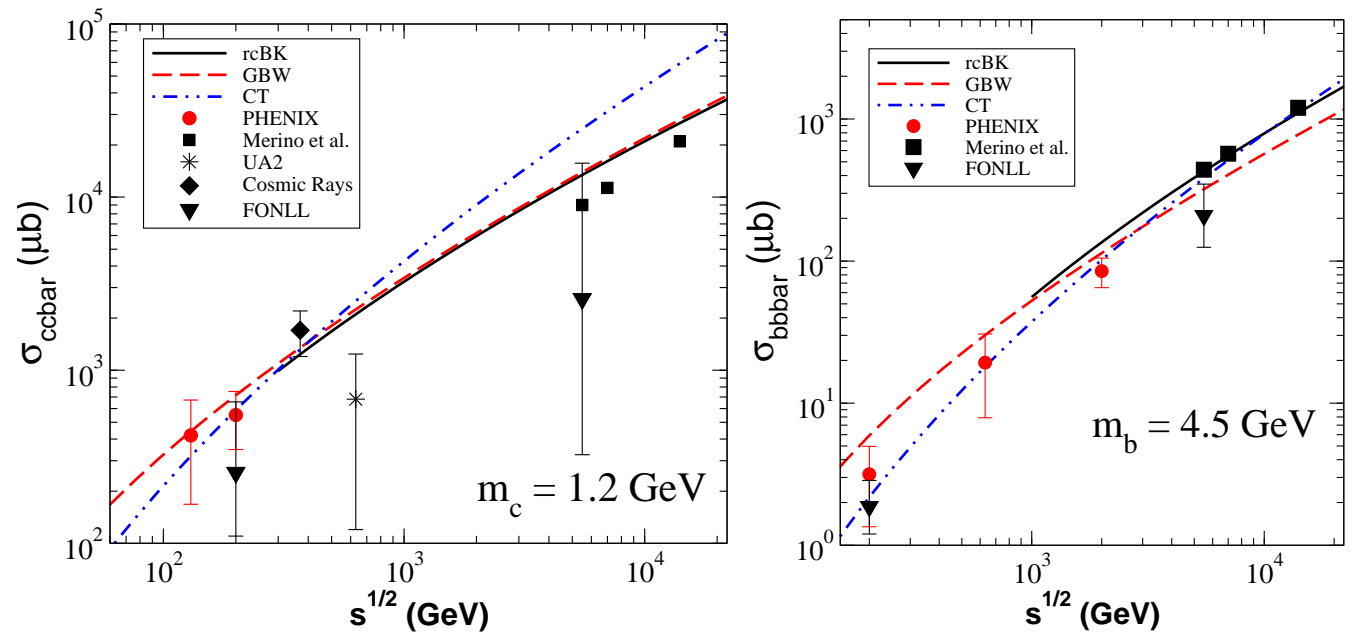

Figura 6.2: Seções de choque de produção de charme (esquerdo) e bottom (direito) em colisões prótonpróton como função da energia total no centro de massa da colisão $(\sqrt{s})$.

a Eq. (6.8), com o modelo de GBW para determinar $\sigma_{q \bar{q}}(r)$, são citadas nas legendas como "CGC". É importante observar que no limite diluído, onde a seção de choque $\sigma_{q \bar{q}}$ é pequena, as Eqs. (6.7) e (6.8) se reduzem à Eq. (6.6).

\subsubsection{Resultados}

Na Fig. 6.2 temos, como função da energia total no centro de massa da colisão $\sqrt{s}$, a seção de choque total de produção de charme (painel esquerdo) e de bottom (painel direito) em processos $p p$. Conforme já foi citado, nestes cálculos nós usamos os modelos CT, GBW e rcBK para a seção de choque dipolo-próton. Como a seção de choque de dipolo rcBK só pode ser calculada para pequeno $x\left(\leq 10^{-2}\right)$, não foi possível obter predições deste modelo para a produção de quarks pesados nas energias mais baixas. Nós comparamos os nossos resultados com os dados experimentais obtidos pela colaboração PHENIX [48, 49] (círculos), pela colaboração UA2 [50] (asteriscos) e com os dados extraídos de medidas de raios cósmicos [51] (losângulos). Além disso, nós incluímos nas figuras alguns resultados teóricos obtidos usando fatorização $k_{T}$ [52] (quadrados) e FONLL [53] (triângulos para baixo). Em nossos cálculos nós escolhemos as massas do charme e do bottom como sendo, respectivamente, $m_{c}=1,2 \mathrm{GeV}$ e $m_{b}=4,5 \mathrm{GeV}$. Como podemos ver na Fig. 6.2, com esta escolha para as massas, 

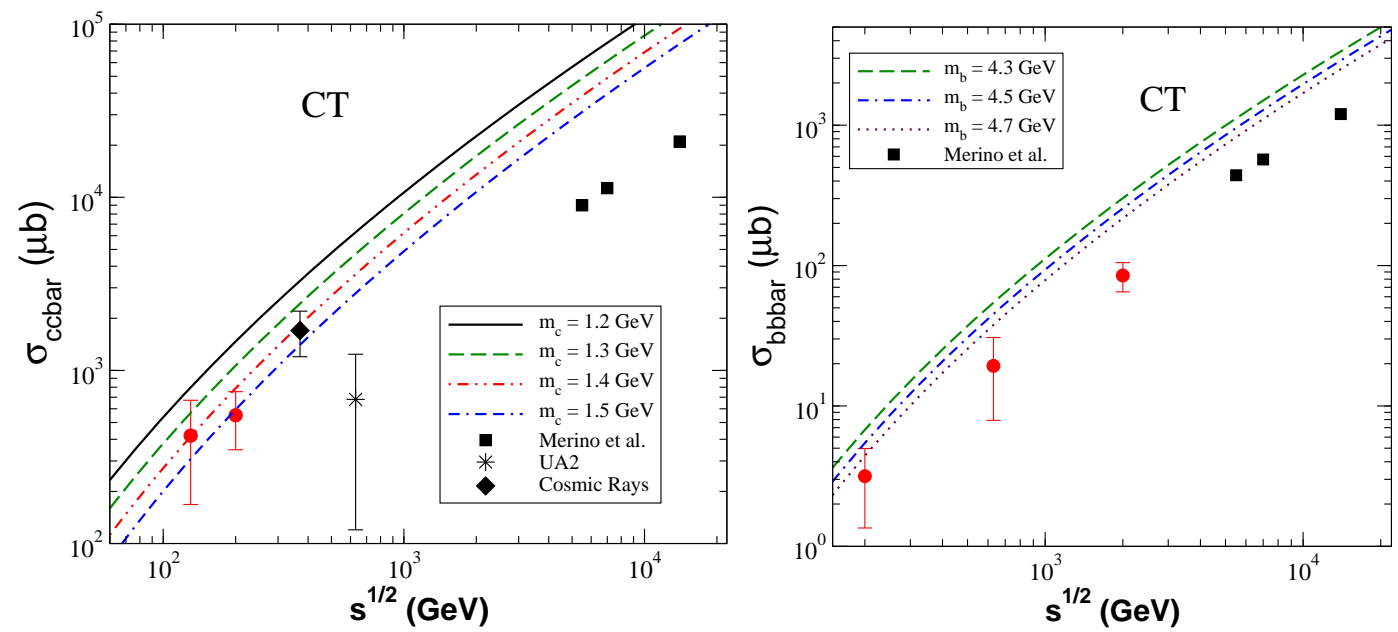

Figura 6.3: Seções de choque de produção de charme (esquerdo) e de bottom (direito), como função da energia no centro de massa $(\sqrt{s})$, em colisões próton-próton, obtidas usando o Modelo CT e diferentes valores para as massas dos quarks pesados.

os modelos GBW e rcBK descrevem de forma satisfatória os dados experimentais. Por outro lado, os resultados obtidos com o Modelo CT usando estes valores para as massas não descreveram os mesmos dados. Para obter as curvas "CT" mostradas em ambos os gráficos da Fig. 6.2, foi necessário multiplicar os resultados obtidos com esse modelo por um fator de normalização $K=0,4$. Este fator poderia ser igual a 1 se tivéssemos escolhido valores um pouco maiores para as massas dos quarks, já que as seções de choque são fortemente dependentes das mesmas. Esta forte dependência dos resultados no valor das massas dos quarks pode ser vista na Fig. 6.3, onde nós calculamos as seções de choque total de produção de charme e de bottom em colisões próton-próton usando diferentes valores para as massas desses quarks. Nos cálculos da Fig. 6.3 nós usamos apenas o Modelo CT para a seção de choque de dipolo, e fizemos o fator de normalização $K=1$. Como podemos ver, a seção de choque de produção depende fortemente da massa do quark. Embora a figura só mostre os resultados obtidos com CT, quando usamos GBW e rcBK esta forte dependência na massa também é observada.

Com exceção dos cálculos mostrados na Fig. 6.3, em todos os outros cálculos nós usamos sempre $m_{c}=1,2 \mathrm{GeV}$ e $m_{b}=4,5 \mathrm{GeV}$. Além disso, a única figura onde nós multiplicamos os resultados do modelo CT pelo fator de normalização $K=0,4$ foi a 
Fig. 6.2. Da Fig. 6.3 em diante nós fizemos $K=1$, já que, à princípio, a existência desse fator não tem nenhuma justificativa teórica.

Olhando para a Fig. 6.2 podemos ver que as predições de rcBK e de GBW para a produção de charme são muito similares entre si. Por outro lado, o Modelo CT prediz um crescimento bem mais acentuado para esta seção de choque, atingindo valores até 5 vezes maiores do que os valores obtidos com os modelos de saturação na região de energias muito altas. Esta diferença de comportamento é devida aos efeitos de saturação, que contribuem significativamente na região onde $Q_{s}^{2}>m_{Q}^{2}$. Lembramos que os efeitos não-lineares agem coibindo o forte crescimento dos observáveis quando aumentamos a energia (diminuímos $x$ ). No caso da produção de bottom, novamente, o Modelo CT prediz um crescimento mais acentuado para a seção de choque do que predizem os dois modelos de saturação. Em energias mais baixas CT prediz os menores valores para as seções de choque, se aproximando de rcBK na região de energias mais altas. É interessante notar que, ao contrário do que ocorre na produção de charme, as curvas rcBK e GBW se comportam de maneiras distintas na produção de bottom, a primeira predizendo valores maiores que a segunda. Para entendermos esta diferença no caso do bottom devemos olhar para a Eq. (2.22). O integrando desta equação contém a função de onda para a transição $G \rightarrow Q \bar{Q}$ e a seção de choque $\sigma_{Q \bar{Q} G}^{h_{2}}$. No caso do charme, a função de onda de transição em função de $\rho$ é bastante larga e possui um pico localizado na região onde os efeitos de saturação dominam. Por isso não vimos muita diferença ao usar o Modelo rcBK ou o Modelo GBW para calcular a seção de choque total, já que ambos os modelos se comportam de maneira similar na região de saturação. Por outro lado, no caso do bottom, a função de onda de transição em função de $\rho$ é bem mais estreita, tendo um pico na região dominada pela física linear. O que ocorre é que as seções de choque de rcBK e de GBW se comportam de maneiras diferentes no regime linear. Neste regime a seção de choque de rcBK assume valores maiores do que a de GBW.

Resumindo, o que a Fig. 6.2 nos mostra é que a seção de choque total para produção de charme em colisões próton-próton, no alcance de energia analisado, é sensível aos 

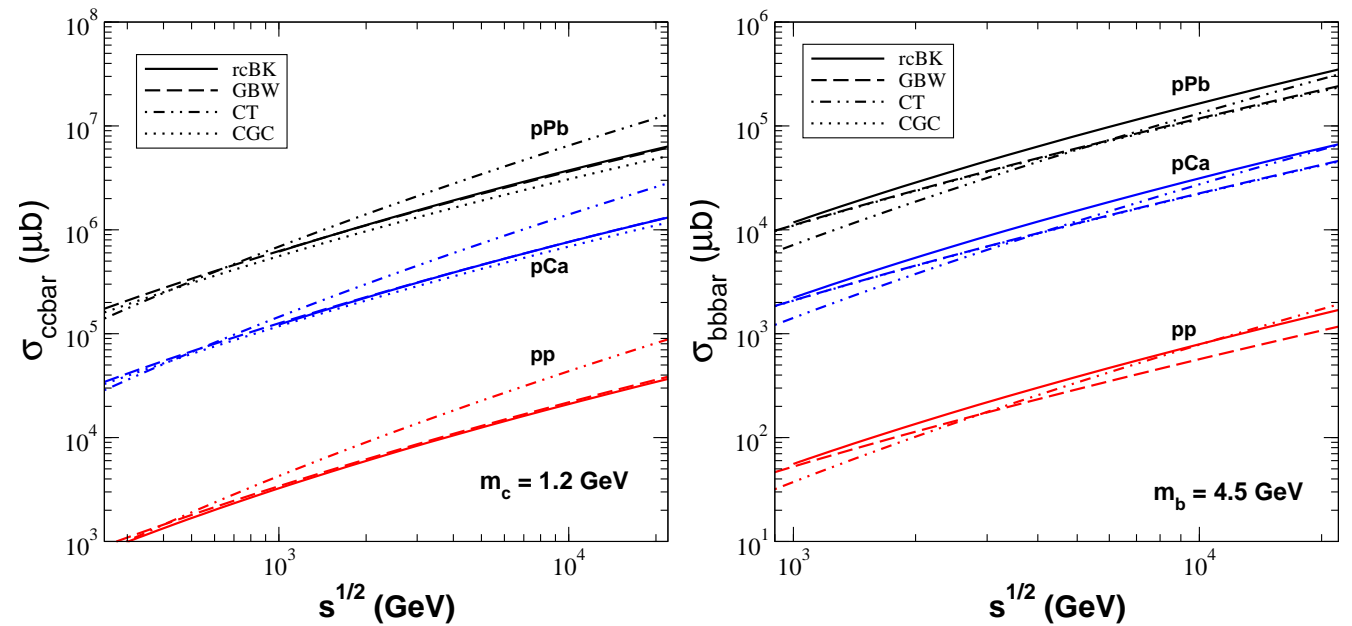

Figura 6.4: Seção de choque total de produção de charme (esquerdo) e de bottom (direito) em colisões $p P b, p C a$ e pp como função da energia no centro de massa $(\sqrt{s})$.

efeitos não-lineares da QCD. Portanto, este observável pode ser usado para identificar sinais de saturação. Já a seção de choque total de produção de bottom, aparentemente, não pode ser usada para esta finalidade.

Agora analisaremos a produção de quarks pesados em colisões $p A$. Na Fig. 6.4 temos a seção de choque total de produção de charme (gráfico esquerdo) e de bottom (gráfico direito) em colisões $p A$. Nós consideramos dois núcleos diferentes: o Cálcio (Ca) que possui número de massa $A=40$ e o Chumbo $(\mathrm{Pb})$ que possui número de massa $A=208$. Para comparação, nós mostramos também as predições para colisões pp. Lembramos que, na legenda, "rcBK" e "GBW" indicam que estamos usando a generalização nuclear de Glauber-Mueller, Eq. (6.7), com os modelos rcBK e GBW determinando a seção de choque dipolo-próton. "CGC" indica que estamos usando a Eq. (6.8) para a generalização nuclear e o Modelo de GBW para determinarmos a seção de choque dipolo-próton. E finalmente, "CT" indica que estamos usando a generalização (6.6), com a seção de choque dipolo-núcleo determinada pelo modelo CT, e o fator de modificação nuclear $R_{g}$ determinado pela parametrização EPS09 [45]. Olhando para a Fig. 6.4 vemos que as predições de rcBK e de GBW, para ambos os núcleos considerados, são praticamente idênticas no caso do charme, o que já tinha sido observado para colisões $p p$. Observamos que a diferença entre estas predições e a de CT aumenta com o número de massa, o que já era de se esperar, 

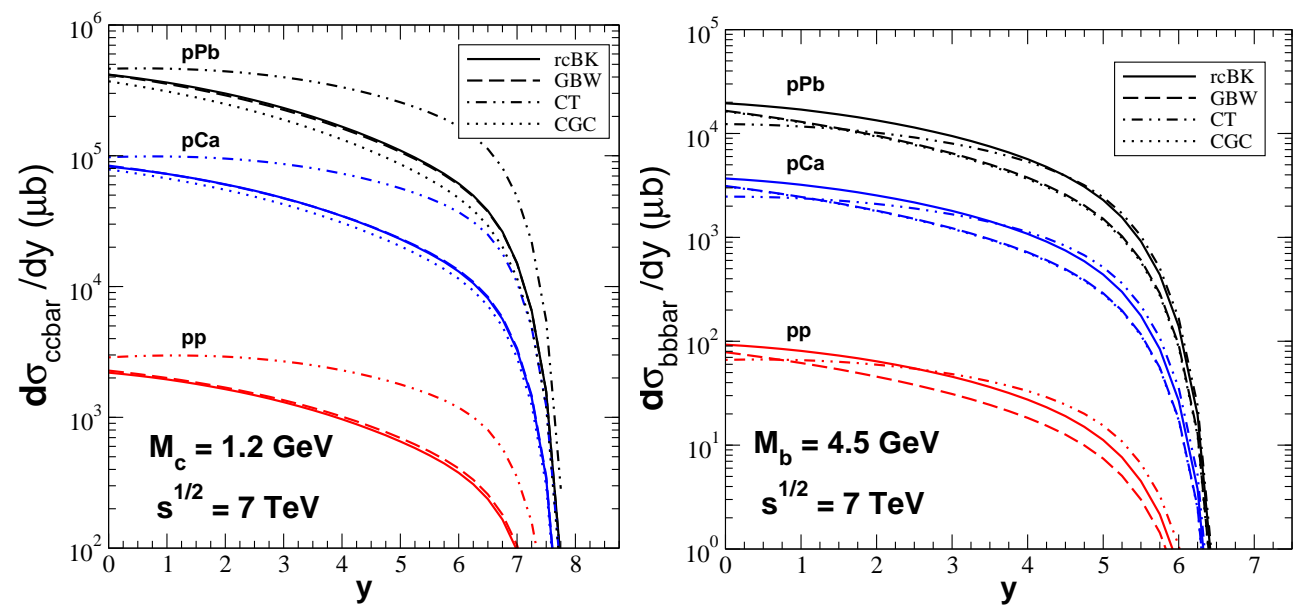

Figura 6.5: Distribuições na rapidez para produção de charme (esquerdo) e de bottom (direito) em colisões pp, pCa e pPb para $\sqrt{s}=7 \mathrm{TeV}$.

já que as contribuições dos efeitos não-lineares da QCD tornam-se maiores quando aumentamos A. Além disso, a parametrização EPS09 prediz um efeito de shadowing muito grande, sendo um dos casos mais extremos disponíveis na literatura. Portanto, a diferença entre as predições dos modelos de saturação e a predição de CT para este observável poderia se tornar ainda maior se tivéssemos escolhido outra parametrização para os efeitos nucleares. Por último, notamos que o modelo que chamamos de CGC é o que cresce mais lentamente com a energia, dando resultados um pouco menores do que os outros modelos de saturação para a produção de charme. Olhando agora para a produção de bottom vemos que GBW se comporta de maneira diferente de rcBK, predizendo valores menores que este para a seção de choque. Nós já havíamos observado este comportamento em colisões $p p$. As predições do Modelo CGC para o bottom são idênticas àquelas de GBW, o que está relacionado à dominância de pequenos tamanhos de dipolo neste último caso.

Em resumo, a conclusão tomada olhando para a Fig. 6.4 é a mesma que havíamos tomado da Fig. 6.2. Novamente, a seção de choque total de produção de charme poderá ser usada para identificar sinais de física de saturação. Já a seção de choque total para produção de bottom parece não ser muito promissora para esse fim.

Na Fig. 6.5 temos a distribuição na rapidez, y, para a produção de charme (gráfico esquerdo) e de bottom (gráfico direito) em colisões $p A$. A energia no centro de massa 
escolhida foi $\sqrt{s}=7 \mathrm{TeV}$, que é uma energia característica do LHC. No caso do charme, novamente, as predições de rcBK, GBW e CGC são muito similares entre si, e são menores do que as de CT, sendo que a diferença aumenta consideravelmente com a rapidez. Por outro lado, no caso do bottom as predições de rcBK e de CT são maiores do que as de GBW e CGC.

Em resumo, a Fig. 6.5 nos leva às mesmas conclusões já tomadas das figuras anteriores, i.e., a produção de charme pode nos auxiliar na detecção de efeitos de saturação.

Para finalizarmos a nossa análise do efeito de saturação na produção de charme e de bottom, nós tomamos a razão entre a distribuição em rapidez obtida para colisões $p A$ e esta mesma distribuição obtida para colisões $p p$, normalizando a razão a $A$. Nesse tipo de análise o efeito da troca de um próton por um núcleo torna-se mais evidente. Nós fizemos esta análise para a energia no centro de massa $\sqrt{s}=8,8 \mathrm{TeV}$, que é uma energia esperada para colisões $p A$ no LHC. Os resultados são mostrados nas Figs. 6.6 e 6.7. Olhando as figuras podemos ver que a razão diminui quando aumentamos $y$ ou $A$, e também quando diminuímos a massa do quark. No caso do charme, a razão é menor do que 1 para todos os modelos considerados. Em todos os casos rcBK prediz os maiores valores. Já o Modelo CT prediz valores sempre menores do que rcBK e GBW, o que é uma consequência de termos usado a parametrização EPS09, que prediz um forte efeito de shadowing nuclear na distribuição de glúons. Para o charme o modelo CGC prediz os menores valores para a razão. No caso do bottom, podemos notar que os três modelos de saturação predizem valores próximos de 1, enquanto o modelo CT prediz que a razão é fortemente reduzida.

Em resumo, o que estes gráficos nos mostram é que o comportamento da razão é fortemente dependente do modelo usado para descrever a interação dipolo-núcleo, o que significa que este observável pode ser bastante útil na determinação de qual destes modelos é o mais correto. No caso da produção de charme, dada a grande diferença entre as predições de GBW e de CGC, acreditamos que este observável será útil na determinação do modelo que descreve corretamente a seção de choque $\sigma_{Q \bar{Q} G}^{A}$. Já no 

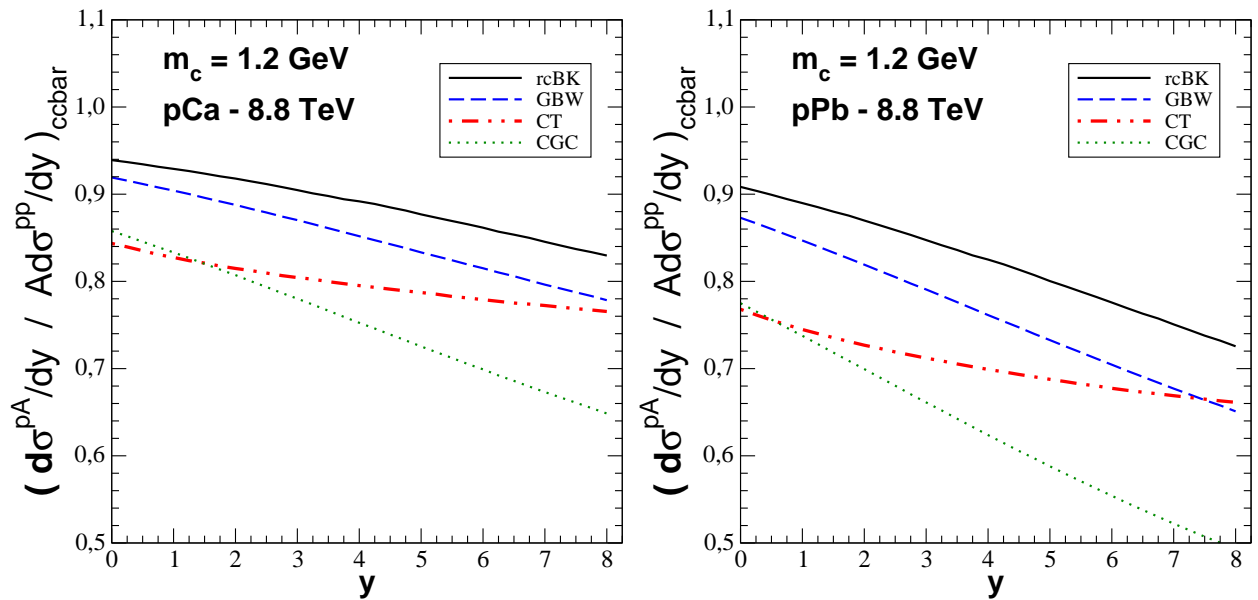

Figura 6.6: Razão normalizada da distribuição em rapidez da seção de choque total de produção de charme em colisões pCa (esquerdo) e pPb (direito) para $\sqrt{s}=8,8 \mathrm{TeV}$.
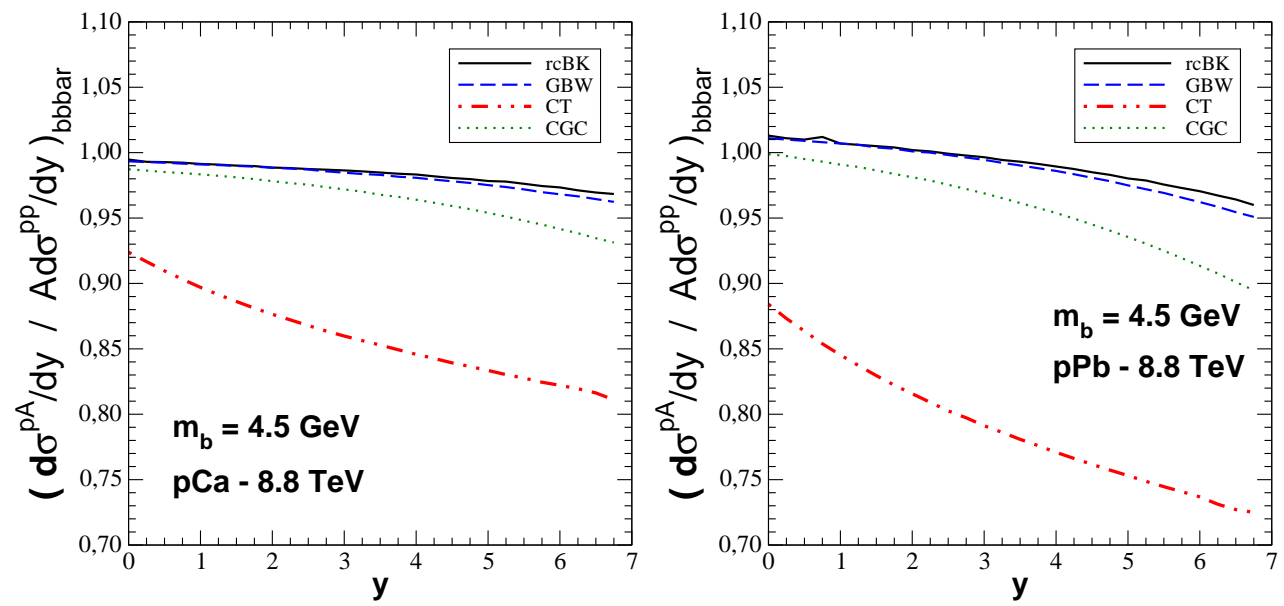

Figura 6.7: Razão normalizada da distribuição em rapidez da seção de choque total de produção de bottom em colisões pCa (esquerdo) e pPb (direito) para $\sqrt{s}=8,8 \mathbf{T e V}$.

caso do bottom, se a parametrização EPS09 for confirmada por outros observáveis, este observável do bottom poderá ser útil para detectar sinais de física de saturação.

\subsection{Efeitos de shadowing na produção de charme e de bottom}

Na referência [6] nós também analisamos o efeito do shadowing nuclear na produção de charme e de bottom. Conforme discutido na Seção 6.1, em colisões $A p$ a distribuição de gluóns do núcleo $A$ pode ser descrita pela física linear. Portanto, esse tipo de processo 
é ideal para o estudo do efeito de shadowing. Em nossa análise, nós consideramos apenas o chumbo, $\mathrm{Pb}$, pois é um núcleo bastante pesado $(A=208)$ e por conta disso o efeito de shadowing torna-se bem mais visível do que em processos envolvendo outros núcleos mais leves. Além do mais, há uma expectativa de que colisões próton-chumbo sejam realizadas no LHC, o que torna importante o cálculo envolvendo este núcleo atômico.

No estudo do shadowing nós calculamos apenas as distribuições de rapidez. Nos processos $P b p$, a distribuição em rapidez é dada por:

$$
\frac{d \sigma(P b p \rightarrow\{Q \bar{Q}\} X)}{d y}=x_{1} G_{P b}\left(x_{1}, \mu_{F}\right) \sigma(G p \rightarrow\{Q \bar{Q}\} X)
$$

Nós usamos as Eqs. (2.22) e (2.23) para determinar $\sigma(G p \rightarrow\{Q \bar{Q}\} X)$, e usamos o modelo rcBK para $\sigma_{q \bar{q}}(r)$. Desta forma, nós estamos considerando que o próton encontra-se num estado de CGC.

Para determinarmos a distribuição de glúons do chumbo nós usamos a Eq. (3.3), ou seja:

$$
x_{1} G_{P b}\left(x_{1}, \mu_{F}^{2}\right)=A R_{g}^{P b}\left(x_{1}, \mu_{F}^{2}\right) x_{1} G_{p}\left(x_{1}, \mu_{F}^{2}\right)
$$

onde $A=208$. A distribuição de glúons do próton, $x_{1} G_{p}$, será determinada pela parametrização de GRV98 [13]. Para o fator de modificação nuclear, $R_{g}^{P b}$, nós usamos duas diferentes parametrizações. São elas, nDS e EPS09. A primeira prediz um efeito de shadowing muito fraco (veja Fig. 1.3), enquanto a segunda prediz um forte efeito.

\subsubsection{Resultados}

A Fig. 6.8 mostra os nossos resultados para colisões $P b p$ para a energia no centro de massa $\sqrt{s}=8,8 \mathrm{TeV}$. Para comparação nós consideramos também o caso onde os efeitos nucleares são desprezados $\left(R_{g}=1\right)$. Os resultados sem efeitos nucleares são citados como "No Shad" nas legendas. A região de rapidez negativa nos fornece 

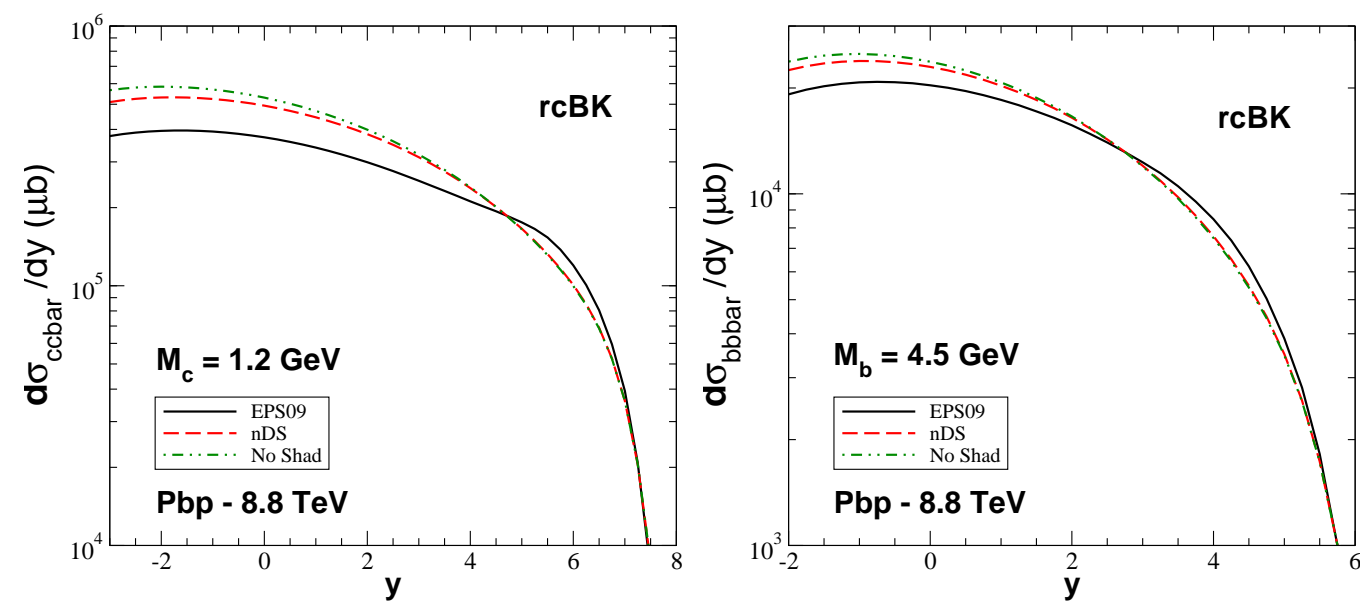

Figura 6.8: Distribuição em rapidez da seção de choque total de produção de charme (esquerdo) e de bottom (direito) em colisões $\boldsymbol{A p}$, onde $\boldsymbol{A}=\boldsymbol{P b}$, para $\sqrt{s}=8,8 \mathbf{T e V}$.

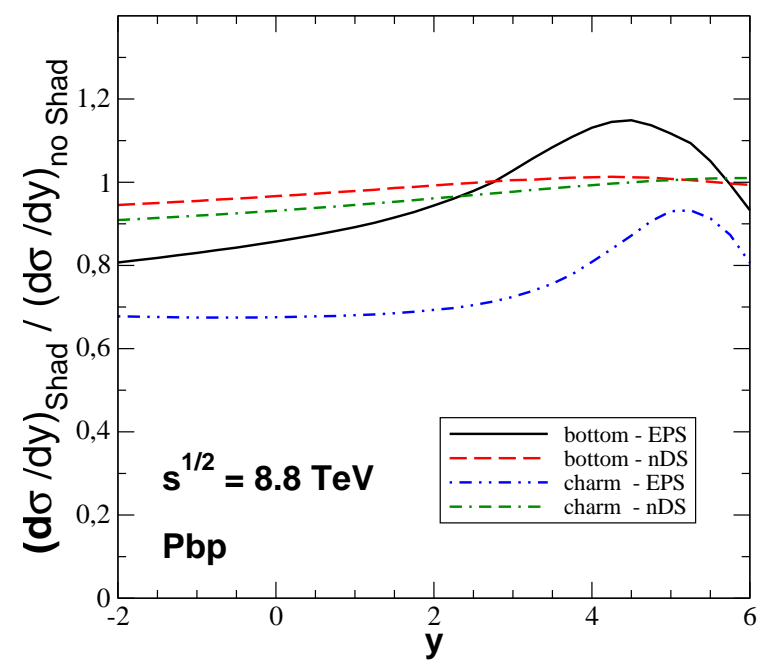

Figura 6.9: Razão entre as distribuições em rapidez, com e sem efeito de shadowing, para colisões $P b p$.

informações sobre a magnitude do efeito de shadowing em pequeno $x_{1}$, uma vez que $x_{1}=\left[m_{Q} / \sqrt{s}\right] e^{+y}$. Nas energias do LHC isto também é válido para rapidez central. Já na região de grande $y$ podemos observar o efeito de antishadowing $\left(R_{g}>1\right)$, presente apenas na parametrização EPS09. Nessa região de maiores valores de $y$ podemos notar que a predição obtida desconsiderando os efeitos nucleares coincide com a predição de nDS, já que esta parametrização não associa nenhum efeito de antishadowing à distribuição de glúons.

Para tirar conclusões mais precisas, nós calculamos a razão entre as distribuições 
com e sem shadowing em função da rapidez. Nossos cálculos são mostrados na Fig. 6.9. Como podemos ver, o efeito de shadowing predito por nDS é realmente muito pequeno, e a razão fica sempre próxima de 1. Por outro lado, a parametrização EPS09 prediz fortes efeitos nucleares. No caso da produção de charme esta parametrização prediz um forte efeito de shadowing, enquanto que na produção de bottom ela prediz um efeito de antishadowing de magnitude considerável.

Em resumo, a Fig. 6.9 nos mostra que a produção de charme poderá ser útil no estudo do efeito de shadowing. Já a produção de bottom poderá ser útil no estudo do efeito de antishadowing.

\subsection{Conclusão}

Nós comparamos entre si as predições de diferentes modelos de saturação, e comparamos também as predições desses modelos com aquelas da física linear. Nós verificamos que há observáveis da produção de charme que poderão ser usados para detectar sinais de física de saturação. Na nossa análise do efeito de shadowing verificamos que a produção de charme poderá nos dar informações sobre este efeito na região de pequeno $x$. Já a produção de bottom poderá nos dar informações sobre o efeito de antishadowing. Nossos cálculos podem ser considerados predições para observáveis que serão medidos em colisões próton-núcleo no LHC. 


\section{Capítulo 7}

\section{Conclusão}

Nesta tese apresentamos o conteúdo dos trabalhos feitos ao longo do meu doutoramento, que foram descritos nos capítulos 4, 5 e 6 . Para que um leitor não familiarizado com a área possa entender estes trabalhos, foram adicionados três capítulos introdutórios. Em todos os trabalhos nós fizemos predições para observáveis que serão medidos em processos de espalhamento.

No capítulo 4 nós comparamos as predições do modelo rcBK com aquelas do modelo b-CGC para a produção exclusiva de mésons vetoriais e também para o DVCS nuclear. Nossa motivação para fazer esta análise é que o uso do modelo rcBK tornouse praticamente unânime, sendo que até recentemente o modelo b-CGC era um dos modelos mais sofisticados dentre aqueles disponíveis na literatura. Nós verificamos que em alguns casos as predições destes dois modelos são muito parecidas, mas em outros casos nem tanto. Nos próximos anos os nossos resultados poderão ser comparados com os dados experimentais do LHeC. Além disso, se o eRHIC for construído os nossos resultados também poderão ser comparados com os dados desse colisor.

No capítulo 5 nós estudamos as seções de choque de colisão fóton-fóton. Nós propomos um novo modelo de saturação para a seção de choque dipolo-dipolo e comparamos os seus resultados com aqueles de um modelo disponível na literatura, o único de que temos conhecimento. Nós verificamos que o nosso modelo prediz um crescimento bem mais lento, tanto para as seções de choque como também para as funções de estru- 
tura, do que prediz o outro modelo. Nós verificamos ainda que os resultados dependem muito pouco do modelo escolhido para a amplitude de espalhamento dipolo-próton. Nós usamos os modelos rcBK e IIM-S para fazer esta verificação. Nossos cálculos podem ser considerados predições para observáveis que serão medidos no futuro International Linear Collider - ILC. A comparação dos nossos resultados com os dados deste futuro colisor poderá nos dar informações sobre como é a dinâmica da interação dipolo-dipolo.

Finalmente, no capítulo 6 nós estudamos o efeito de saturação e o efeito de shadowing nuclear nas seções de choque de produção de charme e de bottom em processos $p A$ nas energias do LHC. Na primeira parte do trabalho nós comparamos as predições da física linear com aquelas da física de saturação e verificamos que os dados provenientes da produção de charme poderão nos dar informações relevantes sobre possíveis efeitos não-lineares da QCD presentes em altas energias. Na nossa análise do efeito de shadowing nuclear nós verificamos que a produção de charme poderá ser útil na determinação da magnitude deste efeito. Já a produção de bottom poderá nos dar informações importantes sobre o efeito de antishadowing. Há uma expectativa de que dentro de alguns meses o LHC realizará colisões $p A$. Assim que começarem a surgir dados provenientes desse tipo de processo nós poderemos comparar os nossos resultados.

Como se pode ver, alguns dos nossos cálculos foram feitos para processos que serão realizados no LHC num futuro próximo. É o caso do primeiro trabalho, de colisões $e A$ que serão realizadas no LHeC. É o caso também do terceiro trabalho, de colisões $p A$ que estão previstas já para os próximos meses no LHC. Apenas o trabalho sobre colisões fóton-fóton é que depende da construção do ILC para poder ser comparado com dados experimentais. Nossa expectativa é a de que os nossos trabalhos possam auxiliar num melhor entendimento de como é a dinâmica da QCD nos regimes cinemáticos estudados nesta tese. 


\section{Bibliografia}

[1] E. R. Cazaroto, Espalhamento Inelástico Profundo em Colisões Elétron-Íon. São Paulo: Instituto de Física da USP, 2009. Dissertação de Mestrado.

[2] E. R. Cazaroto, F. Carvalho, V. P. Gonçalves and F. S. Navarra, Phys. Lett B 669331 (2008).

[3] E. R. Cazaroto, F. Carvalho, V. P. Gonçalves and F. S. Navarra, Phys. Lett B 671233 (2009).

[4] E.R. Cazaroto, F. Carvalho, V.P. Gonçalves, M.S. Kugeratski, F.S. Navarra, Phys. Lett B 696473 (2011).

[5] V.P. Gonçalves, M.S. Kugeratski, E.R. Cazaroto, F. Carvalho, F.S. Navarra, Eur. Phys. J. C 711779 (2011).

[6] E.R. Cazaroto, V.P. Gonçalves, F.S. Navarra, Nucl. Phys. A 872196 (2011).

[7] M. S. Kugeratski Souza, Dipolos de cor e interações a altas energias. São Paulo: Instituto de Física da USP, 2007. Tese de Doutorado.

[8] V. Barone and E. Predazzi, High-Energy Particle Diffraction, Springer-Verlag, Berlin Heidelberg (2002).

[9] R.P. Feynman, Phys. Rev. Lett. 231415 (1969).

[10] R.P. Feynman, Photon Hadron Interactions, W.A. Benjamin, New York, 1972. 
[11] V. P. Gonçalves, A Cromodinâmica Quântica para sistemas densos. Porto Alegre: Instituto de Física da UFRGS, 2000. Tese de Doutorado.

[12] F. Halzen and A. D. Martin, Quarks and Leptons: An Introductory Course in Modern Particle Physics, John Wiley \& Sons (1984), página 184.

[13] M. Glück, E. Reya and A. Vogt, Eur. Phys. J. C 5461 (1998).

[14] V. Guzey, arXiv:hep-ph/09074125; Abhay Deshpande, Richard Milner, Raju Venugopalan, and Werner Vogelsang, Annu. Rev. Nucl. Part. Sci. 55165 (2005).

[15] P. Amaudruz et al. [New Muon Collaboration], Nucl. Phys. B 4413 (1995); M. Arneodo et al. [New Muon Collaboration], Nucl. Phys. B 4813 (1996); Nucl. Phys. B 48123 (1996); M.R. Adams et al. [E665 Collaboration], Z. Phys. 403 (1995); Phys. Rev. Lett. 683266 (1992).

[16] N. Armesto, J. Phys. G: Nucl. Part. Phys. 32 R367 (2006).

[17] K.J. Eskola, V.J. Kolhinen and C.A. Salgado, Eur. Phys. J. C 961 (1999).

[18] D. de Florian and R. Sassot, Phys. Rev. D 69074028 (2004).

[19] M. Hirai, S. Kumano and T.H. Nagai, Phys. Rev. C 76065207 (2007).

[20] K.J. Eskola, H. Paukkunen and C.A. Salgado, JHEP 07, 102 (2008).

[21] N. N. Nikolaev and B. G. Zakharov, Z. Phys. C49, 607 (1991); Z. Phys. C53, 331 (1992); A. H. Mueller, Nucl. Phys. B415, 373 (1994); A. H. Mueller and B. Patel, Nucl. Phys. B425, 471 (1994).

[22] V. P. Gonçalves, M. S. Kugeratski, M. V. T. Machado and F. S. Navarra, Phys. Rev. C 80, 025202 (2009).

[23] B. Z. Kopeliovich, J. Nemchik, A. Schafer and A. V. Tarasov, Phys. Rev. C 65, 035201 (2002). 
[24] H. Kowalski, L. Motyka and G. Watt, Phys. Rev. D 74, 074016 (2006).

[25] J. Raufeisen and J. C. Peng, Phys. Rev. D 67, 054008 (2003).

[26] B. Z. Kopeliovich and A. V. Tarasov, Nucl. Phys. A 710, 180 (2002).

[27] N. N. Nikolaev, B. G. Zakharov, Phys. Lett. B 332, 184 (1994); Z. Phys. C 64, 631 (1994).

[28] L.V. Gribov, E.M. Levin and M.G. Ryskin, Phys. Rep. 100, 1 (1983).

[29] E. Iancu e R. Venugopalan, hep-ph/0303204. Publicado em QGP3, Eds. R.C. Hwa and X.N.Wang, World Scientific; E. Iancu, A. Leonidov and L. McLerran, The Color Glass Condensate: An introduction, hep-ph/0202270, publicado em QCD Perspectives on Hot and Dense Matter, Eds. J. -P. Blaizot and E. Iancu, NATO Science Series, Kluwer, 2002; E. Iancu and R, Venugopalan, The Color Glass Condensate and High Energy Scattering in QCD, hep-ph/0303104; J. JalilianMarian,J. Phys. 751 (2004);

[30] J. Jalilian-Marian, A. Kovner, A. Leonidov and H. Weigert, Nucl. Phys. B504, 415 (1997); Phys. Rev. D59, 014014 (1999); J. Jalilian-Marian, A. Kovner and H. Weigert, Phys. Rev. D59, 014015 (1999); H. Weigert, Nucl. Phys. A703, 823 (2002).

[31] I. I. Balitsky, Nucl. Phys. B463 99 (1996); Y.V. Kovchegov, Phys. Rev. D 60 034008 (1999).

[32] K. Golec-Biernat and M. Wüsthoff, Phys. Rev. D 59, 014017 (1999), ibid. D60 114023 (1999).

[33] E. Iancu, K. Itakura, S. Munier, Phys. Lett. B590, 199 (2004).

[34] G. Soyez, Phys. Lett. B 655, 32 (2007).

[35] H. Kowalski, L. Motyka and G. Watt, Phys. Rev. D 74, 074016 (2006). 
[36] G. Watt and H. Kowalski, arXiv:0712.2670 [hep-ph].

[37] J. L. Albacete, N. Armesto, J. G. Milhano, C. A. Salgado, [arXiv:hepph/0902.1112]; http://www-fp.usc.es/phenom/rcbk

[38] N. Armesto, Eur. Phys. J. C26, 35 (2002).

[39] A. C. Caldwell and M. S. Soares, Nucl. Phys. A 696, 125 (2001).

[40] F. D. Aaron et al. [H1 Collaboration], Phys. Lett. B 659, 796 (2008).

[41] N. Timneanu, J. Kwiecinski, L. Motyka, Eur. Phys. J. C 23, 513 (2002).

[42] M. Acciarri et al. [L3 Collaboration], Phys. Lett. B 519, 33 (2001)

[43] M. Acciarri et al. [L3 Collaboration], Phys. Lett. B 453, 333 (1999).

[44] M. Acciarri et al. [L3 Collaboration], Phys. Lett. B 447, 147 (1999) ; G. Abbiendi et al. [OPAL Collaboration], Eur. Phys. J. C 18, 15 (2000) .

[45] K.J. Eskola, H. Paukkunen and C.A. Salgado, JHEP 0904, 065 (2009).

[46] F. Dominguez, B. W. Xiao, F. Yuan, Phys. Rev. Lett. 106022301 (2011).

[47] F. Dominguez, C. Marquet, B. W. Xiao, F. Yuan, Phys. Rev. D 83105005 (2011).

[48] K. Adcox, et al., PHENIX Collaboration, Phys. Rev. Lett. 88192303 (2002).

[49] A. Adare, et al., PHENIX Collaboration, Phys. Rev. Lett. 97252002 (2006).

[50] O. Botner, et al., UA2 Collaboration, Phys. Lett. B 236488 (1990).

[51] Z. Xu, J. Phys. G 32, S309 (2006), nucl-ex/0607015.

[52] C. Merino, C. Pajares, M.M. Ryzhinskiy, Yu.M. Shabelski and A.G. Shuvaev, Phys. Atom. Nucl. 731781 (2010); [Erratum-ibid. 74173 (2011)].

[53] R. Vogt, Eur. Phys. J. C 61793 (2009). 